\title{
ESTUDO CRONOBIOESTRATIGRÁFICO DA FORMAÇÃO VILA MARIA: LITOESTRATIGRAFIA E PALEONTOLOGIA DO LIMITE ORDOVICIANO-SILURIANO DA BACIA DO PARANÁ, ESTADOS DE GOIÁS E DE MATO GROSSO, BRASIL CENTRAL
}

\author{
Dissertação de Mestrado \\ N³36
}

\author{
Rodrigo Rodrigues Adôrno
}




\section{ESTUDO CRONOBIOESTRATIGRÁFICO DA FORMAÇÃO VILA MARIA: LITOESTRATIGRAFIA E PALEONTOLOGIA DO LIMITE ORDOVICIANO- SILURIANO DA BACIA DO PARANÁ, ESTADOS DE GOIÁS E DE MATO GROSSO, BRASIL CENTRAL}

Dissertação submetida à Coordenação do Programa de Pós-graduação em Geologia, Universidade de Brasília, como requisito parcial para obtenção de grau de Mestre em Geologia.

Área de Concentração: Geologia Regional

\section{Orientador:}

Prof. Dr. Dermeval Aparecido do Carmo Data da defesa: 06/11/2014.

\section{Banca Examinadora}

Prof. Dr. Dermeval Aparecido do Carmo (Orientador - IG/UnB)

Prof. Dr. José Alexandre de J. Perinotto (UNESP/Rio Claro)

Prof. Dr. Carlos Jose Souza de Alvarenga (IG/UnB) 


\section{DEDICATÓRIA}

Dedico este trabalho à minha esposa Gabriela Adôrno, familiares e amigos. 


\section{AGRADECIMENTOS}

Agradeço à pesquisadora Dra. Maria José Salas e toda equipe de pesquisadores do Centro de Investigaciones en Ciencias de la Tierra (CICTERRA) Universidad Nacional de Córdoba, Argentina, pelo apoio durante a visita técnica para a realização do estudo taxonômico das espécies de Ostracoda. Ao Mestre Lucas S. Antonietto e Abel N. Oliveira Filho pela realização das imagens MEV no Laboratório de Micropaleontologia. Ao Prof. Dr Mário Luis Assine, Profa. Dra. Carolina Zabini, Profa. Lucieth Cruz Vieira, Prof. Dr. Álvaro de Faria, Prof. Dr. Carlos Jorge Abreu e Profa. Dra. Edi Mendes Guimarães, pelas participações especiais nos trabalhos de campo e pelas construtivas discussões. Ao Laboratório de Microssonda eletrônica, Instituto de Geociências e ao Laboratório de Microscopia Eletrônica do Instituto de Ciências Biológicas da Universidade de Brasília pelos serviços de metalização do material ilustrado.

Ao Conselho Nacional de Desenvolvimento Científico e Tecnológico - CNPq pelo apoio financeiro e concessão de bolsa de iniciação científica. Á FUB - Fundação Universidade de Brasília/FINATEC - Fundação de Empreendimentos Científicos e Tecnológicos, via Petróleo Brasileiro S.A. - PETROBRAS/ANP - Agência Nacional de Petróleo, Gás e Biocombustíveis, pela concessão de bolsa de pesquisa para o Projeto EDIACARIANO. Agradeço também ao Serviço Geológico do Brasil - CPRM, ASSPRO-DGM-REPO Geólogo Anderson Alves Souza e à Chefe da Residência de Porto Velho, Helena Costa Bezerra pelo apoio à finalização dos trabalhos durante o período de 2014. Em especial agradeço aos meus pais, familiares e amigos pelo apoio incondicional, sempre presentes em cada etapa de minha vida. Também sou grato à minha esposa Gabriela Adôrno pelo carinho, compreensão e dedicação que muito contribuíram na execução deste trabalho. 


\section{RESUMO}

O Grupo Rio Ivaí é constituído por três Formações: Alto Garças, Iapó e Vila Maria. Os principais afloramentos deste grupo, no norte da bacia do Paraná, estão localizados em uma estreita faixa com direção aproximadamente leste-oeste. Esta faixa, na borda norte da bacia do Paraná, se estende a aproximadamente $150 \mathrm{~km}$, onde se localizam os quatro importantes afloramentos da Formação Vila Maria, estudados no presente trabalho: seção-tipo, seção-tipo suplementar, seção da Fazenda Três Barras e seção do Bairro COHAB. Na porção superior da Formação Iapó e na base da Formação Vila Maria, na localidade dos afloramentos da seção-tipo e seção do Bairro $\mathrm{COHAB}$, foram identificadas ocorrências de braquiópodes bentônicos epifaunal Orbiculoidea? sp. e infaunal Dignomia? sp. Nos folhelhos basais da seção-tipo suplementar da Formação Vila Maria há ocorrências de moldes internos e externos de três espécies de Ostracoda: Satiellina jamairiensis Vannier 1986; Conchoprimitia circularis n. sp., e Gen. 1 et sp. 1. Adicionalmente a esta comunidade bentônica de Ostracoda, foram identificadas ocorrências de Brachiopoda Orbiculoidea? sp., Bivalvia Nuculites? sp. e Gastropoda Bucanella? sp., bem como incertae sedis. A porção intermediária da Formação Vila Maria nesta localidade é composta por pelitos micáceos, a ocorrência fossilífera é restrita à Orbiculoidea? sp e palinomorfos. Na porção superior, francamente arenosa, há ocorrência da icnoespécie Arthrophycus alleghaniensis (Hall, 1852). Com base nas espécies de Ostracoda, a porção inferior pelítica da Formação Vila Maria foi reposicionada no Ordoviciano mais superior. Com base nas ocorrências da espécie de palinomorfo Laevolancis divellomedia Burgess \& Richardson, 1991 na porção intermediária da Formação Vila Maria, referida em trabalhos cronoestratigráficos prévios, e no posicionamento das ocorrências de Arthrophycus alleghaniensis na porção arenosa superior no presente trabalho, pode-se considerar estes intervalos como sendo Landoveriano (Siluriano inferior). Assim sendo, com base no posicionamento destas ocorrências fossilíferas nos distintos intervalos litoestratigráficos, pode-se indicar que a base da Formação Vila Maria pertence ao Ordoviciano mais superior e as porções intermediária e superior ao Siluriano inferior (Landoveriano). Adicionalmente ao estudo cronobioestratigráfico da Formação Vila Maria, são atualizadas as informações cartográficas para os principais afloramentos na região estudada.

Palavras-Chave: Formação Vila Maria, Grupo Rio Ivaí, bacia do Paraná. 


\section{Abstract}

The Rio Ivaí Group consists of three formations: Alto Garças, Iapó and Vila Maria. The main outcrops of this group in northern Paraná basin. These outcrops are located in a narrow belt with roughly east-west direction. This belt in the northern border of the Paraná basin, extends approximately $150 \mathrm{~km}$, where are located the four major outcrops of the Vila Maria Formation, studied in this work: Type-section, supplementary type-section, Três Barras Farm section and Neighborhood COHAB section. At the top of Iapó Formation and the base of the Vila Maria Formation occurrences of benthic Brachiopoda, epiphaunal Orbiculoidea? sp. and inphaunal Dignomia? sp. from outcrops of the type-section and Neighborhood COHAB section. In the basal shales of the supplemental type-section of the Vila Maria Formation occurrences of internal and external molds of three species of Ostracoda are described: Satiellina jamairiensis Vannier 1986; Conchoprimitia circularis n. sp., and Gen. 1 et sp. 1. In addition to this community of benthic Ostracoda, occurrences of Brachiopoda Orbiculoidea? sp., Bivalvia Nuculites? sp. and Gastropoda Bucanella? sp. were described as well as Incertae Sedis. The intermediate portion of the Vila Maria Formation, consists of fossiliferous and micaceous siltstone. In this interval, the fossiliferous occurrence is restricted to Orbiculoidea? sp and palynomorphs. The upper portion is sandy frankly, with occurrence of ichnospecies Arthrophycus alleghaniensis (Hall, 1852). Based on the species of Ostracoda, the pelitic basal portion of the Vila Maria Formation was repositioned in the uppermost Ordovician. Based on the occurrence of palynomorph species Laevolancis divellomedia Burgess \& Richardson, 1991 in the middle portion of the Vila Maria Formation mentioned in previous chronostratigraphics works, as well as, the occurrences Arthrophycus alleghaniensis in the superior sandy portion herein presented, it is possible to consider these intervals as Llandovery (lower Silurian). Thus, the positioning of these occurrences indicates that the fossil assemblage of the lower portion of Vila Maria Formation belongs to uppermost Ordovician and the intermediate and upper portions to lower Silurian (Llandovery). In addition to this chronobiostratigraphic study of Vila Maria Formation, it was update cartographic information for all major outcrops in the study area.

Key-words: Vila Maria Formation, Rio Ivaí Group, Paraná basin. 


\section{SUMÁRIO}

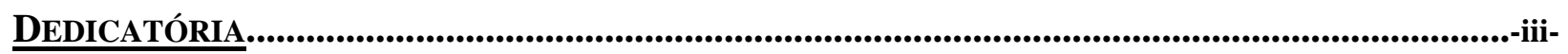

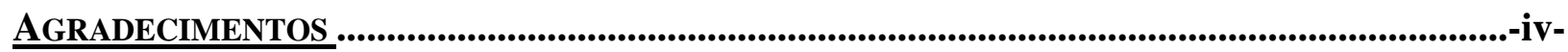

RESUMO

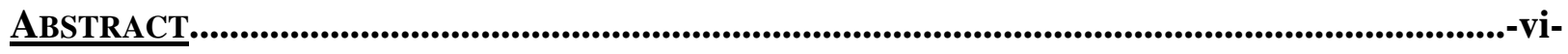

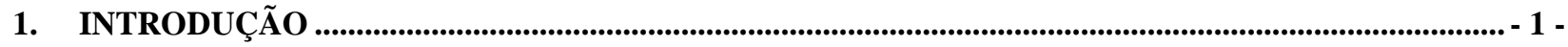

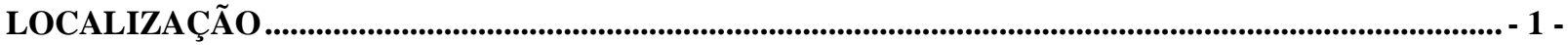

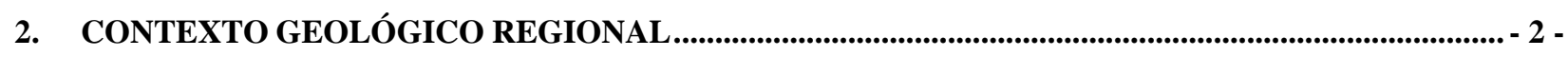

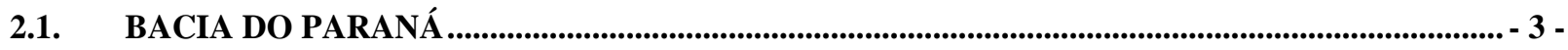

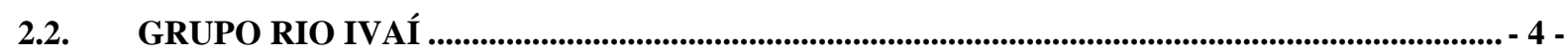

2.3. HISTÓRICO E EVOLUÇÃO DO GRUPO RIO IVAÍ .............................................................. - 6 -

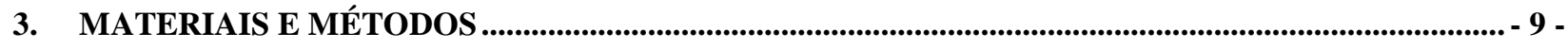

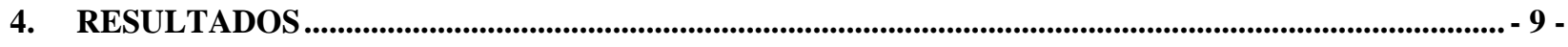

4.1 ATUALIZAÇÃO CARTOGRÁFICA................................................................................................. - 10 -

4.2 REDESCRIÇÃO DOS PRINCIPAIS AFLORAMENTOS...................................................................12

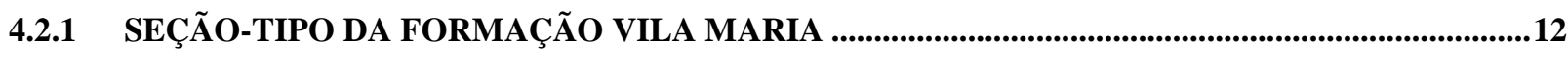

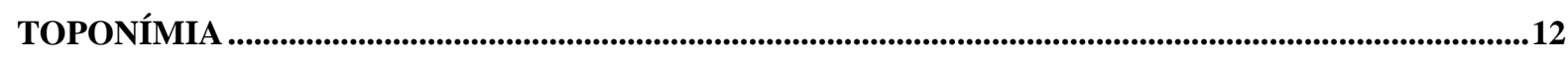

EMBASAMENTO .........................................................................................................................................13

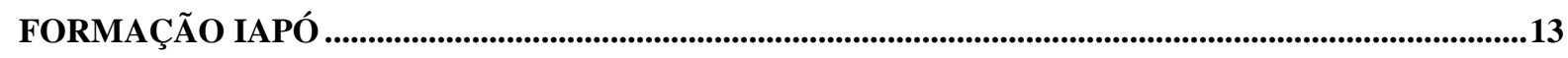

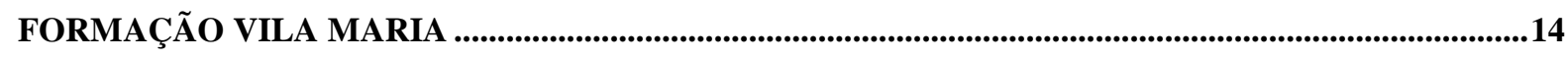

4.2.2 SEÇÃO-TIPO SUPLEMENTAR DA FORMAÇÃO VILA MARIA .........................................................16

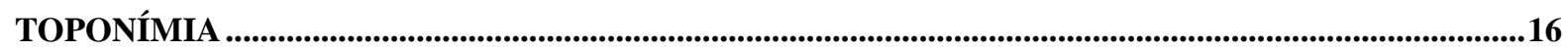

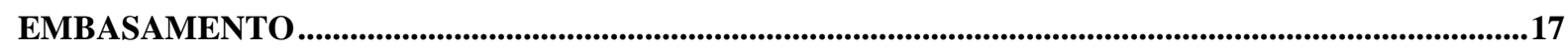

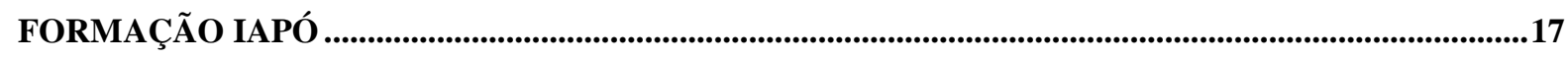

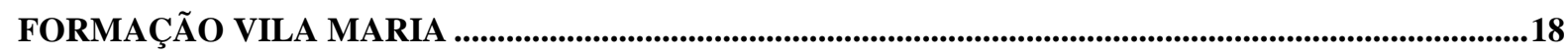

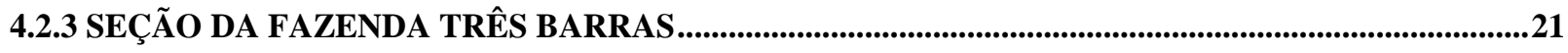

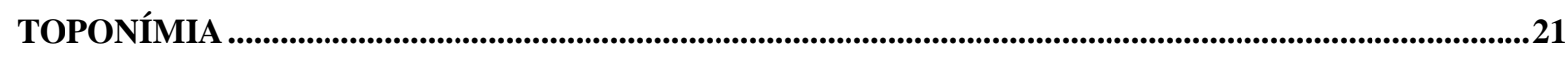

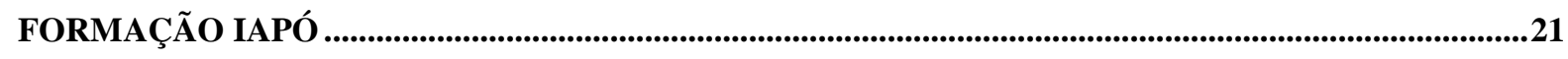

FORMAÇÃ O VILA MARIA ............................................................................................................................21

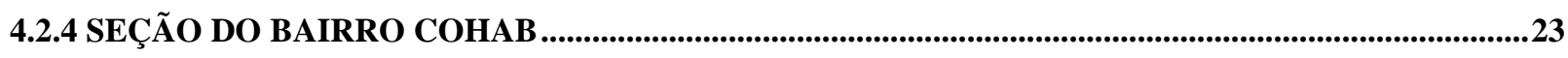

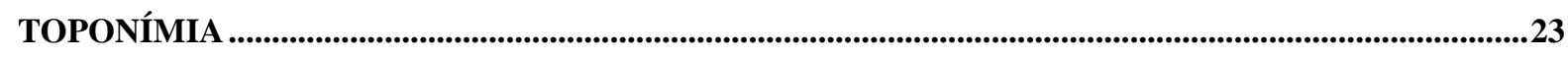

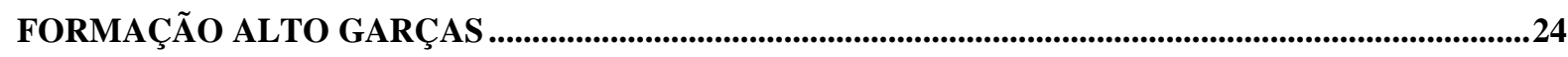

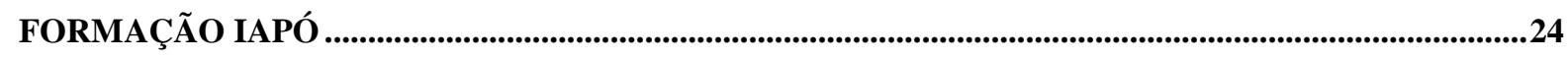

FORMAÇÃ̃ VILA MARIA …....................................................................................................................26 


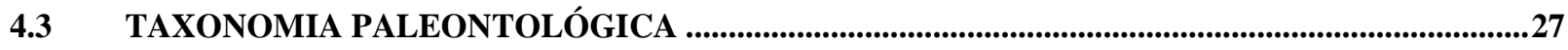

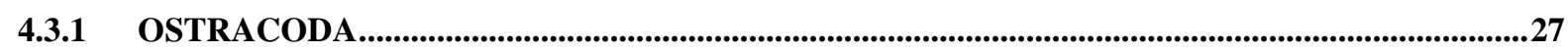

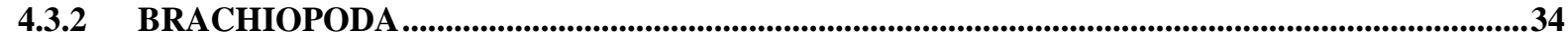

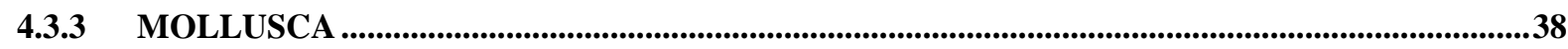

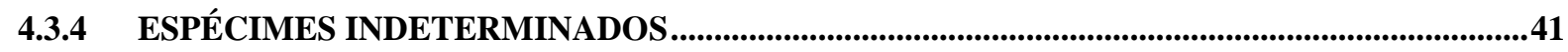

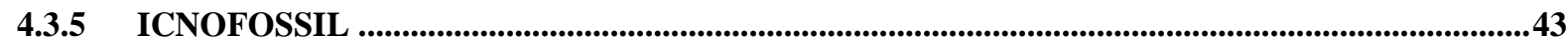

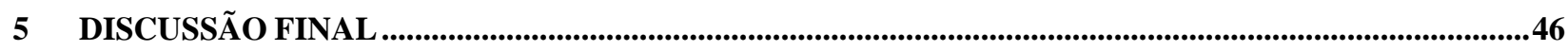

ANÁLISE PALEAMBIENTAL E ESTUDO DE CORRELAÇÃO .............................................................

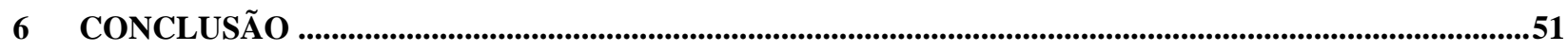

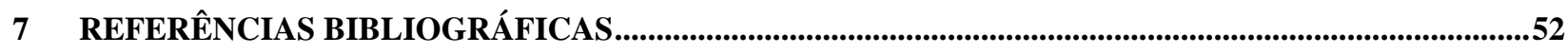

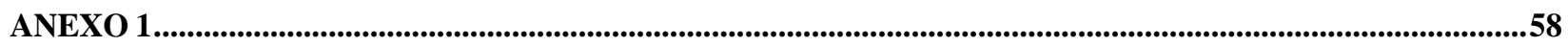




\section{ÍNDICE DE FIGURAS}

\section{INTRODUÇÃO}

FIGURA 1. 1. MAPA DE LOCALIZAÇÃO E VIAS DE ACESSO DOS PRINCIPAIS AFLORAMENTOS ESTUDADOS NO TRABALHO

\section{CONTEXTO GEOLÓGICO REGIONAL}

FIGURA 2. 1. MAPA GEOLÓGICO DA BACIA DO PARANÁ COM ISÓPACAS. (ADAPTADO DE MILANI ET AL., 1997). - 3 -

FIGURA 2. 2. CARTA CRONOESTRATIGRÁFICA DA BACIA DO PARANÁ (MILANI ET AL., 2007). - 5 -

FIgURA 2. 3. PERFIL ESTRATIGRÁFICO dA SEÇÃO-TIPO dA FORMAÇÃO VILA MARIA SENSU FARIA (1982). NOTAR QUE DIAMICTITOS FAZIAM PARTE DESTA FORMAÇÃO E CONTATO SUPERIOR COM FORMAÇÃO FURNAS ERA ADMITIDO COMO CONCORDANTE (MODIFICADA DE

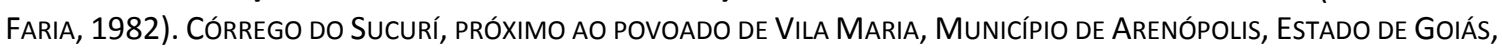
BRASIL CENTRAL.

$-6-$

FIGURA 2. 4. DISTRIBUIÇÃO CRONOESTRATIGRÁFICA DAS FORMAÇÕES DO INTERVALO DO ORDOCIANO AO DEVONIANO DA BACIA DO Paraná (SEgundo Zalán et Al. 1987 e Milani et AL. 1994; AdAPTAdo de Quintas et AL., 1999).

\section{RESULTADOS}

FIGURA 4. 1. MAPA GEOLÓGICO DA ÁREA DE OCORRÊNCIA DO GRUPO RIO IVAí NA REGIÃO SUDOESTE DO ESTADO DE GOIÁS E SUDESTE DO Estado de Mato Grosso, Brasil (Adaptado de Alvarenga et Al., 1998).

FIGURA 4. 2. IMAGEM GOOGLE EARTH MOSTRANDO PRINCIPAIS VIAS DE ACESSO AO AFLORAMENTO DA SEÇÃO-TIPO DA FORMAÇÃO VILA MARIA.

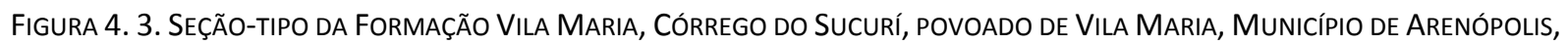
ESTADO DE GOIÁs, BRASIL CENTRAL. A) DIAMICTITO POLIMÍTICO DA FM. IAPÓ EM CONTATO EROSIVO SOBRE FILITOS DO GRUPO CUIABÁ. B) ESQUEMA ILUSTRANDO FOTO A. C) INTERCALAÇÃO DE SILTITO FOSSILÍFERO FERRUGINIZADO COM ARENITOS DA FORMAÇÃo IAPÓ. D) AMOSTRA DE SILTITO FOSSILÍFERO E DETALHE PARA ORBICULOIDEA SP. E) SILTITOS E ARENITOS ROXOS E MICÁCEOS DA FORMAÇÃO VILA MARIA. F) DETALHE PARA AMOSTRAS CONTENDO ICNOFÓSSEIS ARTHROPHYCUS ALLEGHANIENSIS. 15

Figura 4. 4. PERFIL ESTRATIGRÁFICO dA SEÇÃO-TIPO dA FORMAÇÃo VILA MARIA SENSU ASSINE ET AL. (1994), INCLUINDO O POSICIONAMENTO DAS OCORRÊNCIAS FOSSILÍFERAS. CÓRREGO DO SUCURI, MUNICÍPIO DE ARENÓPOLIS, ESTADO DE GOIÁS, BRASIL CENTRAL.

FIGURA 4. 5. IMAGEM GOOGLE EARTH MOSTRANDO PRINCIPAIS VIAS DE ACESSO AO AFLORAMENTO DA SEÇÃO-TIPO SUPLEMENTAR DA FORMAÇÃO VILA MARIA E SEÇÃO dA FAZENDA TRÊS BARRAS.

FIGURA 4. 6. COLUNA ESTRATIGRÁFICA COM POSICIONAMENTO DAS OCORRÊNCIAS FOSSILÍFERAS PARA A SEÇÃO-TIPO SUPLEMENTAR NO

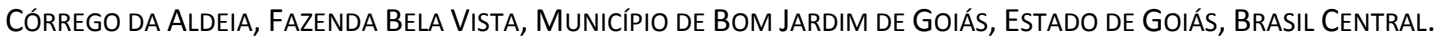

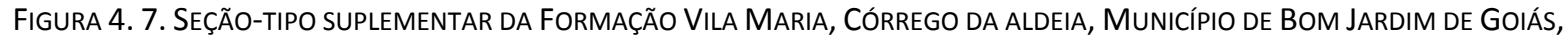
Estado de Golás, Brasil Central. A) EMbasamento cristalino. B-D) Formação Iapó. e-G) Formação Vila Maria. H) Vista GERAL DO AFLORAMENTO.

Figura 4. 8. Seção da Fazenda Três BarRas, Município de Bom Jardim de Golás, Estado de Goiás, Brasil Central. A) DiAMICTITO dA FORMAÇÃo IAPÓ. B VISTA GERAL AFLORAMENTO DA FORMAÇÃo VILA MARIA EM CACHOEIRA. C) DETALHE DA PORÇÃO INTERMEDIÁRIA DA FORMAÇÃO VILA MARIA COM SILTITOS MICÁCEOS ROXOS. D) TRAÇOS FÓSSEIS E GRETAS DE SINERESE NO TOPO DA FORMAÇÃO VILA MARIA.

Figura 4. 9. Coluna estratigráfica para localidade da Fazenda TrÊs BarRas. SeÇão da Fazenda Três BarRas, MunicípIO de BOM JARDIM DE GOIÁS, ESTADO DE GOIÁS, BRASIL CENTRAL.

FIGURA 4. 10. IMAGEM GOOGLE EARTH MOSTRANDO PRINCIPAIS VIAS DE ACESSO AO AFLORAMENTO DO BAIRRO COHAB-BARRA DO GARÇAS, MATO GROSSO.

FIGURA 4. 11. SEÇÃo do BAIRRO COHAB, BARRA do GARÇAS, MT. A) EM PRIMEIRO PLANO ARENITOS AMARELADOS DA FORMAÇÃO ALTO GaRÇAS, EM SEGUNdO PLANO FORMAÇÃo VILA MARIA. B) PACOTES ARENOSOS DA FORMAÇÃo IAPÓ. B) ForMAÇÃO IAPÓ COM BANCOS DE ARENITOS INTERCALADOS AO DIAMICTITO. D) DETALHE PARA DIAMICTITO. E) SILTITOS FOSILÍFEROS DA FORMAÇÃO VILA MARIA. F) ARENITOS DO TOPO DA FORMAÇÃO VILA MARIA.

Figura 4. 12. Coluna estratigráfica PARA localidade do Bairro COHAB, Cidade de BARRA do GarÇAS., ESTAdo de Mato Grosso, BRASIl CENTRAL (AdAPTAdo de ASSINE ET AL., 1994).

FIGURA 4. 13. 1-7, SATIELLINA JAMAIRIENSIS VANNIER, 1986. 1-2, CP-634, VISTAS LATERAIS DAS VALVAS DIREITAS, 1 MOLDE EXTERNO, 2 RÉPLICA EM LATEX DO MOLDE; 3, CP-645, VISTA LATERAL DE MOLDE INTERNO DE VALVA DIREITA; 4-7, VISTAS LATERAIS DE 
MOLDES INTERNOS DE VALVAS ESQUERDAS, 4, CP-637; 5, CP-643; 6, CP-651; 7, CP-646. 8-12, CONCHOPRIMITIA CIRCULARIS N. SP; 8-11, VISTAS LATERAIS DE MOLDES INTERNOS DE VALVAS ESQUERDAS, 8, HolóTIPO CP-631; 9, PARÁTIPO CP-635; 10, PARÁtIPo CP-639; 11, PARÁtIPo CP-660, VALVA DIREITA; 12, PARÁTIPO CP-649, VALVA ESQUERDA. 13-14, 15, GEN. ET SP. 1 (ESPÉCIE INDETERMINADA), 13, CP-636 VISTAS LATERAIS DE MOLDES INTERNOS DE VALVAS ESQUERDAS; 14, CP-644, VISTAS LATERAIS DE MOLDES INTERNOS DE VALVAS DIREITAS; 15, CP-780, CARAPAÇA ABERTA, VALVA DIREITA (ABAIXO) E VALVA ESQUERDA (ACIMA).

FIGURA 4. 14. BRAQUIÓPODES FÓSSEIS DAS FORMAÇõES IAPÓ E VILA MARIA. 1-6, 8-9) ESPÉCIMES PROVENIENTES DO AFLORAMENTO DO

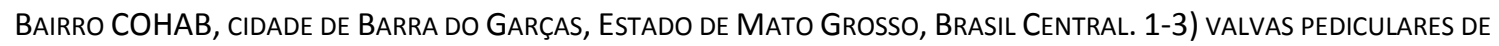
ORBICULOIDEA? SP, NOTAR A PRESENÇA BEM MARCADA DA FENDA PEDICULAR. 1) ESPÉCIME CP-770. 2) ESPÉCIME CP-771. 3) ESPÉCIME CP-772. 4-6) MOLDES EXTERNOS DE VALVAS DORSAIS DE ORBICULOIDEA? SP. 4) ESPÉCIME CP-773. 5) ESPÉCIME CP774. 6) ESPÉCIME MP-2023-7. 8-9) MP-2023-1, PARTE E CONTRA PARTE DE MOLDE EXTERNO DE DIGNOMIA? SP. DA FORMAÇÃO VILA MARIA. 7) CP-775, MOLDE ITERNO DE ORBICULOIDEA? SP. COM PROVÁVEL CICATRIZ MUSCULAR PRESERVADA NA VALVA DORSAL, PROVENIENTE DO AFLORAMENTO SEÇÃO TIPO DA FORMAÇÃO VILA MARIA, CÓRREGO dO SUCURI, MUNICÍPIO DE ARENÓPOlis, ESTAdo de GoiÁs, BRASil CENTRAL.

FIGURA 4. 15. MoluSCOS E FÓSSEIS dA PORÇÃO BASAL DA FoRMAÇÃo VILA MARIA. 1-3) NUCULITES? SP. 1) ESPÉCIME CP-776, MOLDE EXTENO DA VALVA ESQUERDA. 2A) ESPÉCIME CP-777, MOLDE EXTERNO DE POSSÍVEL VALVA DIREITA. 2B) DETALHE DO ESPÉCIME MP-2033-2. 3) ESPÉCIME MP-2033-3, MOLDE EXTERNO VALVA ESQUERDA. 4) ESPÉCIME CP-778 VISTA APICAL, MOLDE INTERNO DE BUCANELLA? SP. 5-8) FÓSSEIS INVERTEBRADOS COM AFINIDADE TAXONÔMICA INDETERMINADA. 5-6) MOLDES EXERNOS DE INCERTAE SEDIS 1. 5) ESPÉCIME MP-2029. 6) ESPÉCIME CP-779, MOLDES CIRCULARES EVIDENCIANDO ESTRIAS RADIAIS E PORÇÃO CENTRAL PROTUBERANTE. 7, 8) MOLDES CILÍNDRICOS ACHATADOS DE INCERTAE SEDIS 2. 7) ESPÉCIME CP-781 EVIDENCIANDO ESTRIAS ANELARES OU DIVISÃO EM ANÉIS E ACHATAMENTO. 8) ESPÉCIME MP-2027-2 APRESENTADO RAMIFICAÇÃO DICOTÔMICA. 43 Figura 4. 16. ARTHROPHYCUS ALLEGHANIENSIS (HALL, 1852) DO TOPO DA FORMAÇÃO VILA MARIA. A) AFLORAMENTO SEÇÃO-TIPO DA FormaÇÃo Vila Maria, CórRego do SUCURI, POVOAdo de VILA MARIA, MUNICÍPIO de ARENÓPOLIS, ESTAdo de GOIÁS, BRASIL

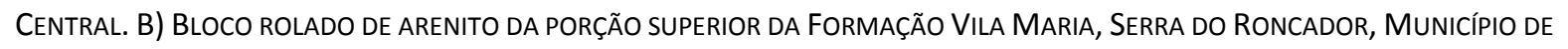
Nova Xavantina, Estado de Mato Grosso, Brasil Central (localidade não detalha no presente trabalho).

\section{DISCUSSÃO FINAL}

FIGURA 5. 1. RECONSTRUÇÃO PALEOGEOGRÁFICA PARA O NEORDOVICIANO E OCORRÊNCIAS DAS ESPÉCIES DE OSTRACODA (MODIFICADO DE GIENNE, 2003).

FIGURA 5. 2. RECONSTRUÇÃO PALEOAMBIENTAL PARA O LIMITE ORDOVICIANO-SILURIANO DA BACIA do PARANÁ (MODIFICADO DE ASSINE ET AL., 1998). .50

\section{ÍNDICE DE TABELAS}

\section{RESULTADOS}

TABELA 4. 1. MedidA dos MOldes das CARAPAÇAS de SATIELLINA JAMAIRIENSIS VANNIER 1986, SEÇÃO-TIPO SUPLEMENTAR CóRREGO

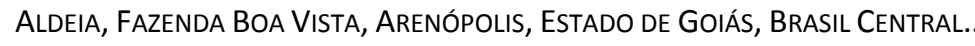

TABELA 4. 2 MEDIDA DOS MOLDES DAS CARAPAÇAS DE CONCHOPRIMITIA CIRCULARIS N. SP., SEÇÃO-TIPO SUPLEMENTAR CÓRREGO ALDEIA, Fazenda Boa Vista, Município de AREnÓPolis, Estado de GoIÁs, BRASIL Central...... 


\section{INTRODUÇÃO}

O objetivo do presente trabalho consiste em posicionar e caracterizar sistematicamente o conteúdo fossilífero da Formação Vila Maria em quatro principais afloramentos-chave: seçãotipo, seção-tipo suplementar, seção da Fazenda Três Barras e seção do Bairro COHAB. Em especial, foram enfatizados os ostracodes dos folhelhos da seção-tipo suplementar, pois além de inéditos, possuem potencial para aplicação em estudos de datação relativa do intervalo inferior pelítico da Formação Vila Maria.

Este estudo teve foco na paleontologia e na sedimentologia da Formação Vila Maria, bem como no resgate histórico dos afloramentos-chave desta formação. Apenas esta formação da bacia do Paraná possui seção-tipo no Estado de Goiás. Adicionalmente é apresenta atualização cartográfica resultante da pesquisa realizada a partir de consultas bibliográficas, bem como da revisão detalhada dos principais afloramentos do Grupo Rio Ivaí na região limite entre o sudoeste do Estado de Goiás e sudeste do Estado de Mato Grosso (Fig. 1.1).

A Formação Vila Maria, desde sua proposição, têm diversas publicações que abordam a datação e a subdivisão litoestratigráfica. Neste sentido, o presente trabalho apresenta o estado da arte, trazendo uma abordagem histórica da evolução do conhecimento a respeito das subdivisões das unidades que integram o Grupo Rio Ivaí. Com isso, espera-se esclarecer as diferentes interpretações dadas à Formação Vila Maria desde sua formalização.

Os trabalhos realizados na Formação Vila Maria, em geral apresentam escala de trabalho de pouco detalhe, tendo caráter regional predominante. Os afloramentos-chave estudados neste trabalho foram descritos entre as décadas de 1970 e 1990 apresentando toponímias pouco precisas para os padrões modernos de descrição. O presente trabalho traz atualizações das descrições destes afloramentos, adicionando coordenadas UTM, bem como mapas da geologia e de vias de acesso atualizados.

\section{LOCALIZAÇÃO}

As rochas do Grupo Rio Ivaí afloram em duas porções da bacia do Paraná: flanco leste na região do Estado do Paraná e no flanco norte, região limite entre os estados de Goiás e de Mato Grosso (Figs 1.1; 2.1). 
Os afloramentos estudados neste trabalho são localizados nos municípios de Arenópolis e Bom Jardim de Goiás no Estado de Goiás e, Bairro COHAB no Município de Barra do Garças, Estado de Mato Grosso (Fig. 1.1).

O acesso aos afloramentos da seção-tipo suplementar e Fazenda Três Barras se dá pela BR 158 até o Município de Bom Jardim de Goiás e a partir da sede deste município, segue-se por estrada não pavimentada em direção à serra Negra. O acesso ao afloramento da seção-tipo da Formação Vila Maria é pela estrada não pavimentada GO-472 que segue ao sul do Município de Arenópolis até o Córrego do Sucuri onde está localizada a seção-tipo da Formação Vila Maria. Quanto ao afloramento na Cidade de Barra do Garças, a partir de Brasília, o principal acesso é pela BR 070 (Fig. 1.1).

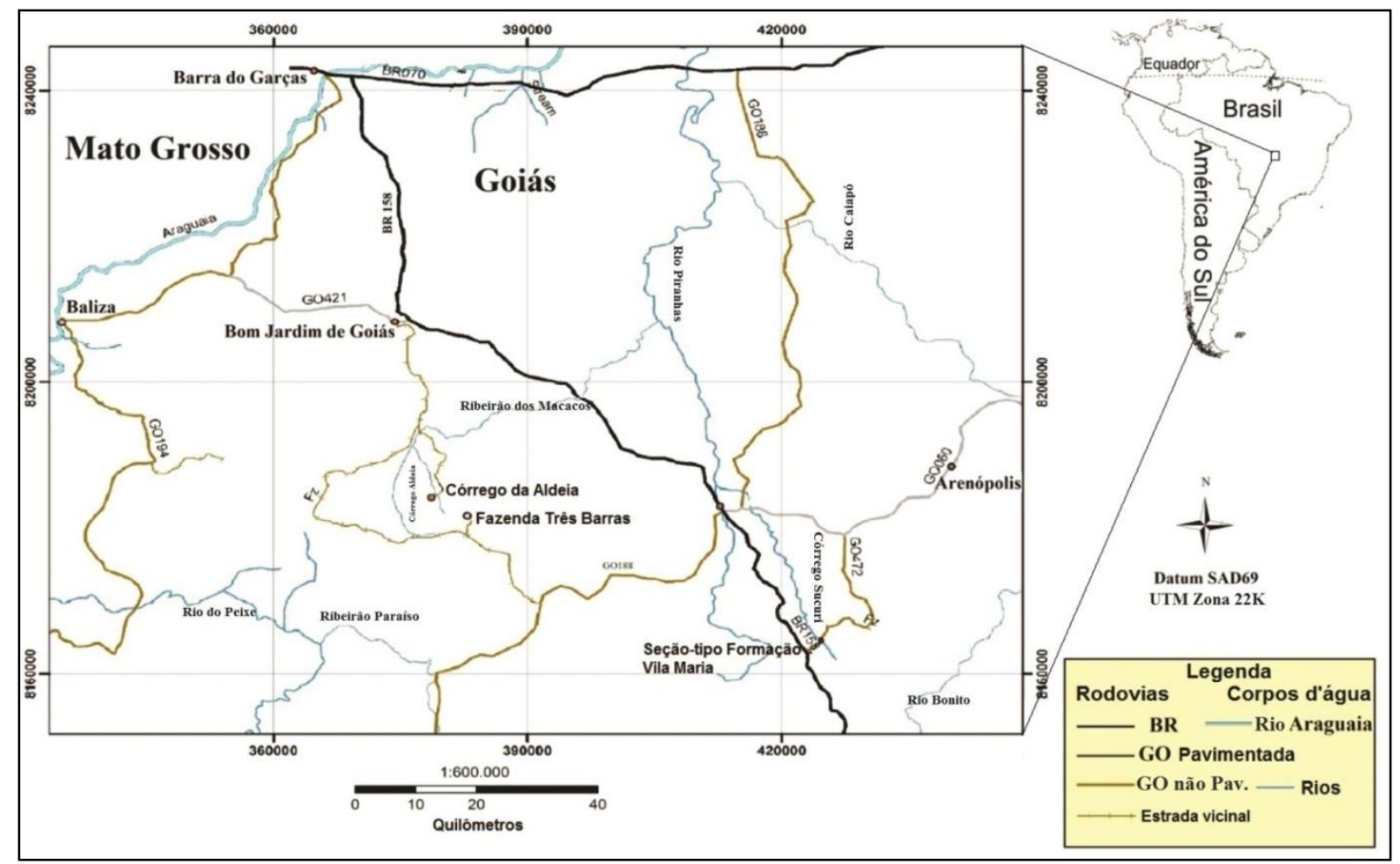

Figura 1. 1. Mapa de localização e vias de acesso dos principais afloramentos estudados no trabalho.

\section{CONTEXTO GEOLÓGICO REGIONAL}

Neste item são apresentados resultados do levantamento bibliográfico abordando dados gerais sobre a geologia da bacia do Paraná com ênfase na geologia do Grupo Rio Ivaí. Nesse sentido, apresenta-se histórico da evolução do conhecimento do Grupo Rio Ivaí e seus impactos no entendimento da Formação Vila Maria desde sua formalização em 1982. 


\subsection{BACIA DO PARANÁ}

A bacia do Paraná é a maior bacia sedimentar intracratônica do continente sul-americano, com área de $1.400 .000 \mathrm{Km}^{2}$ distribuída de forma elíptica, com o maior eixo orientado segundo a direção NNE-SSW (Fig. 2.1). Esta bacia conta com pacote magmático-sedimentar com espessura de 7000m, depositados entre o Ordoviciano e o Cretáceo Superior (Milani et al., 2007).

Seis unidades aloestratigráficas de segunda ordem ou supersequiências no sensu de Vail et al. (1977), são identificadas. Estas supersequências são enquadradas na categoria estratigráfica de grupo, sendo: Grupo Rio Ivaí (Ordoviciano-Siluriano), Grupo Paraná (Devoniano), Grupo Itararé "Gondwana I" (Carbonífero-Permiano), Grupo Guatá “Gondwana II" (Permiano), Grupo Passa Dois “Gondwana III” (Permiano-Triássico) e Grupo Bauru (Cretáceo) (Milani et al., 1998; Milani et al., 2007) (Fig. 2.1 e 2.2).

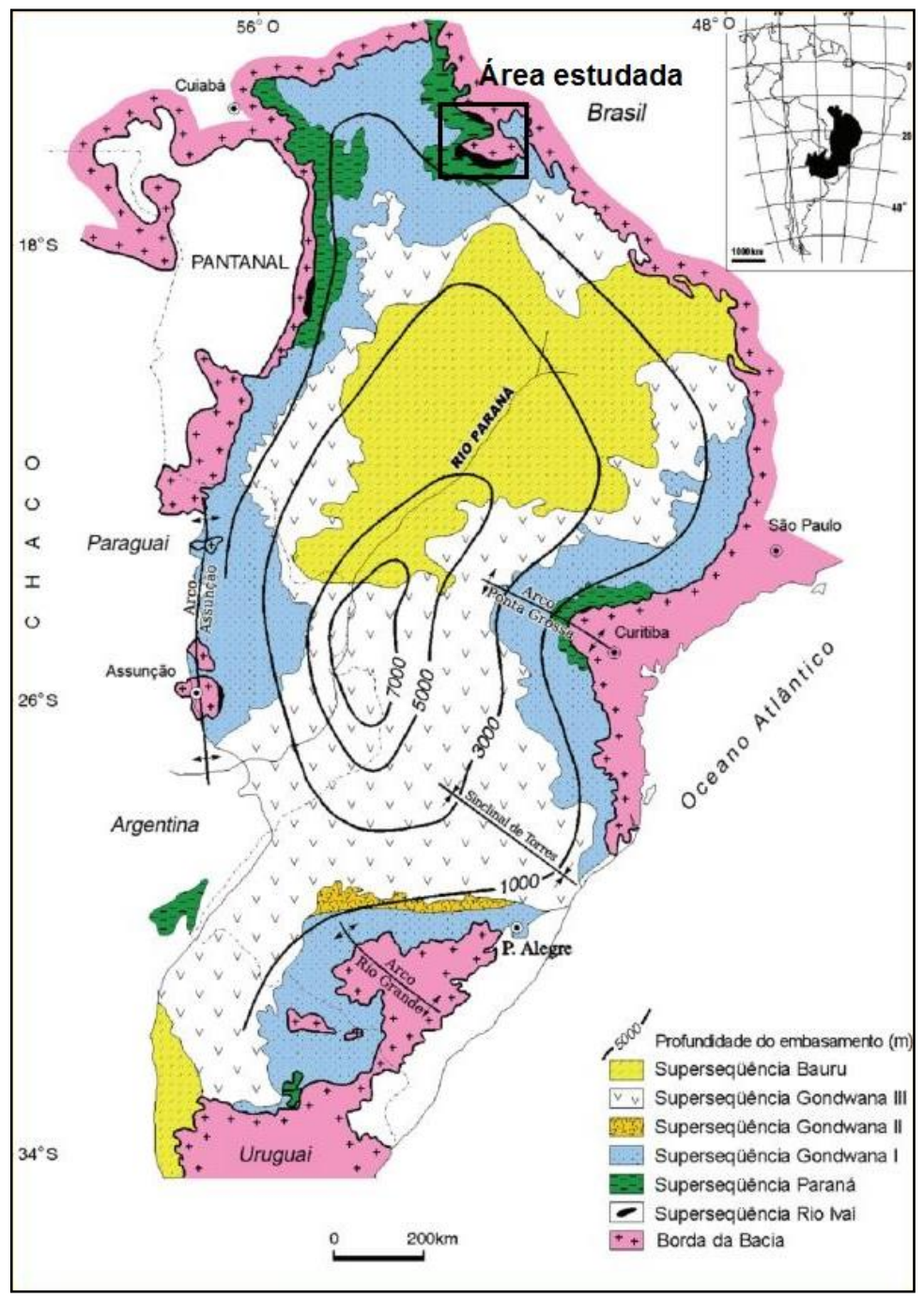

Figura 2. 1. Mapa geológico da bacia do Paraná com isópacas. (adaptado de Milani et al., 1997). 


\subsection{GRUPO RIO IVAÍ}

O Grupo Rio Ivaí é composto, da base para o topo, pelas formações Alto Garças, Iapó e Vila Maria (Assine et al., 1994) (Fig. 2.2). Sua idade foi obtida através do estudo do conteúdo fossilífero da Formação Vila Maria e por correlações litoestratigráficas com unidades de outras bacias, como o Grupo Trombetas da bacia do Amazonas (Milani et al, 2007) e também com o Grupo Serra Grande, bacia do Parnaíba (Goes et al., 1994; Vaz et al., 2007).

A Formação Vila Maria foi formalizada primeiramente por Faria (1982), sendo modernamente entendida como uma das três formações que integram o Grupo Rio Ivaí (Assine et al., 1994). Esta formação aflora no flanco norte da bacia do Paraná em escarpas, cachoeiras e vales, sempre próximos do contato entre a bacia sedimentar e o embasamento.

A importância litoestratigráfica da Formação Vila Maria como unidade formal foi reconhecida desde sua proposição, pois até aquele momento, a Formação Furnas era a unidade mais antiga da bacia do Paraná. Atrelada a esta importância estratigráfica, cita-se também seu importante e diversificado conteúdo fossilífero, sendo o mais diversificado do Paleozoico inferior, composto por palinomorfos, braquiópodes, gastrópodes, bivalves e icnofósseis (Popp et al., 1981; Burjack e Popp, 1981; Faria, 1982, Gray et al., 1985). Estes fósseis compõem o registro paleontológico mais rico do intervalo Ordoviciano/Siluriano da bacia do Paraná (Milani et al., 2007). 


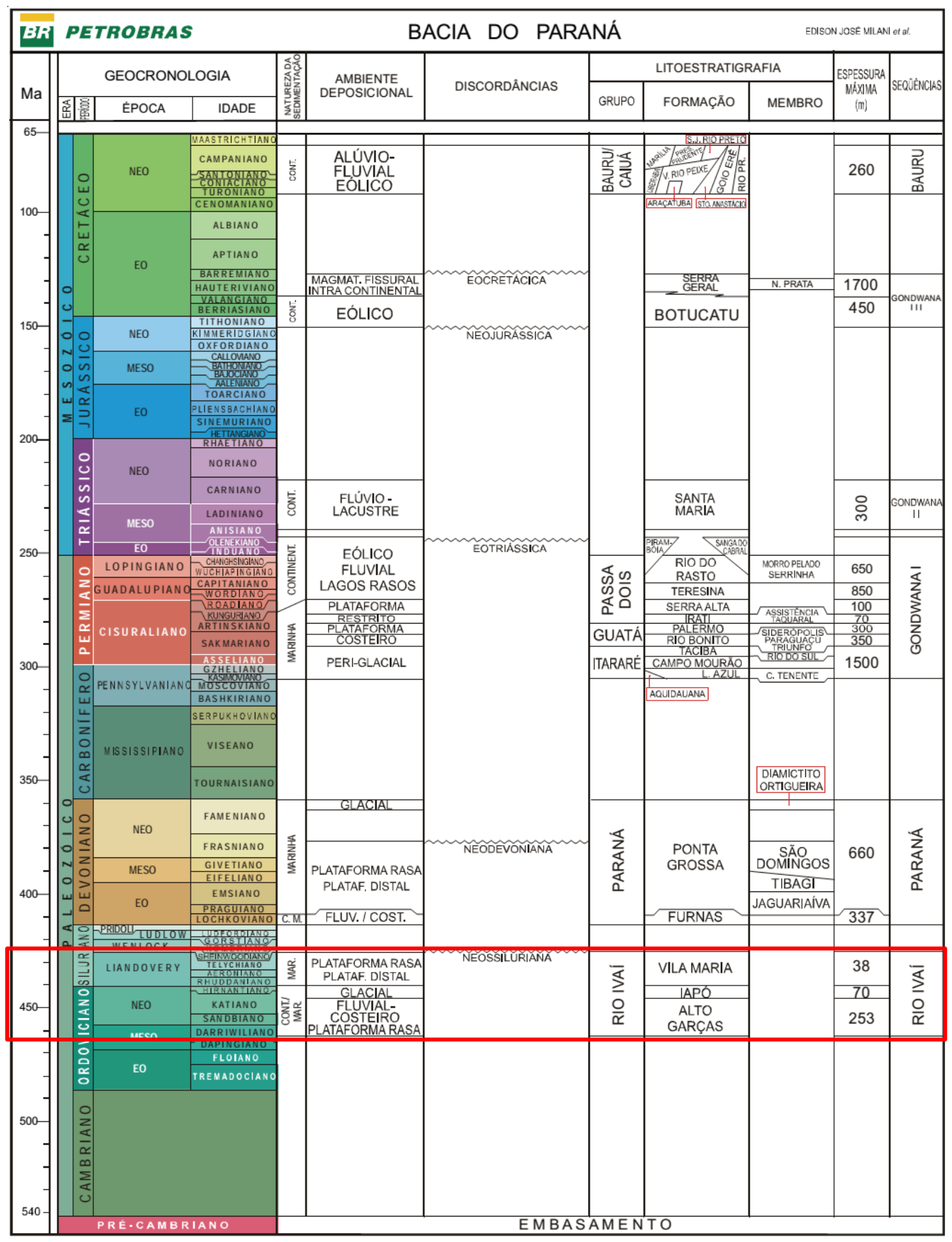

Figura 2. 2. Carta cronoestratigráfica da bacia do Paraná (Milani et al., 2007). 


\subsection{HISTÓRICO E EVOLUÇÃO DO GRUPO RIO IVAÍ}

A Formação Furnas, Grupo Paraná, foi considerada por muito tempo, a unidade mais antiga da bacia do Paraná, mesmo que Maack, (1947) já houvesse documentado a existência de um pacote glaciogênico sotoposto à Formação Furnas no Estado do Paraná (Assine et al., 1994). Somente no fim da década de 1970, a nova unidade mapeável denominada Formação Vila Maria foi reconhecida pela comunidade científica (Faria \& Reis Neto, 1978; Faria, 1982).

O estudo do intervalo cronoestratigráfico anterior ao Devoniano da bacia do Paraná ganhou força após a publicação da Formação Vila Maria como unidade litoestratigráfica formal (Faria, 1982). A Formação Vila Maria e a base da Formação Furnas foram posicionadas no Eosiluriano (Landoveriano). Este posicionamento foi baseado na ocorrência do icnofóssil Arthrophycus alleghaniensis (Hall, 1852) na Formação Vila Maria (Burjack e Popp, 1981) e a caracterização de contato concordante entre as formações Vila Maria e Furnas (Fig. 2.3) (Faria, 1982; Zalán et al., (1987). A Formação Vila Maria originalmente compreendia os diamictitos glaciais e a sucessão marinha fossilífera sobreposta aos diamictitos, depositados diretamente sobre o embasamento pré-Cambriano (Faria, 1982).

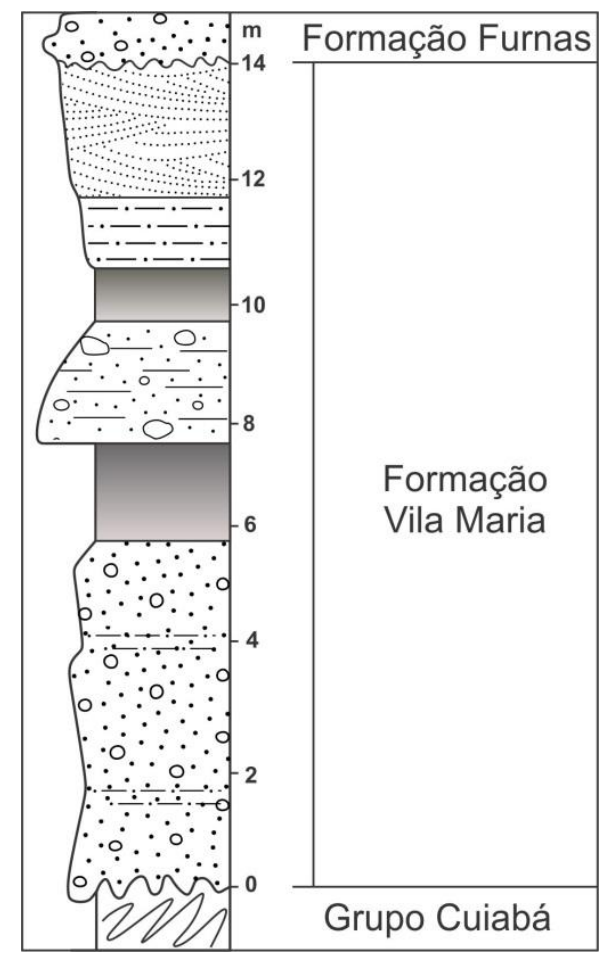

Figura 2. 3. Perfil estratigráfico da seção-tipo da Formação Vila Maria sensu Faria (1982). Notar que diamictitos faziam parte desta formação e contato superior com Formação Furnas era admitido como concordante (modificada de Faria, 1982). Córrego do Sucurí, próximo ao povoado de Vila Maria, Município de Arenópolis, Estado de Goiás, Brasil Central. 
O registro palinológico do afloramento da Fazenda Três Barras descrito por Gray et al. (1985) é composto por várias espécies indeterminadas, possíveis tétrades e por Elektoriskos pogonius Loeblich, 1970, deste conjunto palinológico, apenas E. pogonius é restrito ao Eosiluriano. Mizusaki et al. (2002) apresenta palinoflora mais diversificada composta por várias espécies que indicariam idades compreendidas no intervalo Caradociano-Landoveriano. De toda associação palinológica apresentada naquele trabalho, apenas Laevolancis divellomedia Burgess \& Richardson, 1991, proveniente de uma amostra da porção intermediária da Formação Vila Maria, seria restrita ao Landoveriano. Os palinomorfos da porção intermediária da Formação Vila Maria, assim como Arthrophycus alleghaniensis da porção superior da Formação Vila Maria, indicam que estes intervalos pertenceriam ao Eosiluriano (Landoveriano).

Zalán et al. (1987) reconheceram a ocorrência de um pacote arenoso sotoposto aos diamictitos da Formação Vila Maria. A partir desta observação, propuseram uma nova unidade que abrigava os arenitos descritos e os diamictitos originalmente atribuídos à Formação Vila Maria. Esta unidade arenosa foi denominada então Formação Rio Ivaí (Fig.2.4). O contato entre as formações Rio Ivaí, Vila Maria e Furnas foi admitido como concordante. Esta interpretação ficou reconhecida como "divisão tripartite do Siluriano da bacia do Paraná" (Zalán et al. 1987; Milani et. al., 1998; Quintas et al. 1999).

O estudo das diversas perfurações executadas pela PETROBRAS na bacia do Paraná revelou que havia continuidade entre as unidades descritas na borda da bacia em direção ao seu depocentro (Assine e Soares, 1989; Assine et al., 1994; Milani et al., 1995). A análise destas perfurações e o estudo das porções aflorantes revelaram que a unidade predominantemente arenosa abaixo da Formação Vila Maria se tratava de uma nova unidade, separada dos diamicititos por discordância erosiva (Fig. 2.4). Esta unidade arenosa foi denominada Formação Alto Garças, sua seção-tipo foi designada a partir do poço 2-AG-1-MT no Município de Alto Garças, Estado de Mato Grosso (Assine e Soares, 1989). 


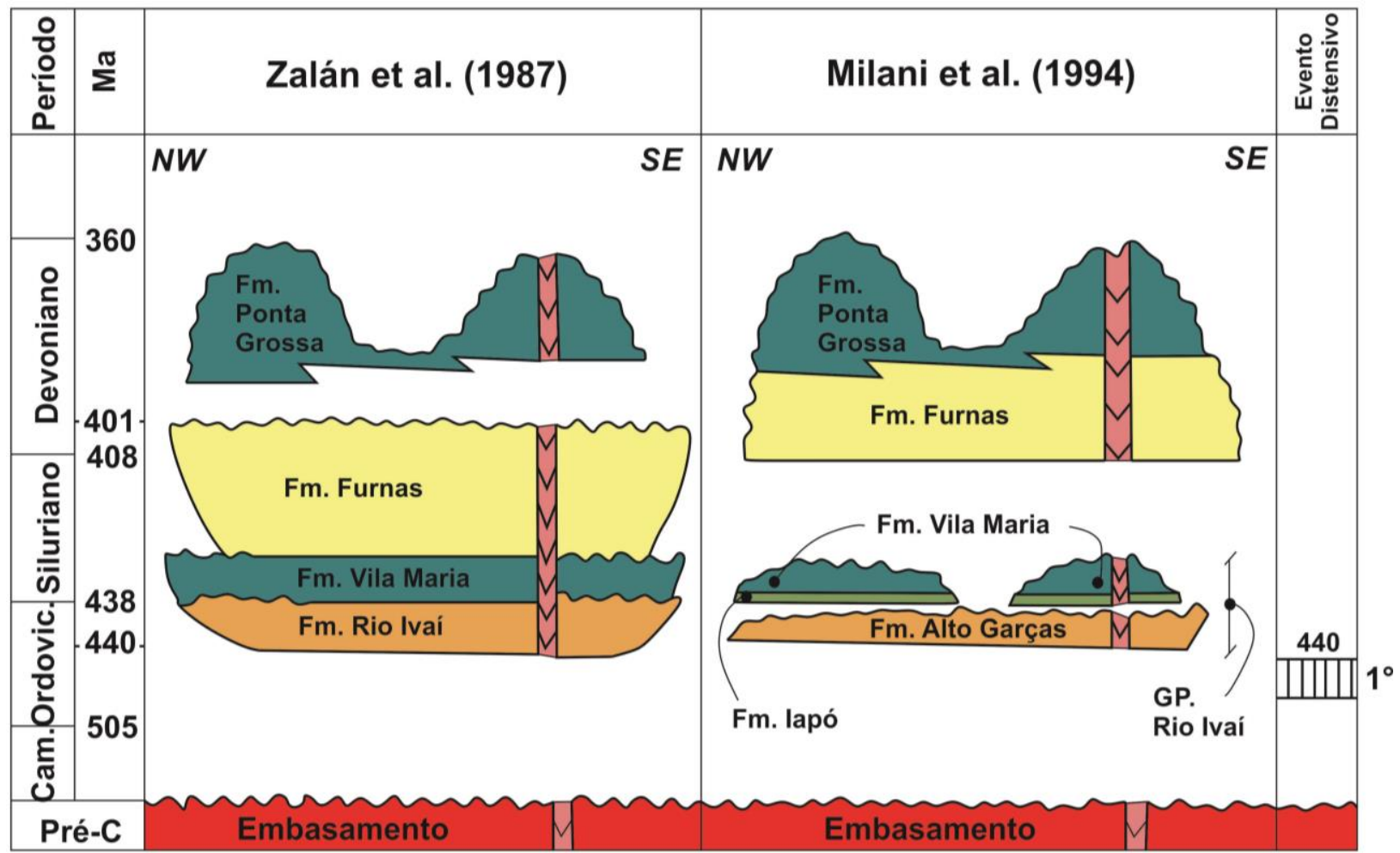

Figura 2. 4. Distribuição cronoestratigráfica das formações do intervalo do Ordociano ao Devoniano da bacia do Paraná (segundo Zalán et al. 1987 e Milani et al. 1994; adaptado de Quintas et al., 1999).

A análise daqueles poços também revelou que a unidade glaciogênica descrita em Maack (1947) no Estado do Paraná, era correlata àquela registrada por Faria na porção norte da bacia e então atribuída à base da Formação Vila Maria (Faria, 1982). O pacote arenoso basal foi desmembrado dos diamictitos glaciais. Estes diamictitos ganharam novamente o nome de Formação Iapó (Assine \& Soares, 1989) tal qual havia sido descrito no Estado do Paraná no trabalho original (Maack, 1947).

A partir desta subdivisão surgiu o conceito de uma nova unidade denominada Grupo Rio Ivaí, integrando três formações: Alto Garças, Iapó e Vila Maria (Assine et al. 1994). A partir de então, esta interpretação é a mais usada, porém há autores que preferem seguir a designação Formação Vila Maria sensu (Faria, 1982) entre eles citam-se (Pereira, 1998; Moreira e Borghi 1999, Mizusaki et al., 2002).

A única datação absoluta da Formação Vila Maria foi realizada a partir dos pelitos da seção da Fazenda Três Barras. Esta datação indicou idade de 435.9 — 7.8Ma através do método 
$\mathrm{Rb} / \mathrm{Sr}$ (Mizusaki et al., 2002). Se considerado o valor do erro obtido nesta datação, o limite inferior do intervalo indicado se posiciona no limite Ordoviciano-Siluriano.

\section{MATERIAIS E MÉTODOS}

O trabalho de pesquisa se iniciou com levantamento bibliográfico sobre a geologia da porção basal da bacia do Paraná, com ênfase nas rochas do Grupo Rio Ivaí. Foram feitas cinco principais campanhas de campo na região de estudo entre 2010 e 2013, uma delas com a participação especial do Prof. Dr. Álvaro de Faria, propositor da Formação Vila Maria. A partir destes trabalhos de campo, os principais afloramentos da Formação Vila Maria puderam ser cartografados e estudados do ponto de vista sedimentológico, estratigráfico e paleontológico.

As amostras coletadas foram tombadas na coleção de pesquisa do Laboratório de Micropaleontologia da Universidade de Brasília sob o prefixo MP-. Os fósseis recuperados foram separados e cortados em blocos pequenos, possibilitando estudo sob microscópio estereoscópico e microscopia eletrônica de varredura (MEV). Os espécimes imageados em MEV foram metalizados com ouro ou carbono respectivamente nos laboratórios de microscopia eletrônica do Instituto de Ciências Biológicas-UnB e Microssonda do Instituto de Geociências (IG) da Universidade de Brasília (UnB). As imagens foram obtidas no MEV do Laboratório de Micropaleontologia do IG/UnB.

A coleção de moldes de Ostracoda recuperados foi tombada na coleção especial de pesquisa do Laboratório de Micropaleontologia da sob o prefixo CP-. Por ser a mais atual, optouse neste trabalho por utilizar a nomenclatura apresentada na Carta Cronoestratigráfica Internacional v2014/02.

\section{RESULTADOS}

O presente trabalho apresenta a taxonomia paleontológica descritiva para os principais grupos fósseis identificados: Ostracoda, Brachiopoda, Icnofóssil, com ênfase nas descrições inéditas de Ostracoda na Formação Vila Maria. A obtenção dos dados para execução deste trabalho foi um grande desafio, uma vez que não havia coordenadas UTM para os afloramentos descritos nos trabalhos clássicos publicados. A participação do Prof. Dr. Álvaro de Faria em uma das campanhas de campo foi crucial para localização exata dos afloramentos da seção-tipo e 
seção-tipo suplementar da Formação Vila Maria, bem como o importante afloramento da seção da Fazenda Três Barras.

Para cada um dos quatro afloramentos descritos, são abordados localização geográfica, levantamento sedimentológico, paleontológico, estratigráfico e registro fotográfico das rochas das unidades reconhecidas. Os fósseis recuperados foram posicionados nas colunas estratigráficas construídas a partir das descrições de cada afloramento. Na sequência apresenta-se uma discussão sobre as implicações paleoambientais e geocronológicas da Formação Vila Maria com base nos produtos apresentados.

\subsection{ATUALIZAÇÃO CARTOGRÁFICA}

Neste trabalho é apresentada a atualização da cartografia geológica para a região dos principais afloramentos do Grupo Rio Ivaí na localidade dos afloramentos-chave da Formação Vila Maria (Fig. 4.1). O mapa apresentado é uma atualização daquele publicado em Alvarenga et al. (1998) com incersão de corrdenadas UTM, vias de acesso e localidade dos afloramentos-chave descritos neste trabalho.

A pequena escala do mapa 1.1.000.000 impossibilita a divisão do Grupo Rio Ivaí em suas formações, o que levou a representação indivisa no mapa geológico. Foram adicionadas coordenadas UTM ao mapa com intuito de facilitar a navegação durante revisitas aos afloramentos em futuros trabalhos de campo. As principais cidades foram plotadas neste mapa como referência geográfica e possíveis bases de apoio para execução das atividades de campo. Os afloramentos estudados no presente trabalho foram adicionados ao mapa geológico (Fig. 4.1). 


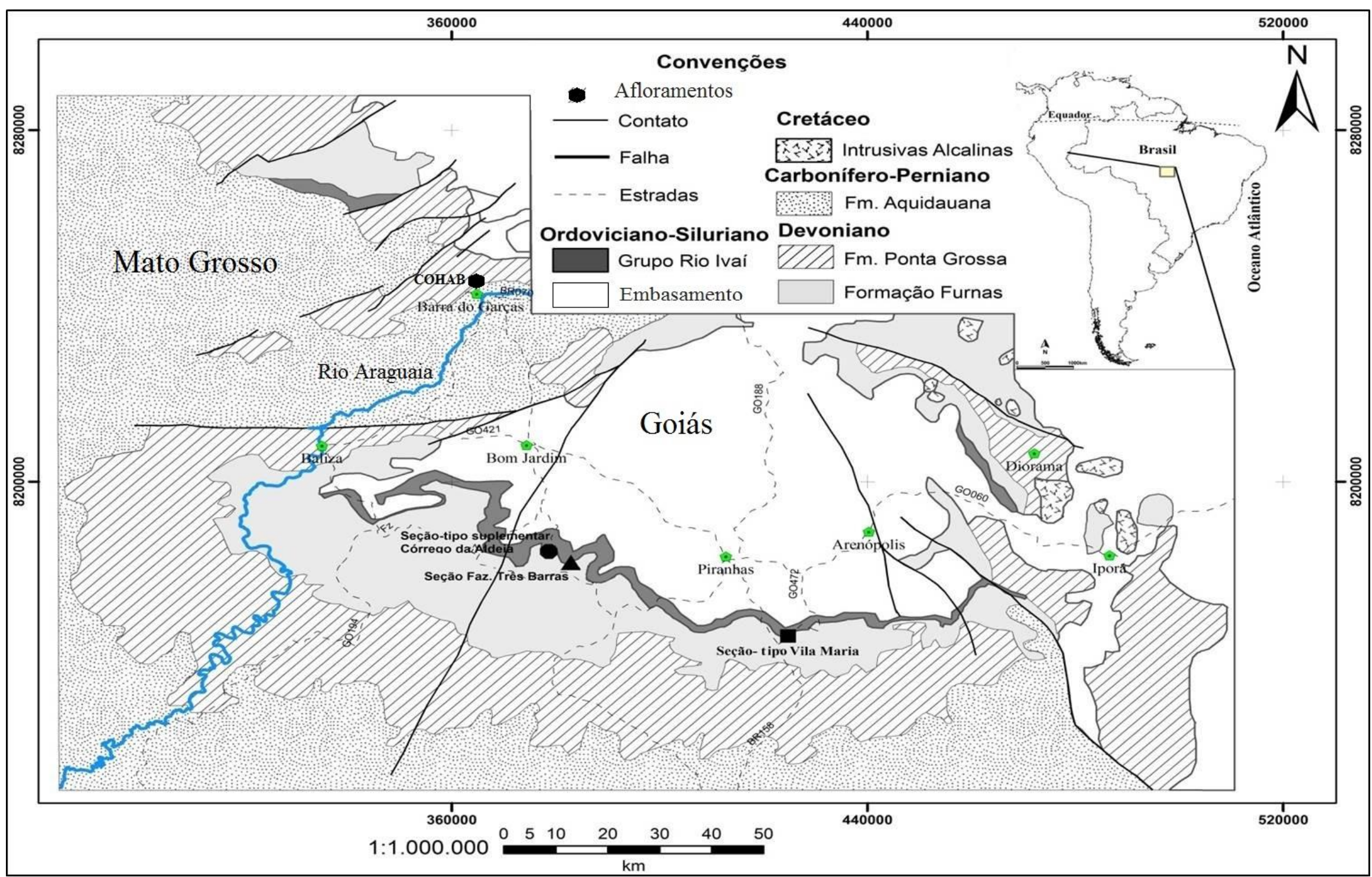

Figura 4. 1. Mapa geológico da área de ocorrência do Grupo Rio Ivaí na região sudoeste do Estado de Goiás e sudeste do Estado de Mato Grosso, Brasil (Adaptado de Alvarenga et al., 1998). 


\subsection{REDESCRIÇÃO DOS PRINCIPAIS AFLORAMENTOS}

Neste tópico apresentam-se descrições detalhadas dos quatro afloramentos estudados: seção-tipo, seção-tipo suplementar, seção da Fazenda Três Barras, seção do Bairro COHAB. Será dada atenção especial ao afloramento da seção-tipo suplementar no Córrego da Aldeia, devido a maior abundância de seu registro fóssil.

\subsubsection{SEÇÃO-TIPO DA FORMAÇÃO VILA MARIA}

O Grupo Rio Ivaí na localidade da seção-tipo da Formação Vila Mria é representado por um pacote de rochas sedimentares de aproximadamente 14 metros de espessura, dos quais aproximadamente dez metros são compostos por diamictitos glaciogênicos atribuídos à Formação Iapó.

\section{TOPONÍMIA}

Coordenadas UTM: 424.698E / 8164.778N, Zona 22K, Datum SAD69.

A seção-tipo da Formação Vila Maria encontra-se nas proximidades do povoado homônimo situado a sul do Município de Arenópolis, Estado de Goiás, Brasil Central. O acesso a partir de Arenópolis se dá pela GO-060 em direção ao Município de Piranhas até a GO-472. Segue-se na GO-472 até o córrego do Sucuri onde se situa a seção-tipo (Fig. 4.2).

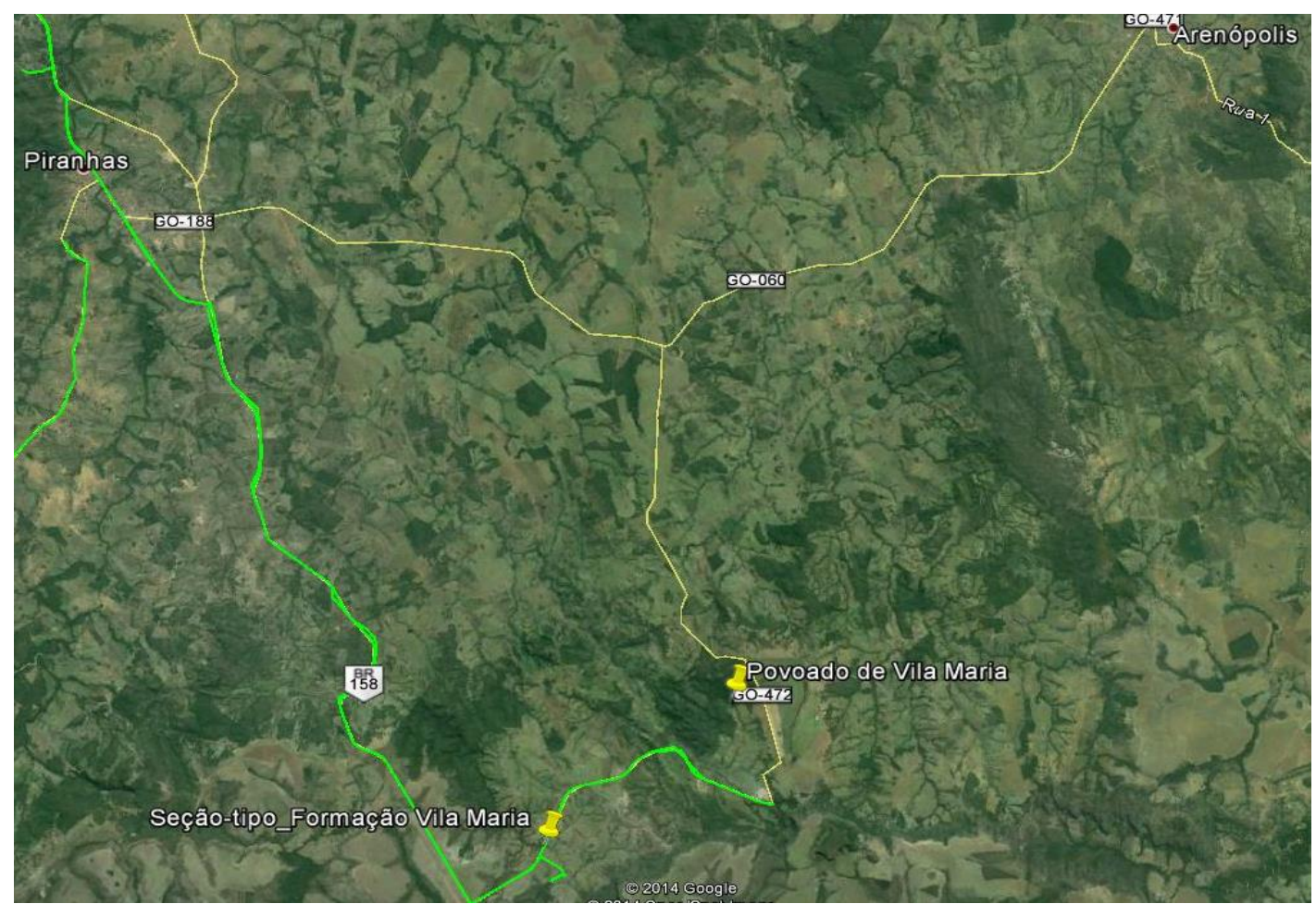

Figura 4. 2. Imagem Google Earth mostrando principais vias de acesso ao afloramento da seção-tipo da Formação Vila Maria. 


\section{EMBASAMENTO}

O Grupo Rio Ivaí, nesta localidade, repousa discordantemente sobre os filitos do Grupo Cuiabá. O Grupo Cuiabá é constituído por filitos com muscovita, sericita, quartzo e clorita. Esta paragênese indica protólito pelítico metaforizado em condições de baixo grau. É possível notar a presença de veios de quartzo dobrados concordantes com a foliação também dobrada indicando deformação dúcil associada (Fig. 4.3A).

Os sedimentos compostos por arenitos conglomeráticos e diamictitos da Formação Iapó, recobrem discordantemente o embasamento, acompanhando o paleorelevo. É possível acompanhar a superfície do paleorelevo do embasamento na escala do afloramento (Fig. 4.3A e 4.3B).

\section{FORMAÇÃO IAPÓ}

A Formação Iapó repousa discordantemente sobre o embasamento Neoproterozóico na localidade da seção-tipo da Formação Vila Maria. Esta Formação é representada por conglomerados, siltitos e diamictitos roxos com ocorrência de Orbiculoidea? sp.

As rochas da Formação Iapó são classificadas como grauvacas líticas mal selecionadas, imaturas textural e mineralogicamente, com níveis conglomeráticos intercalados. A abundância de óxido de ferro confere à rocha coloração roxoavermelhada. Os clastos são arredondados de composição predominantemente quartzítica de tamanho variável entre $5 \mathrm{~mm}$ e $10 \mathrm{~cm}$, apresentando imbricação sutil.

A matriz destes conglomerados é arenosa e possui grãos angulosos apresentando baixa esfericidade, com importante composição modal de argilominerais e óxidos de ferro. A maioria da argila presente na matriz da grauvaca é sinsedimentar, porém há alguns grãos pseudomorfos de caolinita que são fruto de alteração de feldspatos potássicos (caolinitização). Os óxidos de ferro parecem fazer parte do material sinsedimentar com posterior enriquecimento supergênico e limonitização associada.

A Formação Iapó contém diamictitos polimíticos, com seixos de composição e geometria amplamente variável, apresentando seixos facetados, angulosos e eventualmente estriados compostos por: granito, riodacito, quartzito, carbonato e fragmentos de xistos que possuem tamanhos que variam de milimétricos a decimétricos.

Nessa unidade predominantemente rudácea, encontram-se lâminas de siltitos e arenitos vermelho-arroxeados e micáceos, que devido à ação intempérica, se encontra 
fortemente limonitizados, evidenciando os processos de remobilização e precipitação de íons de Ferro.

Nestas lentes siltosas ocorrem moldes de fósseis de braquiópodes Orbiculoidea? sp. preservados em meio a intercalações de ruditos e pelitos com seixos caídos (Fig. 4.3C e 4.3D). Esta ocorrência é discutida como sendo um marco importante para correlação temporal entre as formações Iapó e Vila Maria, indicando que possivelmente não há diferença significativa de idades entre o topo da Formação Iapó e base da Formação Vila Maria, uma vez que estes fósseis ocorrem em ambas formações.

\section{FORMAÇÃO VILA MARIA}

O limite entre as formações Iapó e Vila Maria foi posicionado onde a influência do regime glacial desaparece. Isso equivale, em termos litotípicos, ao fim da camada de lamitos seixosos do topo da Formação Iapó. O contato entre estas duas formações não é muito claro devido à sua natureza transicional. O limite superior da Formação Vila Maria é marcado por contato discordante com os arenitos esbranquiçados e caolínicos da Formação Furnas (Fig. 4.4).

A porção basal da Formação Vila Maria é composta por folhelhos e siltitos micáceos, de coloração arroxeada. A poção superior desta formação é composta por arenitos micáceos. Os pelitos da porção basal abrigam o conteúdo fossilífero mais abundante da seção-tipo, composto por braquiópodes Orbiculoidea? sp. A porção superior da Formação Vila Maria na seção-tipo marca o fim de ciclo de granocrescência ascendente, composta por arenito micáceo arroxeado com estratificações cruzadas acanaladas e tabulares. A fauna composta por braquiópodes desaparece nesta porção dando lugar aos icnofósseis Arthrophycus alleghaniensis (Hall, 1852) que ocorrem impressos nas finas lâminas de siltito que se encontram intercaladas entre pacotes de arenitos. Este iconfóssil marca bem o topo da Formação Vila Maria na localidade da seção-tipo (Fig. 4.3E e 4.3F). 


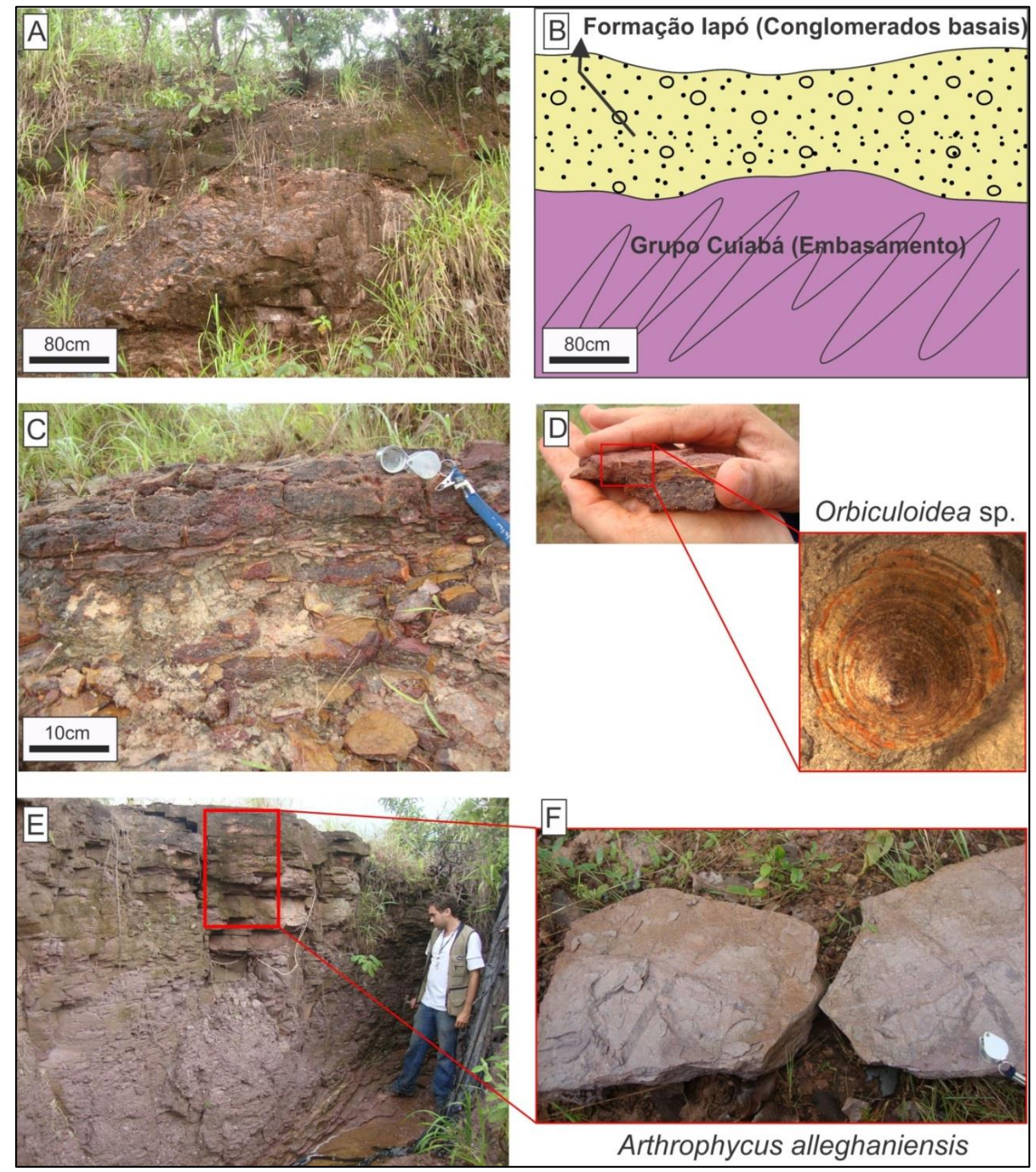

Figura 4. 3. Seção-tipo da Formação Vila Maria, Córrego do Sucurí, povoado de Vila Maria, Município de Arenópolis, Estado de Goiás, Brasil Central. A) Diamictito polimítico da Fm. Iapó em contato erosivo sobre filitos do Grupo Cuiabá. B) Esquema ilustrando foto A. C) Intercalação de siltito fossilífero ferruginizado com arenitos da Formação Iapó. D) Amostra de siltito fossilífero e detalhe para Orbiculoidea sp. E) Siltitos e arenitos roxos e micáceos da Formação Vila Maria. F) Detalhe para amostras contendo icnofósseis Arthrophycus alleghaniensis. 


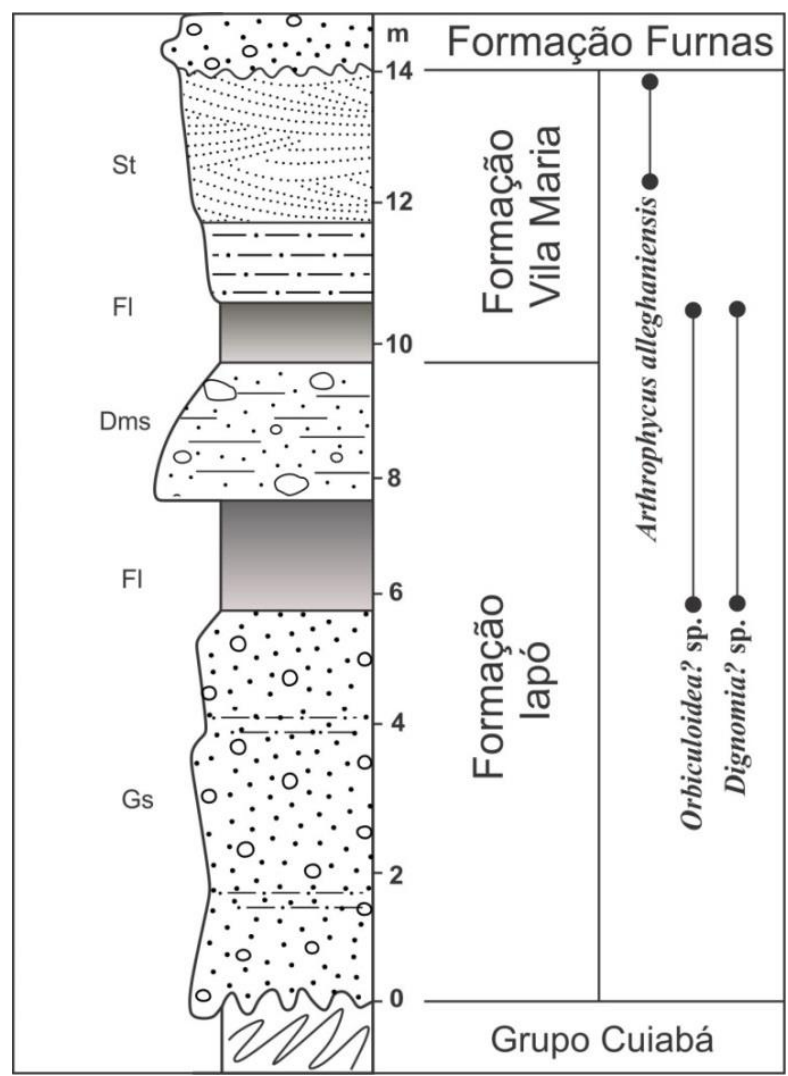

Figura 4. 4. Perfil estratigráfico da seção-tipo da Formação Vila Maria sensu Assine et al. (1994), incluindo o posicionamento das ocorrências fossilíferas. Córrego do Sucuri, Município de Arenópolis, Estado de Goiás, Brasil Central.

\subsubsection{SEÇÃO-TIPO SUPLEMENTAR DA FORMAÇÃO VILA MARIA}

A seção-tipo suplementar está situada ao sul do Município de Bom Jardim de Goiás. O acesso se dá pela estrada que liga Bom Jardim à Fazenda Boa Vista na localidade reconhecida como Serra Negra.

A seção-tipo suplementar abriga a maior abundância fossilífera dentre as quatro localidades estudadas. Nesta localidade a camada de folhelho da base da Formação Vila Maria atinge a maior espessura dentre as seções visitadas. A partir destes folhelhos foi possível recuperar moldes de ostracodes, braquiópodes, icnofóssil, bivalves, moluscos indeerminados, arqueogastrópodes e Incertae Sedis.

\section{TOPONÍMIA}

Coodenadas UTM: 22K. 378862E e 8183928N Datum: SAD69.

A seção-tipo suplementar está localizada na Fazenda Boa Vista, também conhecida como Bela Vista, ao sul do Município de Bom Jardim de Goiás (Fig. 4.5). A seção se inicia no leito do Córrego da Aldeia na Fazenda Boa Vista, nesta localidade é 
possível acompanhar a estratigrafia desde o embasamento até o início do pacote sedimentar.

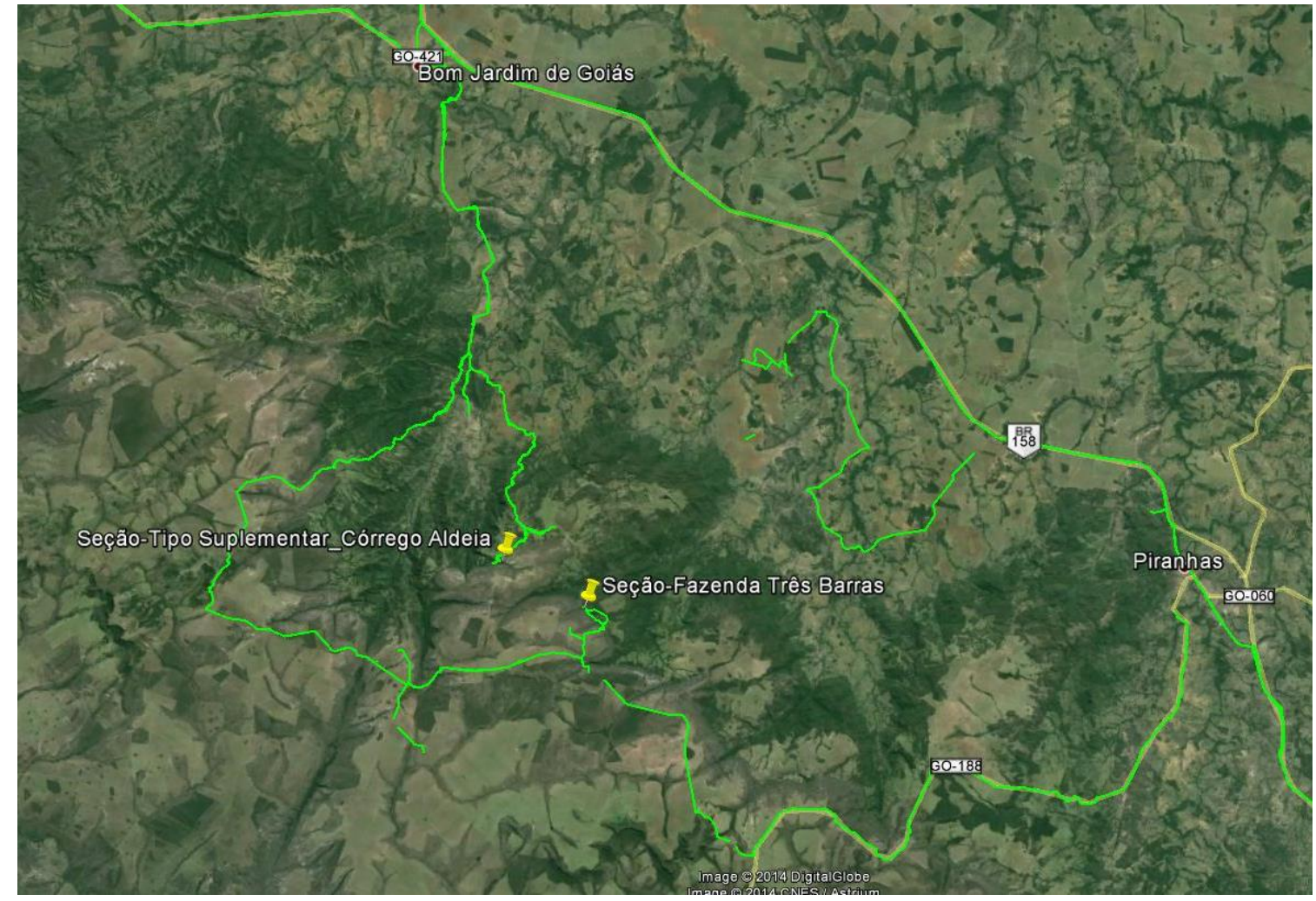

Figura 4. 5. Imagem Google Earth mostrando principais vias de acesso ao afloramento da seção-tipo suplementar da Formação Vila Maria e seção da Fazenda Três Barras.

\section{EMBASAMENTO}

O embasamento nesta localidade é composto por rocha ígnea extrusiva ácida, riodacito. Esta rocha é afanítica a subfanerítica que apresenta coloração cinza escuro (Fig. 4.6a). Há evidência de alteração nas bordas ou próximo às fraturas da rocha, estas bandas de alteração apresentam caolinitização dos feldspatos devido à ação intempérica. Estas rochas provavelmente estão associadas à porção sul do arco magmático de Goiás (Fuck et al., 1994).

\section{FORMAÇÃO IAPÓ}

O pacote inferior da Formação Iapó é formado por diamictito estratificado com clastos angulosos e polimíticos compostos por quartzito, rochas vulcânicas e xistos, imersos em matriz esverdeada areno-siltosa, estratificada e rica em matéria orgânica. Este pacote atinge espessura de 1,5 metro depositado diretamente sobre a superfície irregular do embasamento. O pacote superior é representado por diamictitos estratificados e diamictitos maciços intercalados. A composição dos clastos, e sua 
relação com a matriz, se assemelham muito ao pacote basal. Estes diamictitos têm espessura maior que os basais, chegando a atingir 7 metros de espessura (Figs 4.6b, $4.6 \mathrm{c})$.

\section{FORMAÇÃO VILA MARIA}

A Formação Vila Maria nesta localidade é composta por três intervalos: inferior, intermediário e superior, totalizando 20 metros de espessura. O contato com a Formação Iapó é gradacional. O intervalo inferior da Formação Vila Maria é composto por folhelhos pretos fossilíferos, sucedidos por siltitos micáceos em posição intermediária, capeados por arenitos micáceos na porção superior.

A porção basal da Formação Vila Maria é caracterizada por espesso pacote de folhelho preto que têm espessura de aproximadamente 11 metros (Fig. 4.6f). No intervalo inferior são encontrados abundantes moldes internos e externos de ostracodes, braquiópodes discinídeos Orbiculoidea? sp., bivalves Nuculites? sp., gastrópodes Bucanella? sp. e Incertae Sedis 1 e Incertae Sedis 2 (Fig. 4.6). Estes folhelhos são sucedidos abruptamente por camada de siltitos com laminações plano-paralelas que constituem a porção intermediária da Formação Vila Maria.

A porção intermediária da Formação Vila Maria é constituída por siltitos roxos e micáceos com intercalações de finas lentes e lâminas de arenitos finos, formando acamamento do tipo heterolítico lenticular (Fig. 4.6g). Sobrepondo-se a este intervalo intermediário constituído por siltito, sucede-se gradativamente o intervalo superior de arenito.

A porção superior da Formação Vila Maria atinge a espessura máxima de 7 metros e está em contato discordante com os arenitos esbranquiçados e caoliníticos da Formação Furnas. Os arenitos do intervalo superior da Formação Vila Maria variam de muito finos a médios, são bem selecionados, possuem grãos subangulosos a arredondados. Internamente estes arenitos podem ser maciços, porém há intervalos com laminação plano-paralela, hummocky e estratificação cruzada de baixo-ângulo (figs 4.6h, 4.6j). Nesta porção, notam-se intercalações de finas lâminas de siltito micáceo entre os pacotes de arenitos. Nestas interfaces siltito-arenito, ocorre a icnoespécie Arthrophycus alleghaniensis (Fig. 4.6i). A Formação Vila Maria encontra-se capeada pelos arenitos caoliníticos e esbranquiçados da Formação Furnas. O contato entre o topo da Formação Vila Maria e a base da Formação Furnas se dá por paraconformidade. 


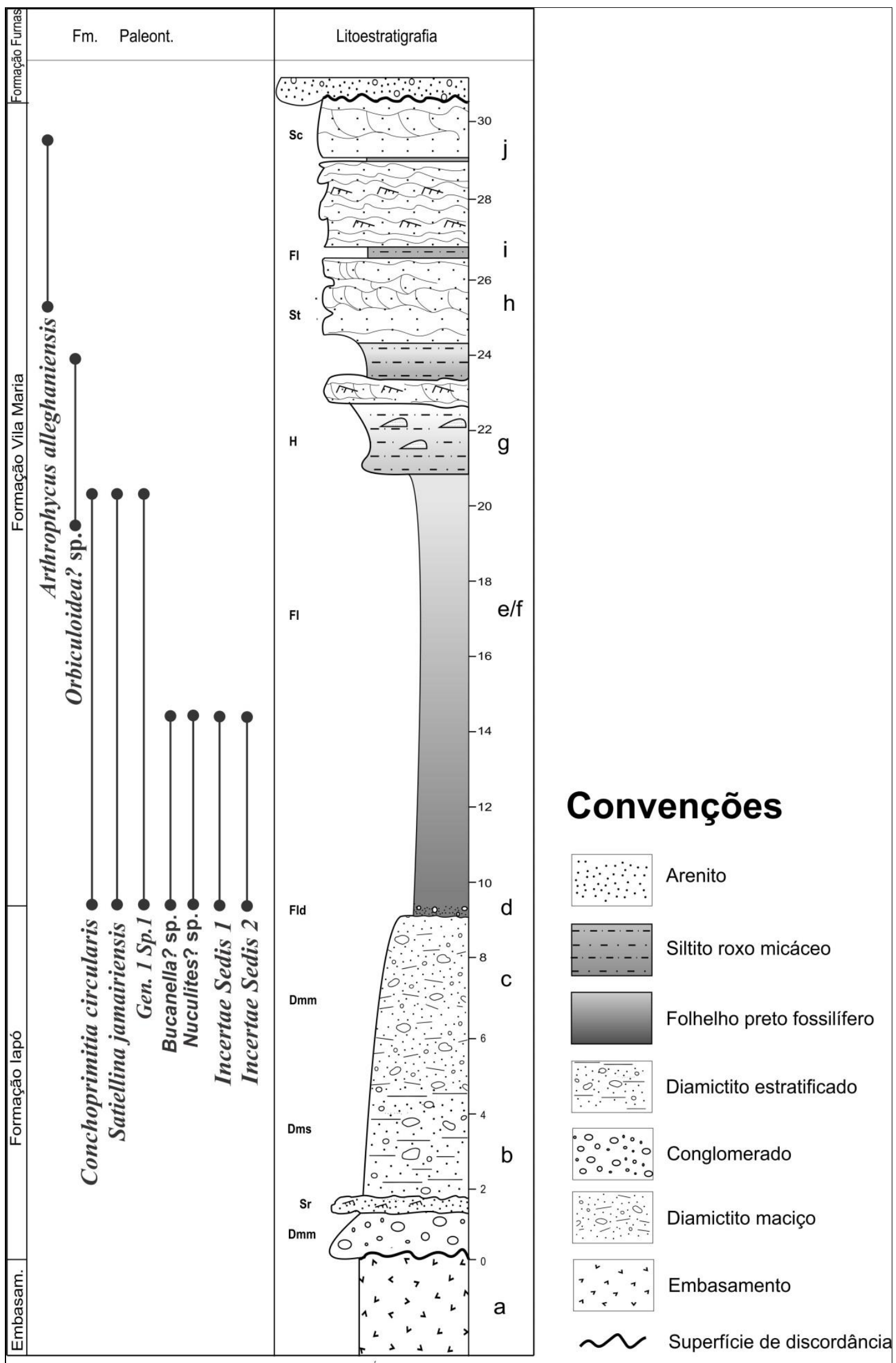

Figura 4. 6. Coluna estratigráfica com posicionamento das ocorrências fossilíferas para a seção-tipo suplementar no Córrego da Aldeia, Fazenda Bela Vista, Município de Bom Jardim de Goiás, Estado de Goiás, Brasil Central. 

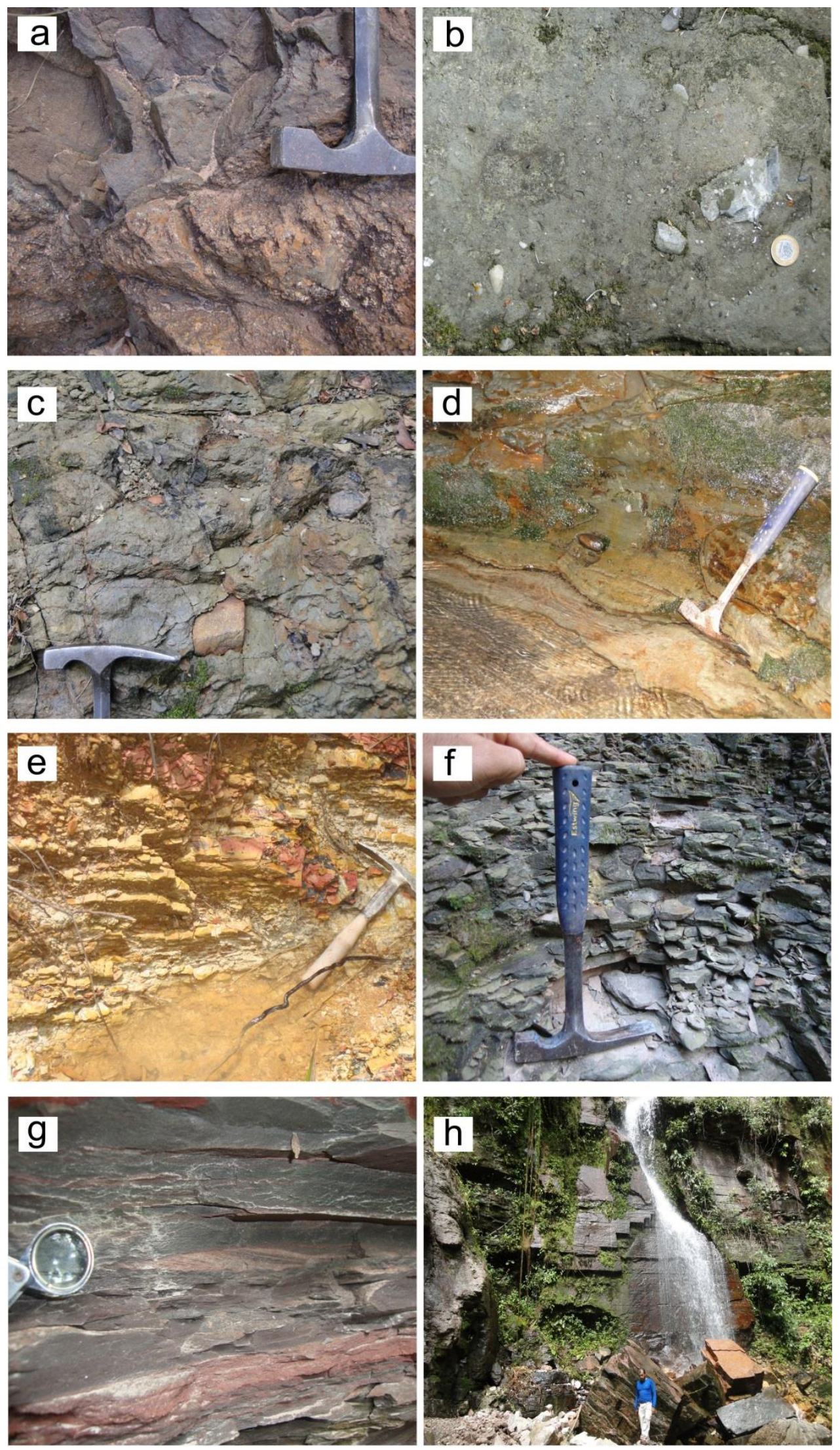

Figura 4. 7. Seção-tipo suplementar da Formação Vila Maria, Córrego da aldeia, Município de Bom Jardim de Goiás, Estado de Goiás, Brasil Central. a) Embasamento cristalino. b-d) Formação Iapó. e-g) Formação Vila Maria. h) Vista geral do afloramento. 


\subsubsection{SEÇÃO DA FAZENDA TRÊS BARRAS}

A seção da Fazenda três Barras foi incluída neste trabalho devido a sua importância, tendo em vista que nesta localidade foi feito trabalho de datação absoluta $\mathrm{Rb} / \mathrm{Sr}$ a partir dos folhelhos basais da Formação Vila Maria (Mizusaki et al., 2002). A Formação Vila Maria aflora na região da Fazenda Três Barras, em escarpas e cachoeiras, onde a exposição da formação pode ser completa ou parcial chegando a exposições com aproximadamente $15 \mathrm{~m}$ de espessura (Fig. 4.8).

\section{TOPONÍMIA}

Coodenadas UTM: Zona 22K, 382877E e 8181679N elevação 770m. Esta seção se localiza na Fazenda Três Barras, localizada a sul de Bom Jardim de Goiás e a oeste de Piranhas pela estrada não pavimentada GO188 e depois por estrada sem denominação que liga a cidade de Piranhas a Bom Jardim de Goiás (Fig. 4.5, mesma da seção-tipo suplementar).

\section{FORMAÇÃO IAPÓ}

A Formação Iapó aflora discordantemente sobre o embasamento na seção da Fazenda Três Barras e é representado litologicamente por diamictitos maciços polimíticos, com seixos dispersos na matriz pelítico-arenosa, de cor esverdeada (Fig. 4.8A). Logo acima deste pacote psefítico está localizado uma delgada camada de arenito.

\section{FORMAÇÃO VILA MARIA}

A sedimentação da Formação Vila Maria inicia-se com pacote pelítico fossilífero de espessura de aproximadamente 2 metros, com coloração cinza esverdeada, onde ocorrem abundante quantidade de moldes de Bivalvia Nuculites? sp., Gastropoda Bucanella? sp. e incertae sedis1 e incertaes 2.

A partir dos pelitos da Formação Vila Maria nesta localidade, foram descritas ocorrência de diversos palinomorfos (Gray et al. 1985, Mizusaki et al., 2002; Grahn e Pereira, 2000), que indicaram idade próxima do limite Neordoviciano-Eosiluriano para esta formação (porção inferior da figura 4.9).

Acima deste pacote pelítico aparecem os primeiros registros de areia e silte, este intervalo coincide com o desaparecimento dos fósseis no perfil (Fig. 4.9C). Este aumento na granulometria indica mudanças no paleoambiente, que passa de parálico 
para ambiente com influência de ação de correntes de fundo. Em direção ao topo do perfil nota-se engrossamento para o topo (coarsening upward) com cada vez maior aporte de areia, até que o pacote pelítico dá lugar aos arenitos da porção superior. Neste intervalo superior ocorre somente icnofósseis Arthrophycus alleghaniensis.

$\mathrm{Na}$ porção superior da seção o pacote de arenitos marca uma importante expressão sedimentar que registra um evento progressivo de regressão marinha. Estes arenitos são indicativos de plataforma marinha rasa, com marcas onduladas, estratificações cruzadas acanaladas, hummoky, e eventualmente gretas de contrações são presentes, bem como gretas de sinérese (Fig 4.9D).
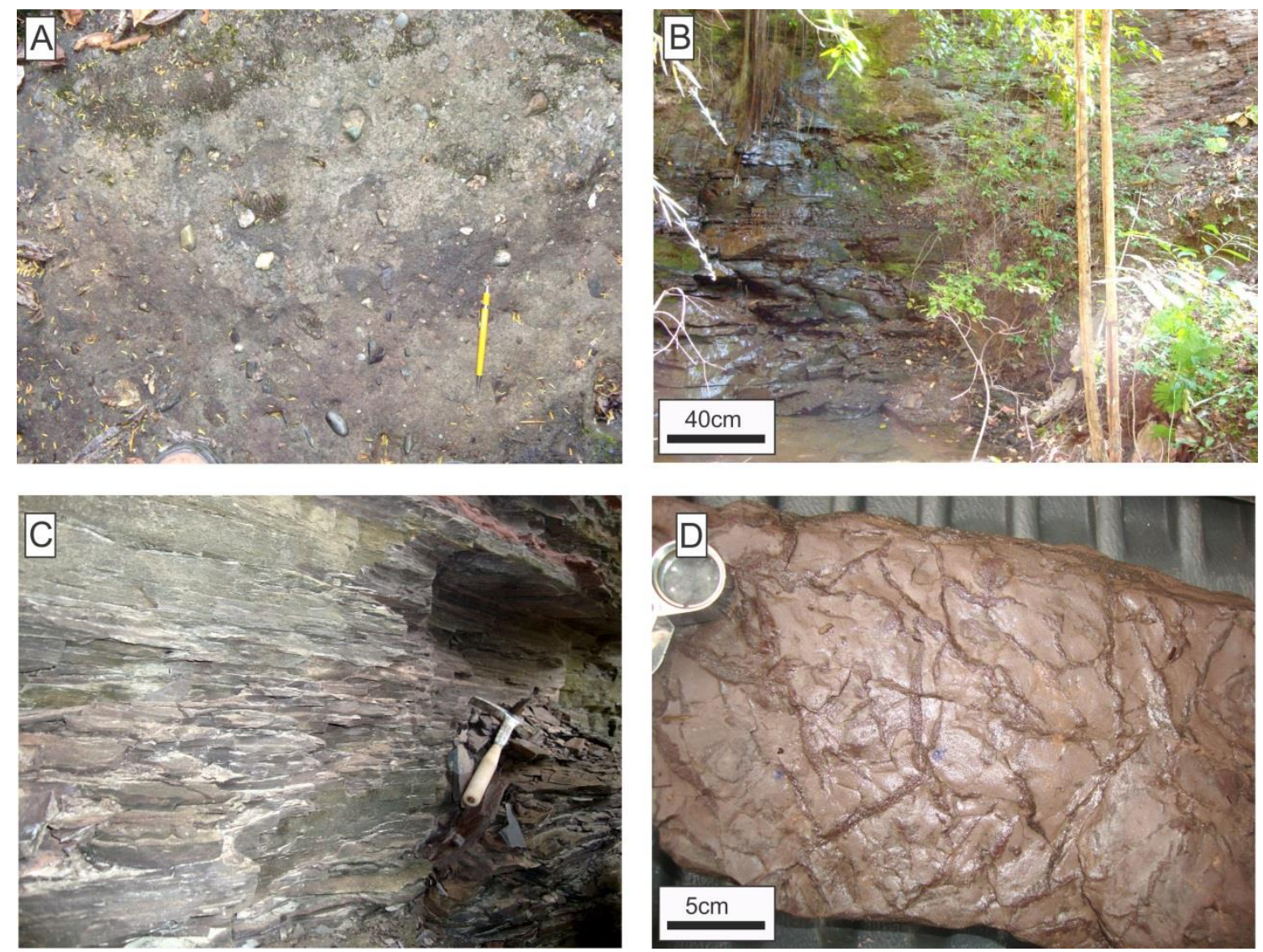

Figura 4. 8. Seção da Fazenda Três Barras, Município de Bom Jardim de Goiás, Estado de Goiás, Brasil Central. A) Diamictito da Formação Iapó. B Vista geral afloramento da Formação Vila Maria em cachoeira. C) Detalhe da porção intermediária da Formação Vila Maria com siltitos micáceos roxos. D) Traços fósseis e gretas de sinerese no topo da Formação Vila Maria.

O empilhamento das rochas do Grupo Rio Ivaí na localidade da seção da Fazenda Três Barras compõe um perfil de aproximadamente $14 \mathrm{~m}$ de espessura. Neste perfil foram posicionados as ocorrências fossilíferas encontradas (Fig. 4.9). 


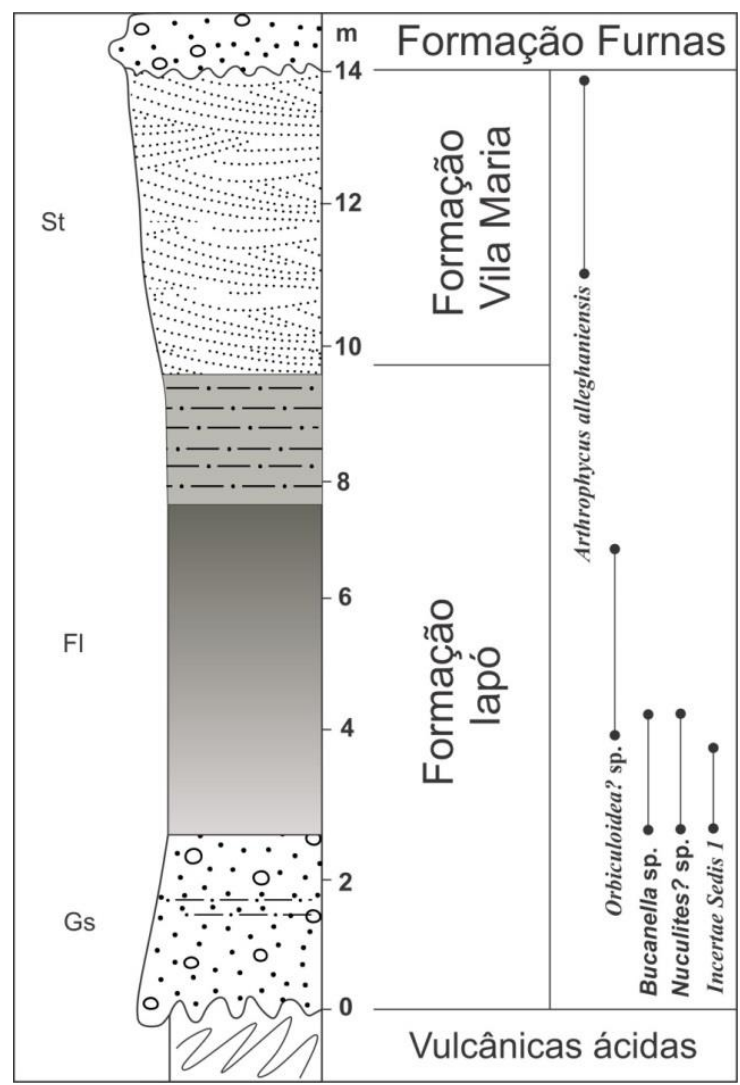

Figura 4. 9. Coluna estratigráfica para localidade da Fazenda Três Barras. Seção da Fazenda Três Barras, Município de Bom Jardim de Goiás, Estado de Goiás, Brasil Central.

\subsubsection{SEÇÃO DO BAIRRO COHAB}

A seção do Bairro COHAB foi incluída neste trabalho por se tratar de uma importante exposição de rochas das três formações pertencentes ao Grupo Rio Ivaí. Estes afloramentos são controlados por falhas que soergueram blocos, possibilitando acesso a afloramentos nas escarpas e taludes próximos ao centro da Cidade de Barra do Garças, Estado de Mato Grosso.

\section{TOPONÍMIA}

Coordenadas UTM: Zona 22L, 363869E e 8245820N.

O afloramento se situa na escarpa próxima ao Bairro COHAB, seguindo-se pela Rua D, então margeando a escarpa até local aberto onde as rochas do Grupo Rio Ivaí próximo ao morro do Cristo (Fig. 4.10). 


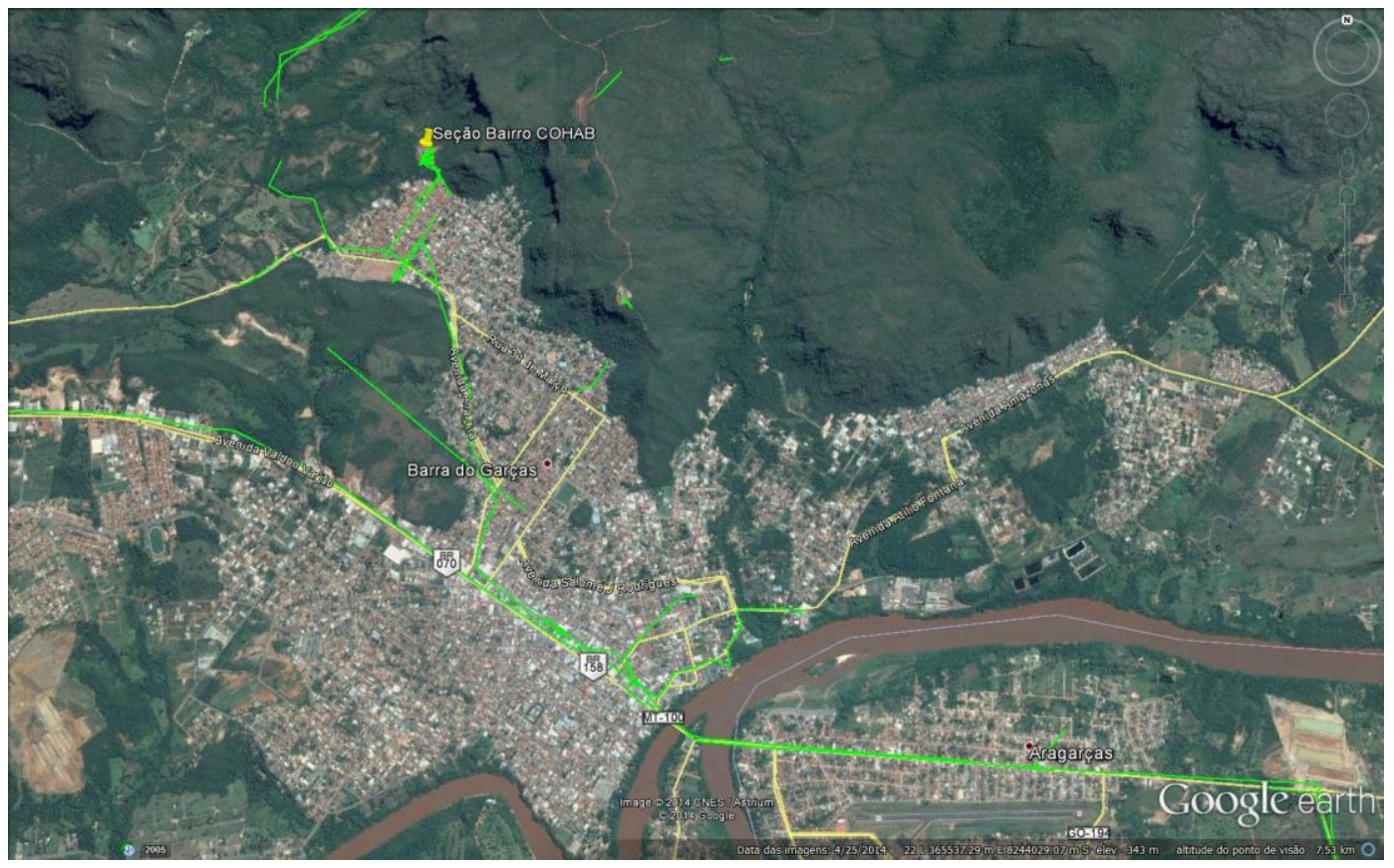

Figura 4. 10. Imagem Google Earth mostrando principais vias de acesso ao afloramento do Bairro COHAB-Barra do Garças, Mato Grosso.

\section{FORMAÇÃO ALTO GARÇAS}

A Formação Alto Garças é composta por arenitos médios a grossos amarelados, feldspáticos, friáveis, mal selecionados, por vezes com lag's seixosos, cuja base, neste perfil, é indeterminada devido à cobertura coluvionar quaternária existente (Fig. 4.11A). Esta formação apresenta laminação interna, estratificação cruzada acanalada e intercalação com níveis argilosos.

Nos níveis superiores estes arenitos apresentam feições de deformações causadas provavelmente devido à passagem do gelo. A carga sobre os sedimentos ainda inconsolidados durante o Ordoviciano, causou uma serie de cisalhamentos internos que foram mantidos após a litificação da Formação Alto Garças.

\section{FORMAÇÃO IAPÓ}

A Formação Iapó repousa discordantemente sobre os arenitos da Formação Alto Garças. Esta formação é composta por lamitos seixosos dispostos em bandas centimétricas com coloração rosada. Em meio a estes lamitos seixosos é possível notar a presença de bolsões de areia mal selecionada, bastante friável com coloração esbranquiçada, com caulinita como resultado de alteração de feldspatos preexistentes.

Avançando-se em direção ao topo desta uniade, nota-se que estes lamitos são substituídos por diamictito propriamente dito, cuja matriz siltico-arenosa abriga seixos 
centimétricos de composições variadas, desde xistos bastante alterados até quartzitos angulosos. Há intercalações de arenitos mal selecionados em meio aos diamictitos da Formação Iapó (Fig. 4.11B-C).

Na porção superior da Formação Iapó, onde ocorrem os lamitos seixosos, iniciase a ocorrência de braquiópodes Orbiculoidea? sp. Esta ocorrência ultrapassa o limite desta formação atingindo a base da Formação Vila Maria (Fig. 4.12).
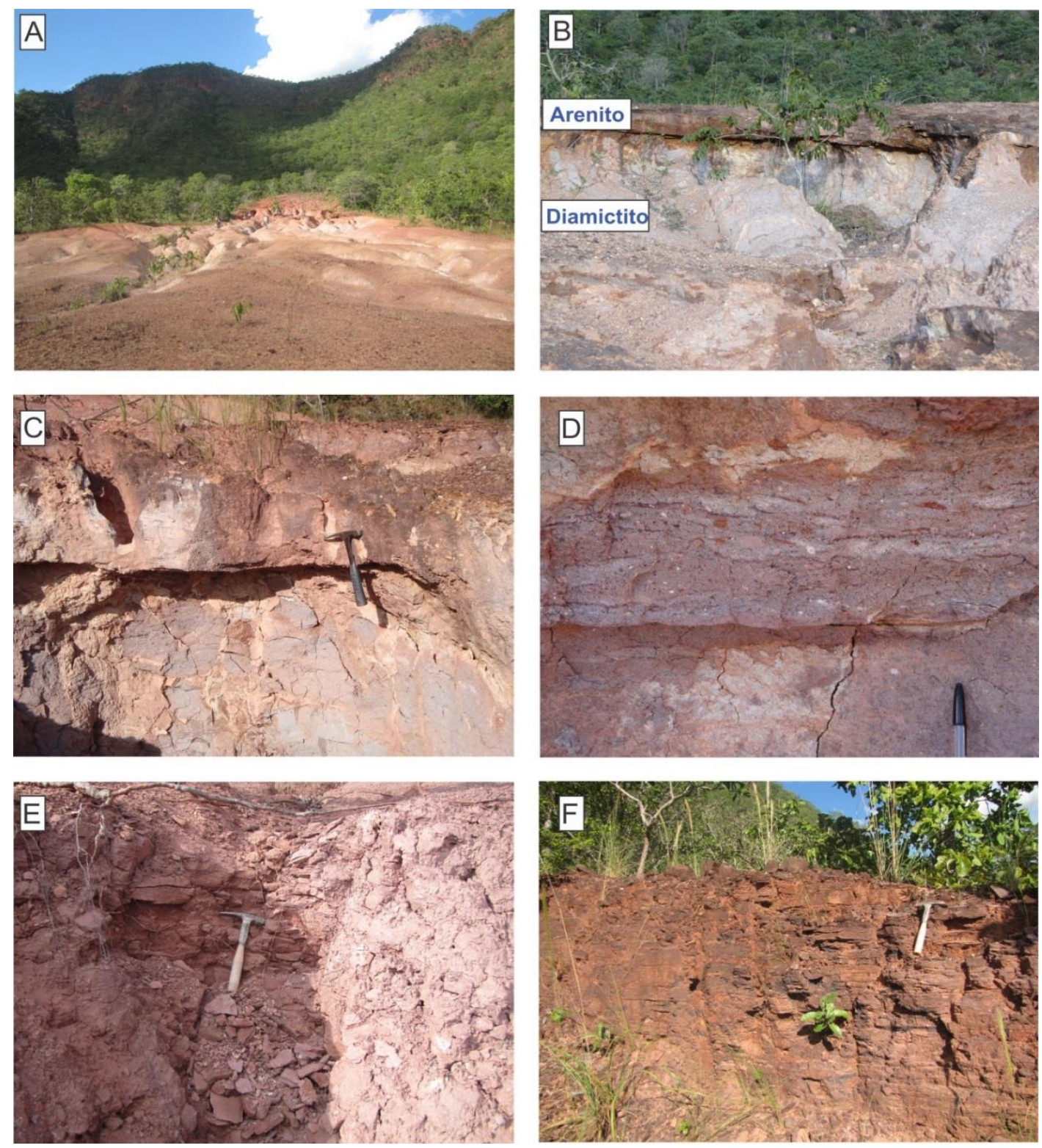

Figura 4. 11. Seção do Bairro COHAB, Barra do Garças, MT. A) Em primeiro plano arenitos amarelados da Formação Alto Garças, em segundo plano Formação Vila Maria. B) Pacotes arenosos da Formação Iapó. B) Formação Iapó com bancos de arenitos intercalados ao diamictito. D) Detalhe para diamictito. E) Siltitos fosilíferos da Formação Vila Maria. F) Arenitos do topo da Formação Vila Maria. 


\section{FORMAÇÃO VILA MARIA}

O contato entre as Formações Iapó e Vila Maria é gradacional. A Formação Vila Maria inicia-se onde os lamitos seixosos dão lugar ao folhelho sem influência de processos glaciogênicos. Esta passagem se dá a aproximadamente sete metros do perfil levantado no Bairro COHAB (Fig. 4.12), a rocha é predominantemente composta por folhelho, de coloração cinza, micáceo, com ocorrência abundante de Orbiculoidea? sp. e restrita de Dignomia? sp.

Acima dos folhelhos fossilíferos estão depositados siltitos e arenitos avermelhados. Nestes níveis o conteúdo fossilífero se torna escasso, se restringindo a fragmentos de moldes de conchas, evidenciando ação de retrabalhamento e transporte por correntes.

$\mathrm{Na}$ cota de 14 metros do perfil notam-se evidências da regressão marinha experimentada pela bacia. Este registro, como já descrito nos outros afloramentos, é materializado pelo pacote francamente arenoso com estruturas que levam a interpretação de ambiente marinho plataformal raso com estratificações cruzadas acanaladas, tabulares e hummoky (Fig. 4.12).

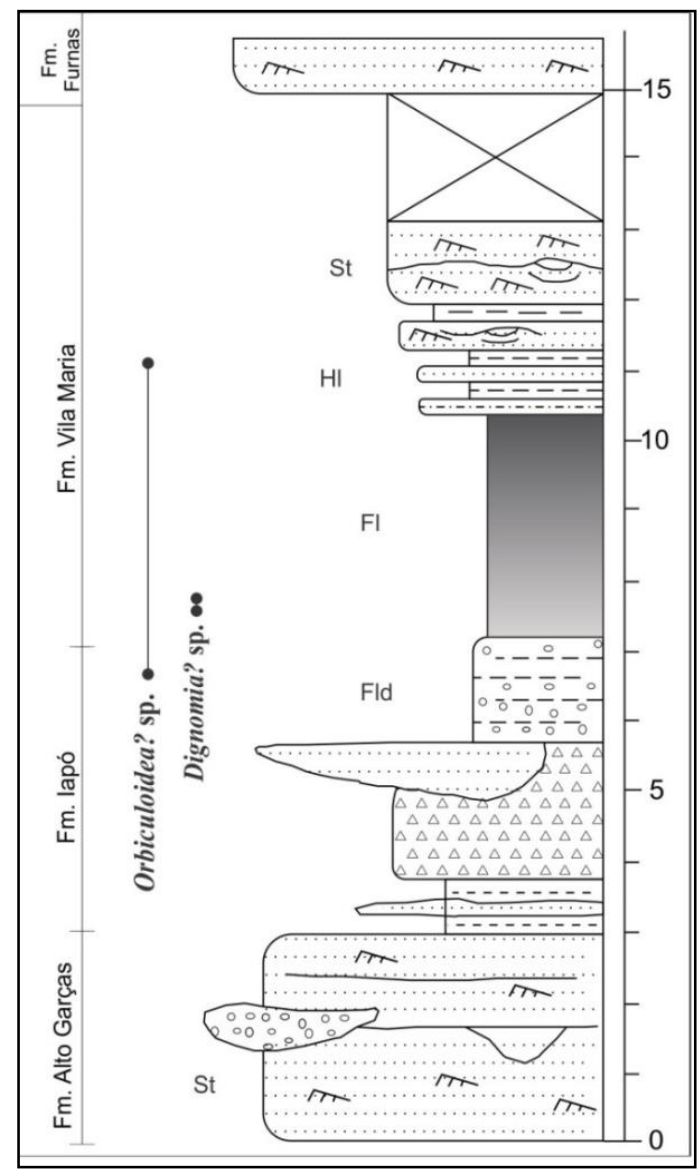

Figura 4. 12. Coluna estratigráfica para localidade do Bairro COHAB, Cidade de Barra do Garças., Estado de Mato Grosso, Brasil Central (Adaptado de Assine et al., 1994). 


\subsection{TAXONOMIA PALEONTOLÓGICA}

Neste tópico serão apresentadas as informações sobre a taxonomia dos fósseis recuperados e ilustrados no presente trabalho. Foram descritas espécies de Ostracoda, de Brachiopoda e de icnofóssil recuperados a partir dos afloramentos estudados.

\subsubsection{OSTRACODA}

Três espécies de ostracodes provenientes dos folhelhos da porção basal da Formação Vila Maria na seção-tipo suplementar foram descritas no presente trabalho: Satiellina jamairiensis Vannier 1986; Conchoprimitia circularis n. sp., e Gen. 1 et sp.1 (Adorno et al. submetido, Anexo I). A taxonomia supragenérica adota da neste trabalho segue a de Vannier (1986) e Salas et al., (2011).

Classe OSTRACODA Latreille, 1806

Ordem PALEOCOPIDA Henningsmoen, 1953

Familia INCERTAE

Gênero SATIELLINA Vannier, 1986

Espécie-tipo do gênero.—Bollia delgadoi Vannier, 1983.

Diagnose.-Contorno da valva subelíptico. Lobos L1 e L2 são ligeiramente desiguais, e proeminentes, ultrapassando a borda dorsal da carapaça, unidos ventralmente por junção mais ou menos clara que forma um arco zygal em formato de U. Há depressão mais ou menos vertical entre os lobos denominada sulco. Superfície extralobar convexa. Ausência de rebordo marginal. Dimorfismo expresso por caracteres heteromórficos com superfície extralobar posterior mais bem desenvolvida (Vannier, 1986).

Diagnose original (francês).-Contour de Ia valve subelliptique. Lobes LI et L2, de taille légèrement inégale, proéminents,pouvant dépasser le bord dorsal, fusionnant ventralement de façon plus ou moins nette, formant un are zygal en $U$ à Ia surface de Ia valve. Dépression subverticale plus ou moins marquée, soulignant Ia base de Farc zygal. Surface extralobaire convexe. Absence de bourrelet marginal. Dimorphisme s'exprimant, chez les hétéromorphes par une surface extralobaire postérieure plus développée (Vannier, 1986).

Discussão.-Satiellina Vannier, 1986 compreende três espécies do Ordoviciano: Satiellina delgadoi (Vannier, 1953), Satiellina henningsmoeni (Nion, 1972) e Satiellina jamairiensis Vannier, 1986. Originalmente, Vannier (1986) enfatizou que Satiellina 
distingue-se de Bollia Jones \& Holl, 1886, Pseudobollia Schallreuter, 1968 e Quadrijugator Kesling \& Hussey, 1953 por apresentar superfície extralobar convexa.

\section{SATIELLINA JAMAIRIENSIS Vannier, 1986}

(Fig. 4.13: 1-7)

Holótipo.—-spécimen IGR 30770/1; molde externo valva direita (Vannier, 1986).

Localidade-tipo.-Sondagem D1-23 (profundidade 1994m) Formação Djeffara, Ashgil? bacia de Ghadames, Libia (Vannier, 1986).

Diagnose.- - espécie do gênero Satiellina que não tem conexão ventral dos dois lobos L1 e L2. O arco zigal é bastante proeminente. O limite entre o arco formado pelos lobos e a superfície extralobar é feita por meio de sulco bem marcado (Vannier, 1986).

Material ilustrado.-Moldes de seis carapaças adultas foram ilustrados a partir do afloramento da seção-tipo suplementar, Córrego da Aldeia, Município de Bom Jardim de Goiás, Brasil Central (Tab. 1) (Fig. 4.6).

Tabela 4. 1. Medida dos moldes das carapaças de Satiellina jamairiensis Vannier 1986, seção-tipo suplementar Córrego Aldeia, Fazenda Boa Vista, Arenópolis, Estado de Goiás, Brasil Central.

\begin{tabular}{rcccc}
\hline Espécime $(\boldsymbol{\mu m})$ & Comprimento & Altura & C:A & Ilustração \\
\hline CP-634 & 630 & 450 & 1,4 & Fig. 4.13: 1-2 \\
CP-637 & - & - & & Fig. 4.13: 4- \\
CP-642 & - & - & & - \\
CP-643 & 550 & 450 & 1,22 & Fig. 4.13: 5 \\
CP-645 & 550 & 400 & 1,37 & Fig. 4.13: 3- \\
CP-646 & 550 & 400 & 1,37 & Fig. 4.13: 6 \\
CP-647 & - & - & & - \\
CP-651 & 630 & 400 & 1,57 & Fig. 4.13: 6 \\
CP-662 & - & - & & - \\
CP-664 & - & - & & - \\
\hline
\end{tabular}

Ocorrência.-Ordoviciano da bacia de Ghadames, norte da Líbia (Vannier, 1986). Brasil, seção-tipo suplementar da Formação Vila Maria, Grupo Rio Ivaí, flanco norte da bacia do Paraná (Adorno et al. Submetido, Anexo I).

Discussão.- -Nos espécimes recuperados a partir da Formação Vila Maria, os lobos terminam antes de atingir a margem dorsal, a região ventral do lobo posterior é a mais larga, assim como a superfície extralobar é convexa, caracteres que coincidem com aqueles descritos originalmente para S. jamairiensis. As espécies de Satiellina incluindo 
S. jamairiensis apresentam dimorfismo sexual, porém o reduzido número de espécimes recuperados neste trabalho não permitiu a observação desta característica. A espécie estudada se assemelha a Satiellina delgadoi Vannier, 1986, por possuir superfície lateral convexa e contorno externo subelíptico-subcircular, por possuir ângulos cardinais obtusos e dois lobos perpendiculares à margem dorsal. Porém se distingue $S$. delgadoi por possuir lobos que não ultrapassam o limite dorsal. O lobo anterior é menos desenvolvido e mais fino do que em S. delgadoi.

\section{Subordem ERIDOSTRACINA Adamczak, 1961}

Familia CONCHOPRIMITIIDAE Henmingsmoen, 1953

Gênero CONCHOPRIMITIA Öpik, 1953

Espécie-tipo do gênero.—Conchoprimitia gammae Öpik, 1935.

Diagnose.-Primitiidae pequeno (1.5 a $3 \mathrm{~mm}$ de comprimento) com linha de charneira retilínea, com um ou dois pares de lobos limitados por sulcos mais ou menos desenvolvidos, assemelhando-se a linhas de crescimento de braquiópodes. Ordovicino Inferior a Superior (Öpik, 1953).

Diagnose original (inglês). - Small (1.5 to $3 \mathrm{~mm}$ long) Primitiidae with a straight hinge line, with one or two pairs of bands. Limited by grooves resembling the growth lines of shells of brachiopods, more or less developed. Lower to Upper Ordovician (Öpik, 1953).

Discussão.- Salas et al., (2011) apresenta discussão detalhada da distribuição paleogeográfica e de características morfológicas deste gênero. A distinção deste gênero está baseada na convexidade da carapaça que possui longa charneira e contorno postplete.

\section{CONCHOPRIMITIA CIRCULARIS n. sp.}

(Fig. 4.13: 8-12)

Material ilustrado.-Holótipo CP-631 (Fig. 4: 8); os parátipos CP-635; CP-639, CP660, e CP-649 foram ilustrados (Fig. 4:12-12) (Tab. 2), provenientes da porção basal da seção-tipo suplementar da Formação Vila Maria, córrego da Aldeia, Município de Bom Jardim de Goiás, Estadod e Goiás, Brasil Central (Fig. 4.6).

Diagnose.-Carapaça com formato circular, postplete, com sulco e nódulo pré-adutorial sutis marcados na região antero-dorsal. Margem dorsal retilínea, margem ventral 
convexa e extremidades anterior e posterior arredondadas. Superfície externa com pontuações sutis em molde externo.

Descrição.-Carapaça apresenta contorno subcircular, exceto para a charneira. Contorno postplete com maior comprimento na metade da maior altura. A margem dorsal é retilínea e se estende a aproximadamente $2 / 3$ do comprimento da valva. A margem ventral convexa, com maior raio de curvatura coincidindo com a maior altura. Extremidade anterior arredondada com maior convexidade na metade da altura. Extremidade posterior arredondada com raio de curvatura maior do que aquele da extremidade anterior. Ângulos cardinais obtusos, anterior $120^{\circ}$ e o posterior $140^{\circ}$. Nódulo préadutorial sutil e localizado na região anterodorsal apresentando formato circular, com baixo relevo e limites mal definidos, alçando a margem dorsal. Sulco préadutorial perpendicular à margem dorsal com pouca profundidade, restrito à extensão do nódulo, não atingindo a margem dorsal. Valvas com descontinuidade na convexidade da superfície externa em toda extensão marginal, mais bem marcada na região posterior do que na anterior. Em vista dorsal, valvas biconvexas, curvatura suave e maior largura na região mediana. A superfície externa apresenta uma série de pontuações.

Etimologia.-A derivação "circularis" foi atribuída a espécie devido ao formato aproximadamente circular da carapaça em vista lateral.

Tabela 4. 2 Medida dos moldes das carapaças de Conchoprimitia circularis n. sp., seção-tipo suplementar Córrego Aldeia, Fazenda Boa Vista, Município de Arenópolis, Estado de Goiás, Brasil Central.

\begin{tabular}{lcrcc}
\hline Espécime ( $\boldsymbol{\mu m})$ & Comprimento & Altura & \multicolumn{1}{c}{ C:A } & Ilustração \\
\hline CP-631 Holótipo & 650 & 430 & 1,51 & Fig. 4.13: 8 \\
\hline Parátipo CP-632 & & & & - \\
Parátipo CP-633 & 655 & 450 & 1,45 & - \\
\hline Parátipo CP635 & 650 & 430 & 1,5 & Fig. 4.13: 9 \\
Parátipo CP-638 & 600 & 450 & 1,33 & - \\
\hline Parátipo CP-639 & 600 & 420 & 1,42 & Fig. 4.13: 10 \\
Parátipo CP-648 & 580 & 400 & 1,45 & - \\
\hline Parátipo CP-649 & 580 & 400 & 1,45 & Fig. 4.13: 12 \\
\hline Parátipo CP-657 & & 300 & & - \\
\hline Parátipo CP-660 & 300 & 200 & 1,5 & Fig. 4.13: 11 \\
Parátipo CP-661 & 300 & 200 & 1,5 & - \\
\hline Parátipo CP-663 & 500 & 300 & 1,67 & - \\
Parátipo CP-666 & 600 & 400 & 2 & - \\
\hline
\end{tabular}


Localidade-tipo.-Folhelhos basais da seção-tipo suplementar da Formação Vila Maria, Grupo Rio Ivaí, Córrego da Aldeia, Fazenda Bela Vista, Município de Bom Jardim de Goiás, Brasil Central. Coordenadas UTM: Zona 22K. 382963E 8181666N.

Ocorrência.-Brasil, seção-tipo suplementar da Formação Vila Maria, Grupo Rio Ivaí, bacia do Paraná, Ordoviciano superior, folhelhos basais da Formação Vila Maria (Fig. 4.6) (Adôrno et al., 2015 Anexo I).

Discussão.-O contorno circular a subcircular da valva é bastante característico do gênero Conchoprimitia. A espécie nova Conchoprimitia. circularis foi comparada outras espécies de Conchoprimitia e também com uma espécie de Vogdesella, Baker, 1924. A espécie nova apresenta contorno circular e dimensões semelhantes às espécies Conchoprimitia socialis (Brogger, 1882), e Vogdesella subovata (Thorslund, 1948). As dimensões das carapaças de C. circularis são compatíveis tanto com Vogdesella subovata quanto com Conchoprimitia socialis. Conchoprimitia circularis difere destas duas por ter o nódulo anterior maior, mais desenvolvido e posicionado mais próximo ao limite anterior. O sulco presente em $C$. circularis é mais bem marcado do que o presente em $C$. socialis. Além disso, C. circularis difere de $C$. socialis por ter superfície externa pontuada enquanto que $C$. socialis tem superfície externa lisa. O contorno da valva de C. circularis é mais alongado e não há presença de marca muscular como há em $V$. subovata diferindo assim desta espécie e gênero o que a caracteriza como nova espécie do gênero Conchoprimitia com quem guarda maiores similaridades.

Gen. 1 et sp. 1

(Figs. 4.13: 13-15)

Material ilustrado.-Espécimes CP-636; CP-644 e CP-668, provenientes da porção basal da Formação Vila Maria, seção-tipo suplementar, córrego da Aldeia, Município de Bom Jardim de Goiás, Estado de Goiás, Brasil Central (Fig. 4.6).

Descrição.-Carapaça apresenta contorno subelíptico, amplete com maior comprimento localizado na região mediana da altura. Valva com margem dorsal retilínea e grande extensão atingindo mais de 3/4 do comprimento. Margem anterior convexa que se curva suavemente até a margem ventral. Margem ventral circular-convexa possui curvatura 
suave. Margem posterior convexa com raio de curvatura pouco menor do que o anterior, maior curvatura encontra-se na região dorso-mediana. Ângulos cardinais obtusos e aproximadamente $120^{\circ}$. Presença de nódulo pré-adutorial pouco marcado de formato circular na região antero-dorsal. Este nódulo tem relevo baixo limites pouco claros que não atingem a margem dorsal. Sulco adutorial com depressão muito sutil, localizado na região do limite posterior do nódulo pré-adutorial. Superfície da carapaça convexa, com curvatura suave com maior largura na região mediana do comprimento.

Localidade.-Folhelhos basais da seção-tipo suplementar da Formação Vila Maria, Grupo Rio Ivaí, Córrego da Aldeia, Fazenda Bela Vista, Município de Bom Jardim de Goiás, Brasil Central. Coordenadas UTM: Zona 22K. 382963E 8181666N.

Ocorrência.-Brasil, seção-tipo suplementar da Formação Vila Maria, Grupo Rio Ivaí, bacia do Paraná,Ordoviciano superior, folhelhos basais da Formação Vila Maria (Fig. 4.6).

Discussão.-A simplicidade morfológica e ausência de caracteres morfológicos presentes na carapaça dificultam a identificação dos espécimes. O contorno da carapaça, tamanho se assemelha com Pariconchoprimitia Schallreuter, 1980 e também com Conchoprimitiella Schallreuter, 1980, porém a posição dos sulcos e nódulos préadutoriais se distingue. Será necessário recuperar mais exemplares para comparações taxonômicas mais seguras. 


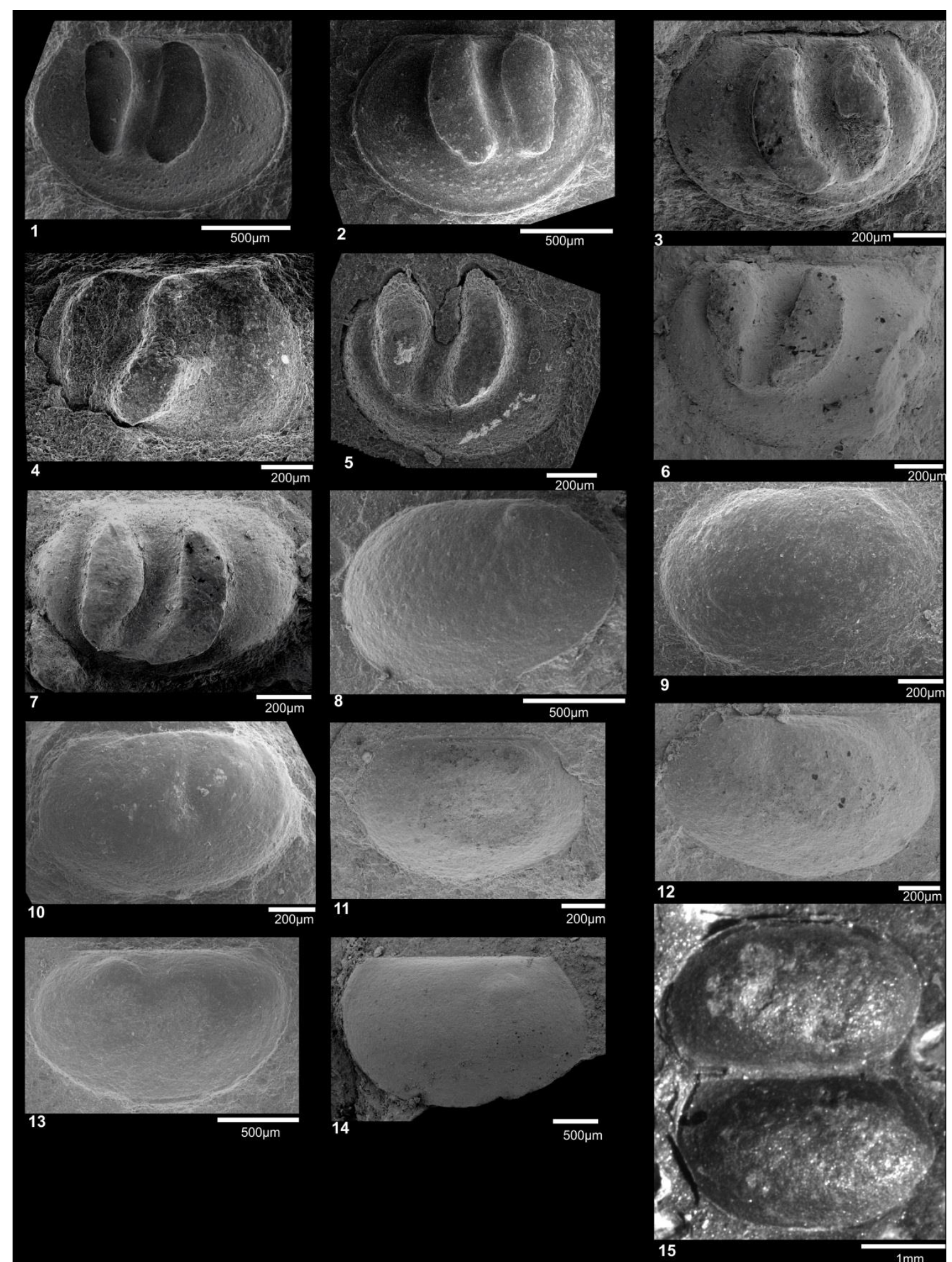

Figura 4. 13. 1-7, Satiellina jamairiensis Vannier, 1986. 1-2, CP-634, vistas laterais das valvas direitas, 1 molde externo, 2 réplica em latex do molde; 3, CP-645, vista lateral de molde interno de valva direita; 4-7, vistas laterais de moldes internos de valvas esquerdas, 4, CP-637; 5, CP643; 6, CP-651; 7, CP-646. 8-12, Conchoprimitia circularis n. sp; 8-11, vistas laterais de moldes internos de valvas esquerdas, 8, Holótipo CP-631; 9, Parátipo CP-635; 10, Parátipo CP639; 11, Parátipo CP-660, valva direita; 12, Parátipo CP-649, valva esquerda. 13-14, 15, Gen. et sp. 1 (espécie indeterminada), 13, CP-636 vistas laterais de moldes internos de valvas esquerdas; 14, CP-644, vistas laterais de moldes internos de valvas direitas; 15, CP-780, carapaça aberta, valva direita (abaixo) e valva esquerda (acima). 


\subsubsection{BRACHIOPODA}

A sistemática paleontológica supragenérica segue aquela apresentada por Moore (1997).

Filo: BRACHIOPODA Duméril, 1806

Subfilo: LiNGULIFORMEA Wiliams et al., 1997

Classe: Lingulata Gorjansky e Popov, 1985

Ordem: LINGULIDA Waagen, 1885

Subordem: ACROTRETIDA Kuhn, 1949

Superfamília: DISCINOIDEA Gray, 1840

Família: DISCINIDAE Gray, 1840

Subfamília: ORBICULOIDEINAE Schuchert \& Levene, 1929

Gênero: ORBICULOIDEA D’Orbigny, 1847

Espécie-tipo do gênero.—Orbucula forbesii Davidson 1848.

Localidade-tipo.-Wenlock (Siluriano), Oeste de Midland, Inglaterra.

Diagnose.-Concha fortemente dorsibiconvexa, subcircular, com contorno da parte posterior subtrapezoidal; Concha com paredes finas; ornamentação de ambas as válvulas compostas de cristas concêntricas regularmente separadas por sulcos amplos;válva dorsal cônica a subcônica com ápce subcentral;válva ventral cônica com ápece subcentral; fenda pedicular estreita, afinando na direção posterior, fechada anteriormente por listrium raso; forame na extremidade posterior do listrium com tubo interno curto (Mergl, 2006).

Diagnose original (inglês).- -Shell strongly dorsibiconvex, subcircular, with subtrapezoidal outline of the posterior shell part; shell thin-walled; ornament of both valves composed of regular raised concentric fila separated by broader interspaces; dorsal valve conical to subconical with subcentral apex; ventral valve depressed conical with subcentral apex; pedicle track narrow, tapering posteriorly, anteriorly closed by shallow listrium; foramen in posterior end of listrium with short internal tube (Mergl, 2006).

Discussão.-Acrosaccus Willard, 1928 difere de Orbiculoidea D’Orbigny, 1847 por sua valva dorsal com ápece submarginal e sua valva ventral com conicidade elevada. Schizotzera Kutorga, 1848 difere de Orbiculoidea em seu contorno oval elongado, fenda pedicular curta e longo tubo pedicular interno. Roemerella Hall \& Clarke , 1890 
difere de Orbiculoidea por ter fenda pedicular com ampla área, porém compartilha característica de ter válva dorsal com conicidade elevada e ornamentada. Roemerella é pouco conhecida e pode ser sinônimo de Orbiculoidea. Gigadiscina Mergl \& Massa, 2005 difere de Orbiculoidea por ter fenda pedicular muito curta e pelo tamanho da carapaça que é muito maior do que Orbiculoidea, porém a convexidade, ornamento e contorno da carapaça indica afinidade entre os dois gêneros (Mergl, 2006).

\section{ORBICULOIDEA? SP.}

(Fig. 4.14: 1-7)

Material ilustrado.-Os espécimes ilustrados neste trabalho são provenientes das formações Iapó e Vila Maria, Grupo Rio Ivaí, bacia do Paraná, tombados na coleção de pesquisa do laboratório de micropaleontologia da Universidade de Brasília sob numeração provisória: MP-2023-2; MP-2023-3; MP-2023-4; MP-2023-5; MP-2023-6; MP-2023-7; MP-2023-8 (Fig. 4. 14: 1-7).

Ocorrência.-Pelitos seixosos, siltitos e folhelhos das Formações Iapó e Vila Maria, Grupo Rio Ivaí, bacia do Paraná, localidades da seção-tipo (Fig. 4.5), folhelho da Formação Vila Maria, seção-tipo suplementar (Fig. 4.6) e pelitos seixosos da Formação Iapó e folhelhos da Formação Vila Maria, seção do Bairro COHAB (Fig. 4.12).

Descrição.-As carapaças aprsentam-se dorsibiconvexas, algumas são plano-convexas, valvas são muito pequenas média $2 \mathrm{~mm}$ de diâmetro, as paredes da carapaça são muito finas e quando preservadas são como filmes sobre os moldes das carapaças. O contorno externo e subcircular a circular, com razão comprimento/largura próximo de 1,0. Valva dorsal apresenta-se com formato convexo e ápice ligeiramente deslocado na direção posterior, algumas valvas apresentam ápice na região central da carapaça. Superfície interna da valva não é muito conhecida devido a modalidade de fossilização. Em alguns raros moldes internos é possível notar ranhuras radiais que se assemelham a costelas finas e com baixo relevo. Em um único espécime foi possível notar uma possível cicatriz muscular (Fig. 4.14: 7). Valva ventral geralmente é menor, e possui formato subcircula a circular. A conicidade é menor, sendo muitas vezes planar, talvez devido à deformação. Em algumas valvas é possível notar fenda pedicular fusiforme ocupando por vezes a metade posterior da carapaça. Ornamentação da Valva dorsal é constituída por dobras, linhas e cristas concêntricas. Estas cristas tem relevo baixo e tem ápices 
agudos ou arredondados. As valvas ventrais possuem ornamentação mais regular e concêntrica do que as valvas eventrais.

Discussão.- Os caracteres morfológicos simples e comuns a várias espécies somados à pobre preservação dos espécimes dificulta os trabalhos de taxonomia. Alguns espécimes foram comparados a Orbiculoidea baini Sharpe, 1856, porém a ordem de grandeza das carapaças é muito diferente, Orbiculoidea? sp. tem tamanho da ordem de 2 a $5 \mathrm{~mm}$ enquanto $O$. baini possui até $15 \mathrm{~cm}$ de diâmetro, Orbiculoidea? sp. também difere de $O$. baini por ter concha mais lisa nas proximidades do umbo. Bosetti et al., (2010) discute alguns aspectos fenotípicos que alterariam o tamanho de algumas populações de braquiópodes em resposta de estresse ambiental denominado "efeito Liliput". Será necessário trabalhos mais refinados de taxonomia para determinar esta espécie, por ora classificada com interrogação como Orbiculoidea.

Subordem: ACROTRETIDA Kuhn, 1949

Superfamília: LiNGULOIDEA Menke, 1828

Família: LinguLIDAE Menke, 1828

Genero: DIGNOMIA Hall, 1871

Espécie-tipo do gênero.—Lingula alveata Hall, 1863.

Distribuição estratigráfica.-Dignomia ocorre do Ordoviciano Médio ao Devoniano Médio (Emig e Herrera, 2006).

Distribuição geográfica.-América do Norte e do Sul (Emig e Herrera, 2006).

Diagnose emendada.-Concha fina, elongada, contorno externo em formato oval; externamente, dois sulcos extendem da região umbinal até a margem anterior, e sulco mediano estreito se extende da região umbinal até a margem anterior da valva dorsal, porém na valva ventral se estende apenas após a metada da concha. Sistema muscular assimétrico com três músculos oblíquos internos; músculos adutoriais posteriores não pareados (Emig e Herrera, 2006).

Diagnose emendada original (inglês).—Shell thin, elongate oval in shape; externally, two diverging medio-lateral grooves (internally ridges) extend from the umbonal region to the anterior margin, and a narrow median groove (a septum internally) extends from the umbonal region to the anterior margin of the dorsal valve but in the ventral valve only over the anterior half of the shell. Asymmetrical muscle system with three internal 
oblique muscles; unpaired posterior adductor muscle; no vascula mediaobserved (Emig and Herrera, 2006).

Discussão.- - O gênero Lingula era usualmente tido como fóssil vivo, tendo surgido no Cambriano e ocorrendo até o recente. Atualmente, alguns autores admitem que tenha surgido no Mesozoico (Holmer \& Popov, 2000, Zabini, 2007; Emig, 2002; Emig, 2003). A taxonomia para espécimes do Paleozoico é baseada exclusivamente nos caracteres morfológicos externos da concha permitindo na maioria dos casos, atribuir os espécimes a classificações dentro do grupo dos linguliformes ou lingulídeos. No presente trabalho apenas dois espécimes foram recuperados, estes espécimes foram comparados e atribuídos à Dignomia Hall, 1871 devido à similaridade morfológica externa da concha.

\section{DIGNOMIA? SP.}

(Fig. 4.14: 8-9)

Material ilustrado.- $\mathrm{O}$ espécime ilustrado neste trabalho consiste de moldes externos, provenientes dos afloramentos da seção-tipo e seção do Bairro COHAB, Formação Vila Maria, Grupo Rio Ivaí, bacia do Paraná. Os espécimes foram tombados sob numeração provisória: MP-2023-1 proveniente da localidade da seção do Bairro COHAB, (Fig. 4.14: 8-9).

Descrição.-A concha tem contorno oblongo ovalado, a maior largura da concha localiza-se na região mediana do comprimento. Comprimento de $12 \mathrm{~mm}$, largura de $5 \mathrm{~mm}$ e razão Largura/Comprimento de 0,41. As margens das valvas se curvam levemente em direção à região posterior, conferindo à concha, formato em cunha. A margem anterior possui contorno arredondado a subretangular. A superfície das valvas são suavemente convexas. As linhas de crescimento acompanham o formato do contorno da concha partindo de um ponto comum localizado na extremidade posterior da concha.

Ocorrência.-Folhelho da base da Formação Vila Maria, Grupo Rio Ivaí, bacia do Paraná, Localidades da seção-tipo (Fig. 4.5) e seção do Bairro COHAB (Fig. 4.12).

Discussão.- Os caracteres morfológicos da concha permitem o posicionamento a nível de família com bastante segurança. Os espécimes apresentam tamanho, formato externo e razões comprimento largura compatíveis com Dignomia. Lingularia apresenta comprimento $0,7 \mathrm{~mm}$ diferente do comprimento dos espécimes descritos (12mm). O formato externo de Lingularia apresenta extremidade posterior mais acuminada do que 
os dos espécimes da Formação Vila Maria. A classificação dos espécimes da Formação Vila Maria como Dignomia? sp. é deixada com interrogação devido ao reduzido número de exemplares e à ausência de caracteres morfológicos diagnósticos internos da carapaça como cicatrizes musculares e preservação de partes moles.

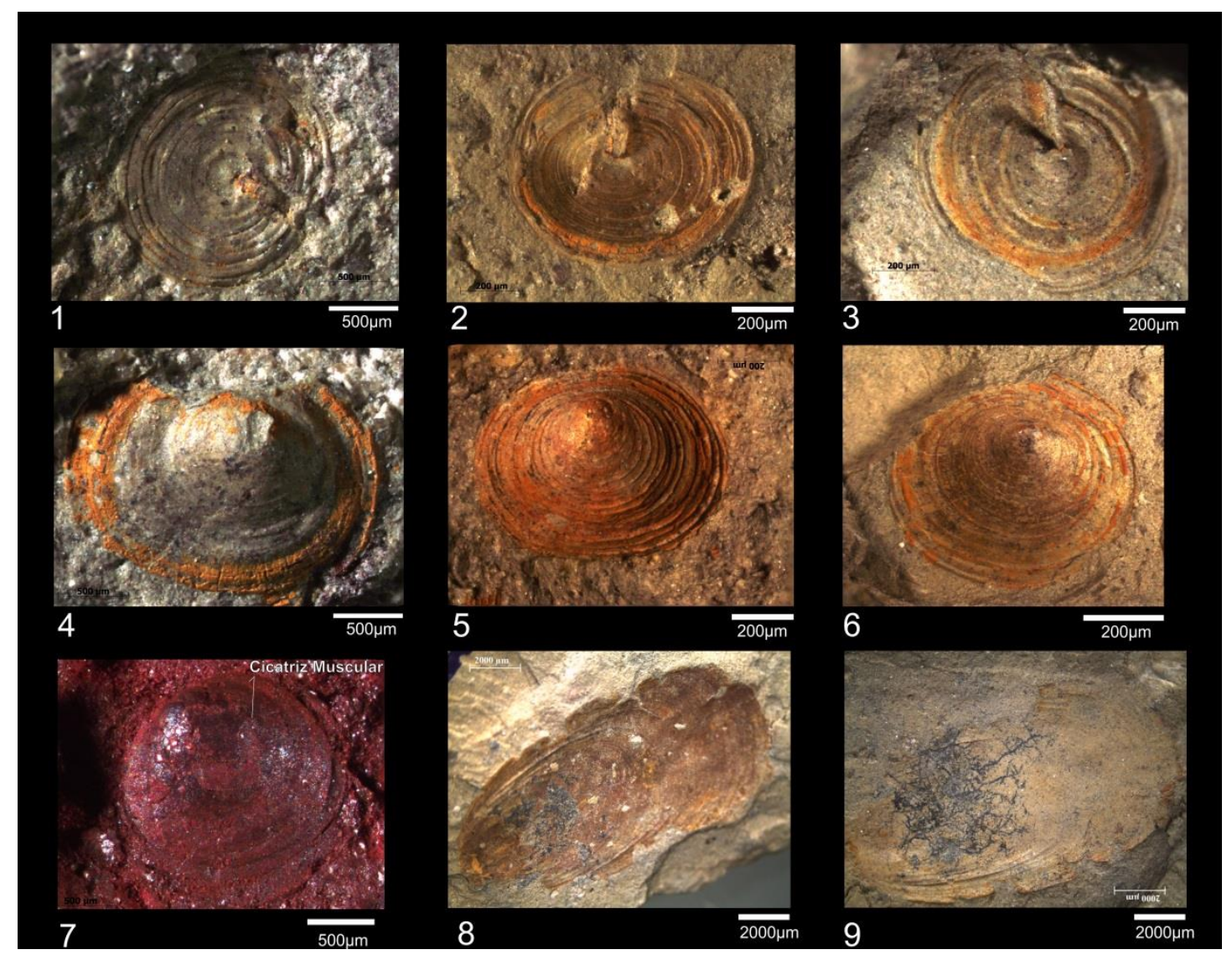

Figura 4. 14. Braquiópodes fósseis das Formações Iapó e Vila Maria. 1-6, 8-9) Espécimes provenientes do afloramento do Bairro COHAB, cidade de Barra do Garças, Estado de Mato Grosso, Brasil Central. 1-3) valvas pediculares de Orbiculoidea? sp, notar a presença bem marcada da fenda pedicular. 1) Espécime CP-770. 2) Espécime CP-771. 3) Espécime CP-772. 4-6) Moldes externos de valvas dorsais de Orbiculoidea? sp. 4) Espécime CP-773. 5) Espécime CP-774. 6) Espécime MP-2023-7. 8-9) MP-20231, parte e contra parte de molde externo de Dignomia? sp. da Formação Vila Maria. 7) CP-775, molde iterno de Orbiculoidea? sp. com provável cicatriz muscular preservada na valva dorsal, proveniente do afloramento seção tipo da Formação Vila Maria, córrego do Sucuri, Município de Arenópolis, Estado de Goiás, Brasil Central.

\subsubsection{MOLLUSCA}

A seguir é apresentada a sistemática paleontológica para os espécimes do Filo Mollusca. Foram identificadas e ilustradas duas classes de Mollusca: Gastropoda e Bivalvia. A sistemática taxonômica de Gastrópoda segue aquela apresentada em Peel, (1974), a de Bivalvia segue Pop et al. (1981) e kř́iž e Steinová, (2009). Considerou-se importante ilustrar e posicionar as ocorrências nos perfis litoestratigráficos pois este 
posicionamento servirá de guia para futuros trabalhos de detalhamento destes moluscos fósseis do Paleozoico inferior da bacia do Paraná.

Classe: GASTROPODA Cuvier, 1797

Subclasse: ProsobranchiA Milne Edwards, 1848

Ordem: ARCHAEOGASTROPODA Thiele, 1925

Subordem: BELLEROPHONTINA Ulrich \& Scofield

Superfamília: BELLEROPHONTHACEA M'Coy

Família: SinUiTIDAE Dall, 1913

Superfamília: BuCANELLINAE Koken, 1925

Gênero: BUCANELLA Clarke, 1899

Espécie-tipo do gênero.-Bucanella nana Meek, 1871.

Diagnose.-Concha trilobada com lobo mediano com relevo elevado e largo (Meek, 1871).

Ocorrência.- Porção basal da Formação Vila Maria, Grupo Rio Ivaí, bacia do Paraná, Seção-tipo suplementa (Fig. 4.6) e seção da Fazenda Três Barras (Fig. 4.8), Ordoviciano superior. Estados Unidos da América Crater's Falls, Colorado, Ordoviciano inferior.

\section{BUCANELLA? SP.}

(Fig. 4.15: 4)

Material ilustrado.-Molde externo recuperado a partir dos folhelhos da porção basal da Formação Vila Maria na localidade da seção-tipo suplementar, córrego da Aldeia, Município de Bom Jardim de Goiás, Estado de Goiás, Brasil Central. Material tombado no laboratório de micropaleontologia sob número MP-2028 (Fig. 4.15: 4).

Ocorrência.-Folhelhos da porção basal da Formação Vila Maria, Grupo Rio Ivaí, bacia do Paraná, seção-tipo suplementar (Fig. 4.6) e seção da Fazenda Três Barras (Fig. 4.8).

Descrição.-Conchas trilobadas de tamanho médio, tendo diâmetro da ordem de 2 a $3 \mathrm{~cm}$, evidenciando o lobo central proeminente em relação ao dois lobos laterais. Superfícies lobares são fortemente curvadas. Ornamentação presente na forma de linhas de crescimento restrita aos lobos laterais (Fig. 4.15:4).

Discussão.-Os espécimes mostram semelhança com Bucanella trilobata Clarke 1899 para o Eosiluriano da bacia do Amazônas. Os espécimes se assemelham quanto à 
morfologia e tamanho a Bucanella nana Meek, 1871, descrita nas rochas do Ordoviciano inferior nos Estados Unidos da América, Crater's Falls, Colorado, porém nota-se que o lobo central dos espécimes aqui apresentados não são ornamentados como em B. nana. A presença restrita a moldes internos impossibilitou a determinação a nível específico.

Classe: Bivalvia Linné 1758

Subclasse: PALAEOTAXODONTA Korolov, 1954

Ordem: NuCULOIDA Dall, 1889

Superfamília: NuCULACEA Gray, 1824

Família: MALLETIIDAE H. AdAMS AND A. AdAMS, 1858

Gênero: NUCULITES Conrad, 1841

Espécie-tipo do gênero.-Nuculites oblongatus Conrad, 1841.

Ocorrência.-Porção basal da Formação Vila Maria, Grupo Rio Ivaí, bacia do Paraná, Seção-tipo suplementar (Fig. 4.6) e seção da Fazenda Três Barras (Fig. 4.8). Ordoviciano superior, Quebec, Canada. Devoniano médio, Nova York, Cidade de Chenango, próximo à Smyrna Estados Unidos da América, (kříž e Steinová, 2009).

NUCULITES? SP.

(Fig. 4.14: 1-3)

Material ilustrado.-Três Moldes externos foram ilustrados no presente trabalho: M2033-1, MP-2033-2 e MP-2033-3, provenientes da porção basal da Formação Vila Maria, seção da Fazenda Três Barras, Município de Bom Jardim de Goiás, Brasil Central (Fig. 4.14: 1-3).

Ocorrência.-Porção basal da Formação Vila Maria, Grupo Rio Ivaí, bacia do Paraná, Seção-tipo suplementar, córrego da Aldeia, (Fig. 4.6) e seção da Fazenda Três Barras (Fig. 4.9) Município de Bom Jardim de Goiás, Estado de Goiás, Brasil Central.

Descrição.-Moldes externos com contorno externo ovalado. Superficie externa marcada por linhas de crescimento concêntricas que acompanham o contoro da conha que são mais bem marcadas na região anterior da concha. A borda ventral é curvilínea e se torna retilínea na região dorsal. A linha de charneira é mais ou menos retilínea. 
Discussão.-Não foi recuperado moldes internos, nem tão pouco moldes que evidenciassem a morfologia da charneira. Estas limitações impossibilitaram a determinação específica, levando a seguir sem alterações a taxonomia apresentada em Pop et al. (1981).

\subsubsection{ESPÉCIMES INDETERMINADOS}

Dois espécimes de invertebrados incertae sedis são ilustrados: incertae sedis 1 e incertae sedis 2. Considerou-se conveniente ilustrar e posicionar as ocorrências nos perfis pois, pode servir de guia futuros trabalhos de detalhamento destes grupos fósseis.

\section{INCERTAE SEDIS 1}

(Fig. 4.15: 5-6)

Material ilustrado.-Dois moldes externos provenientes da porção basal da Formação Vila Maria, seção da Fazenda Três Barras, Município de Bom Jardim de Goiás, Brasil Central foram ilustrados: MP-2029 e MP-2030 (Fig. 4.15: 5-6).

Descrição.-Moldes internos e externos e contra moldes com formato circular, com diâmetro de 1 a $4 \mathrm{~cm}$. Apreseta estrias radiais convergentes num arranjo que sugere formato espiralado incipiente. A região central dos espécimes são mais espessas, afinando em direção à extremidade.

Ocorrência.-Folhelhos da porção inferior da Formção Vila Maria, Grupo Rio Ivaí, Ordoviciano da bacia do Paraná, seção-tipo suplementar, Córrego da Aldeia, Fazenda Bela Vista (Fig. 4.6) e seção da Fazenda Três Barras (Fig. 4.9), Município de Bom Jardim de Goiás, Brasil Central.

Discussão.-Os espécimes descritos apresentam-se deformados e achatados durante a compactação mecânica sedimentar. Aparentemente se tratam de conchas de animal. Pop et al. (1981) discute a possibilidade de se tratarem de formas meduzóides onde as estrias seriam produto da compactação e da deformação. É notável a relação estratigráfica entre estes espécimes e os moluscos identificados, podendo ter alguma relação com esta fauna. 


\section{INCERTAE SEDIS 2}

(Fig. 4.15: 7-8)

Material ilustrado.-Dois moldes foram ilustrados MP 2027-1 e MP-2027-2, provenientes da porção basal da Formação Vila Maria, seção-tipo suplementar no córrego da Aldeia, Município de Bom Jardim de Goiás, Estado de Goiás, Brasil Central. Os espécimes encontram-se tombados na coleção de pesquisa do laboratório de micropaleontologia da Universidade de Brasília: MP-2027-1 e MP-2027-2 (Fig. 4.14: 78).

Ocorrência.-Folhelhos da porção inferior da Formção Vila Maria, Grupo Rio Ivaí, Ordoviciano da bacia do Paraná, seção-tipo suplementar, Córrego da Aldeia, Fazenda Bela Vista, Município de Bom Jardim de Goiás, Brasil Central (Fig. 4.6).

Descrição.-Moldes e contra moldes com formato cilíndrico alongado, com diâmetro de 0,5 a $1,5 \mathrm{~mm}$ e comprimento que pode atingir $5 \mathrm{~cm}$, podendo apresentar ramificação dicotômica e extremidades arredondadas. Os tubos apresentam-se com divisão na porção mediana que pode ser fruto da deformação causada pela compactação de uma estrutura originalmente tubular. A superfície de alguns espécimes apresentam-se segmentada, como se fossem constituídas pela união de anéis Fig. 4.15: 7).

Discussão.-Os espécimes foram comparados com espécies de Graptolitos, mas a ausência de ornamentações ou endentações na superfície dos espécimes impossibilitou a determinação da afinidade taxonômica. Estes moldes poderiam se tratar de fitoclastos, fragmentos de vegetais preservados em meio aos demais fósseis invertebrados. A afinidade taxonômica com vegetais parece improvável pela profundidade da lâmina d'água sugerida pelos demais grupos fósseis que indicam ambiente marinho calmo de águas profundas, abaixo da zona fótica. 


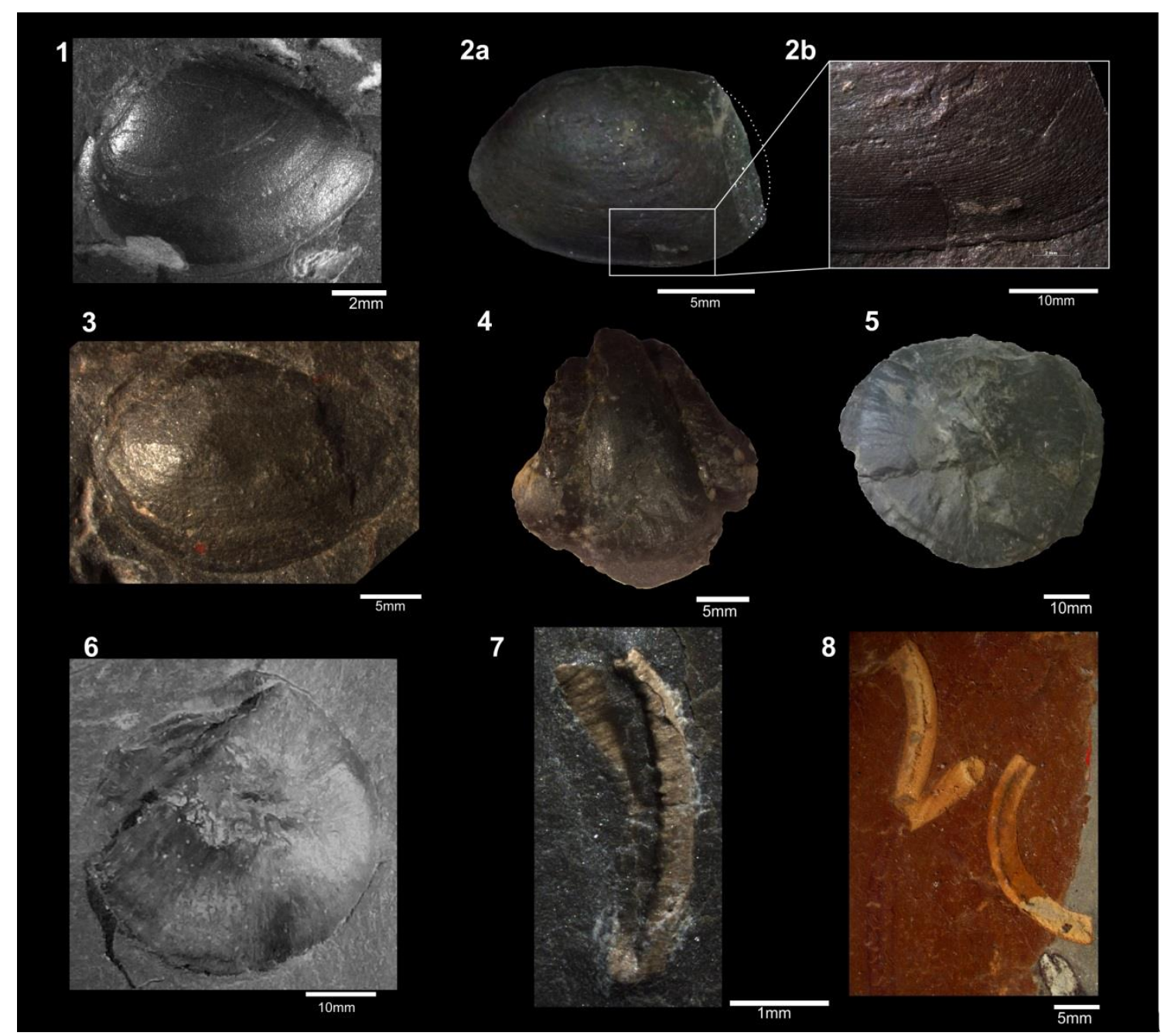

Figura 4. 15. Moluscos e fósseis da porção basal da Formação Vila Maria. 1-3) Nuculites? sp. 1) Espécime CP-776, molde exteno da valva esquerda. 2a) Espécime CP777, molde externo de possível valva direita. 2b) detalhe do espécime MP-2033-2. 3) Espécime MP-2033-3, molde externo valva esquerda. 4) Espécime CP-778 Vista apical, molde interno de Bucanella? sp. 5-8) Fósseis invertebrados com afinidade taxonômica indeterminada. 5-6) Moldes exernos de incertae sedis 1. 5) Espécime MP-2029. 6) Espécime CP-779, moldes circulares evidenciando estrias radiais e porção central protuberante. 7, 8) Moldes cilíndricos achatados de incertae sedis 2. 7) Espécime CP781 evidenciando estrias anelares ou divisão em anéis e achatamento. 8) Espécime MP2027-2 apresentado ramificação dicotômica.

\subsubsection{ICNOFOSSIL}

A sistemática icnotaxonômica supragenérica adotada segue aquela apresentada por Rindsberg e Martin (2002).

Icnofamília ARTHROPHYCIDAE Schimper, 1879

Icnogênero ARTHROPHYCUS (Hall, 1852) 
Espécie-tipo do icnogênero.-Arthrophycus harlani, Hall (1852).

Localidade-tipo.- Formação Medina (Siluriano), Estado de Nova York, Estados Unidos (Rindsberg e Martin, 2002).

Diagnose emendada.-Escavações intraestratais horizontais, simples ou ramificadas, retas ou curvas, de seção circular ou subcircular, com superfícies dotadas de articulações, anéis ou costelas transversais; seção transversal subquadrangular; escavações simples, pouco ramificadas, ou densamente ramificadas em padrão semelhante a um leque de sobreposição; metade inferior da escavação revestida por zona exterior de almofadas espaçadas de sedimentos; superfície inferior das escavações com sulcos transversais espaçados, geralmente com presença de sulco mediano (Rindsberg e Martin, 2002).

Diagnose emendada (inglês).- Subhorizontal to oblique, straightish to curved, bilaterally symmetrical burrows with all arranged in an imbricate series of spoonlike pads; cross section subquadrangular; burrows simple, sparsely branched, or densely branched in an overlapping, fan-like pattern; lower half part of burrow sheathed by outer zone of closely spaced pads of sediment; lower surface of burrow with closely spaced transverse ridges, commonly with median groove (Rindsberg e Martin, 2002).

Ocorrências.- -Siluriano da bacia do Paraná, topo da Formação Vila Maria, Grupo Rio Ivaí, afloramentos da seção-tipo (Fig. 4.5), seção-tipo suplementar (Fig. 4.6) e seção da Fazenda Três Barras (Fig. 4.9). Cambriano ao Devoniano (Rindsberg e Martin, 2002).

Distribuição estratigráfica.-Cambriano médio da Espanha (Legg, 1985). Ordoviciano Inferior ao Ordoviciano Superior da América do Sul, Africa e Europa. Siluriano inferior do leste da América do Norte, América do Sul, África, Ásia e Europa. Devoniano da Líbia (Turner e Benton, 1983). No Brasil ocorre no Grupo Trombetas, Formação Nhamundá (Eosiluriano); bacia do Paraná: Formações Vila Maria (Ordoviciano?Siluriano) e Furnas (Devoniano) (Fernandes et al., 2002).

\section{ARTHROPHYCUS ALLEGHANIENSIS (Hall, 1852)}

(Fig. 4.16)

Material ilustrado.-Os espécimes de Arthrophycus alleghaniensis (Hall, 1852) ilustrados no presente trabalho são provenientes dos afloramentos, não tendo sido coletadas amostras a partir dos afloramentos descritos. A amostra ilustrada na figura $4.13 b$ é proveniente do Portal da Serra do Roncador, Município de Nova Xavantina, esta amostra está depositada provisoriamente na UFMT, campus de Barra do Garças e 
ainda não foi tombada na coleção de pesquisa e foi iserida no presente trabalho devido ao caráter excepcional de preservação.

Localidade tipo.-Aproximadamente $40^{\circ}$ norte latitude e $77^{\circ}$ oeste de longitude num dos eixos mais a leste dos picos montanhosos denominados Alleghany, a $240 \mathrm{~km}$ de Philadelphia USA (Harlan, 1831).

Ocorrências.-Porção arenosa superior dos afloramentos da seção-tipo (Fig. 4.5), Município de Arenópolis, seção-tipo suplementar no córrego da Aldeia (Fig. 4.6), Município de Bom Jardim de Goiás e Fazenda Três Barras (Fig. 4.9), Município de Bom Jardim de Goiás, Estado de Goiás, Brasil Central (Burjack e Pop, 1981; Moreira e Borgui, 1999; Adorno et al. submetido, Anexo I). Ibéria, Ontário, Virgínia, Philadelphia e África (Rindsberg e Martin, 2002).

Distribuição estratigráfica. - Ordoviciano Inferior da Iberia, Jordan. Ordoviciano(?) da Argentina. Siluriano inferior, na América do Norte de Ontario ao oeste de Virginia, na América do Sul e África (Rindsberg e Martin, 2002).

Diagnose emendada.-Arthrophycus com escassas ou abundantes escavações, ramificadas em formato palmado; galerias retilíneas ou suavemente curvilíneas, geralmente com seção transversal subquadrangular, ramificação em ângulo agudo, a auto-penetrante; estrutura interna na superfície inferior é quase transversal; superfície inferior com sulco mediano em alguns espécimes (Rindsberg e Martin, 2002).

Diagnose emendada (inglês).-Arthrophycus with sparse to extensive, palmately branched burrows; galleries straight to gently curved, generally with subquadrangular cross section, branching at acute angle, self-penetrating; internal structure expressed on lower surface as nearly transverse sculpture; lower surface with median groove in some specimens (Rindsberg e Martin, 2002).

Discussão.-Os espécimes são provenientes da Formação Vila Maria são constituídos por aglomerados de galerias retilíneas ou ligeiramente curvilíneas, faciculares que se cruzam e por vezes formam cachos. As galerias possuem em média $2 \mathrm{~cm}$ de diâmetro, formato subcircular com anéis transversais ao longo do comprimento. Por vezes o estado de preservação prejudica a preservação dos anéis, conferindo aspecto liso à superfície das galerias (Fig. 4.15a). Difere de A. lineares Seilacher, 2000, apresentam-se como galerias retilíneas e longas, diferindo das galerias em cachos e ramificadas de $A$. alleghaniensis. A. lateralis Seilacher, 2000 apresentam escavações em cachos e feixes densos que se curvam para um dos lados, sendo diferente de A. alleghaniensis. 

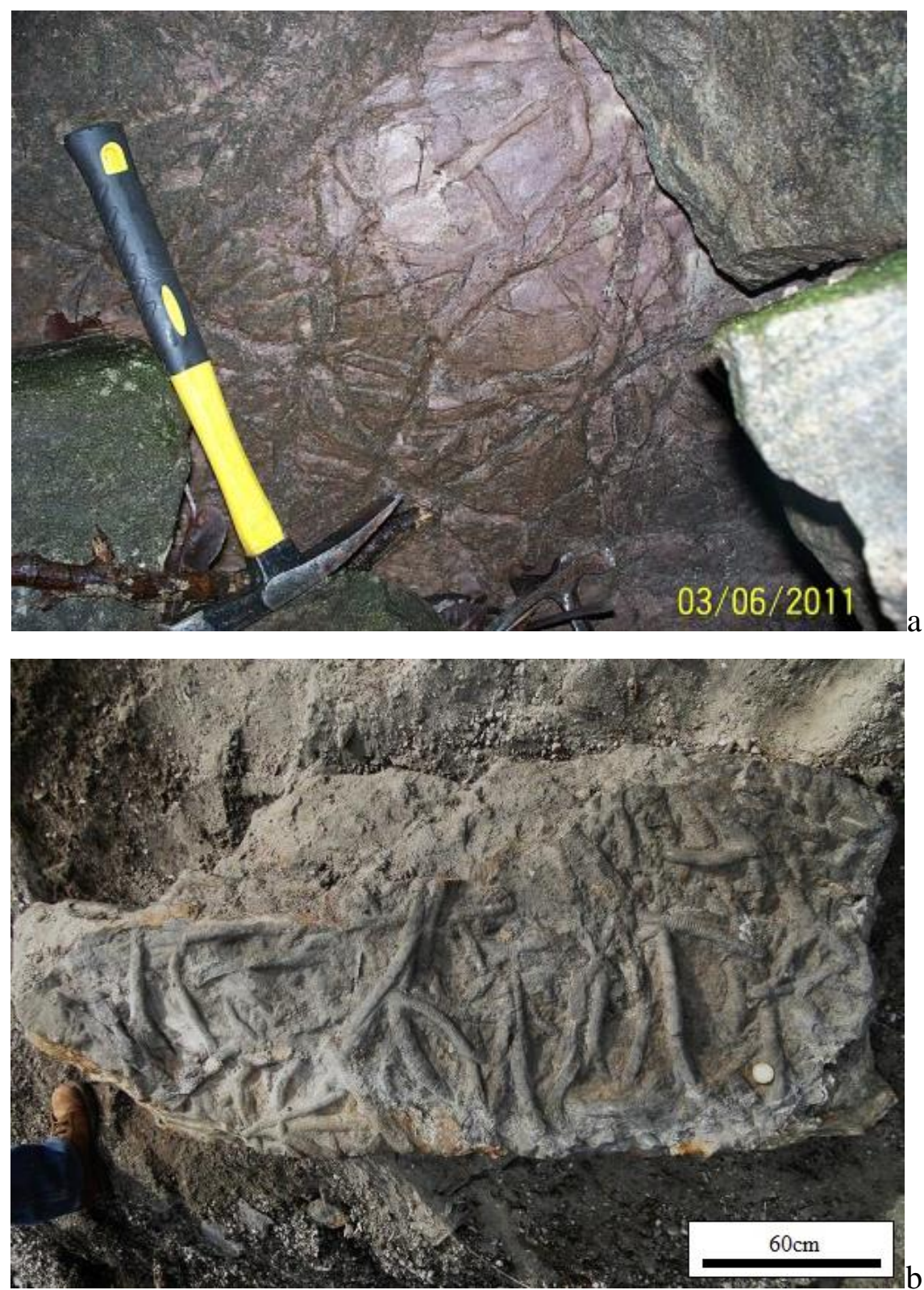

Figura 4. 16. Arthrophycus alleghaniensis (Hall, 1852) do topo da Formação Vila Maria. A) Afloramento seção-tipo da Formação Vila Maria, Córrego do Sucuri, Povoado de Vila Maria, Município de Arenópolis, Estado de Goiás, Brasil Central. B) Bloco rolado de arenito da porção superior da Formação Vila Maria, Serra do Roncador, Município de Nova Xavantina, Estado de Mato Grosso, Brasil Central (localidade não detalha no presente trabalho).

\section{DISCUSSÃO FINAL}

Os ostracodes apresentados neste trabalho são provenientes dos folhelhos da porção basal da Formação Vila Maria na localidade da seção-tipo suplementar. Este pacote pelítico de aproximadamente 11 metros é interpretado como depósitos periglaciais de plataforma marinha média a distal sob condições calmas. Este ambiente 
foi colonizado por rica fauna composta por Brachiopoda, Mollusca, junto com Ostracoda marinhos bentônicos apresentados neste trabalho.

A porção intermediária da Formação Vila Maria consiste de horizonte transicional entre os folhelhos pretos fossilíferos, ricos em matéria orgânica e arenitos micáceos da porção superior. Este horizonte transicional é composto por siltitos com acamamento lenticular linsen, que marcam o início da entrada de correntes de fundo transportando areia em suspensão. Neste intervalo transicional foram encontrados apenas raros moldes de Orbiculoidea? sp. indicando que as condições ambientais se tornaram desfavoráveis à colonização, ou à preservação dos bioclastos.

A contribuição de sedimentos arenosos se torna cada vez maior em direção ao topo da Formação Vila Maria, indicando aumento na energia e progradação. Esta progradação pode ser associada com rebote isostático e também ao aumento do aporte de sedimentos devido ao recuo da geleira após o pico da glaciação conforme discutido em Assine et al. (1998).

Orbiculoidea? sp. ocorre na porção superior da Formação Iapó e nas porções basal e itermediária da Formação Vila Maria na seção-tipo (Fig. 4.4) e na seção do Bairro COHAB (Fig. 4.12). Esta ocorrência comum às duas formações, somadas à natureza transicional do contato entre estas formações, indica que não deve haver um hiato temporal muito amplo entre a deposição das duas formações. A glaciação que deu origem aos diamictitos da Formação Iapó é correlata àquela que deu origem aos depósitos do Grupo Tichitt da bacia do Taoudeni na porão oeste do Continente Africano, esta glaciação é atribuída ao Ordoviciano (Assine et al. 1994). Este fato permite considerar a hipótese de que o intervalo pelítico basal da Formação Vila Maria também pertença ao Ordoviciano mais superior.

A porção superior da Formação Vila Maria é caracterizada por depósitos de arenitos indicando que o nível relativo do mar continuou a diminuir gradualmente. Este ciclo progradacional causou o desaparecimento de todos os elementos da biota registrados nas porções basal e intermediária da Formação Vila Maria. Este ciclo é caracterizado na porção mais superior pela colonização exclusiva por Arthrophycus alleghaniensis, presentes nos afloramentos da seção-tipo, seção-tipo suplementar e da Fazenda Três Barras. 


\section{ANÁLISE PALEAMBIENTAL E ESTUDO DE CORRELAÇÃo}

A interpretação dos dados paleontológicos e estratigráficos estão de acordo com a evolução paleoambiental do Grupo Rio Ivaí apresentada por Assine et al., (1998). Durante o máximo glacial o nível eustático global caiu, porém nos mares periglaciais, sujeitos ao avanço de geleiras, o nível relativo do mar subiu em consequência da subsidência por sobrecarga do peso do gelo. Ao final da glaciação, o recuo da geleira disponibilizou grande aporte de sedimentos que influenciaram os sistemas deposicionais marinhos periglaciais compostos lamitos com dropstones que integram a fácies folhelhos com dropstones (Fld) do topo da Formação Iapó.

No sistema glacial da porção basal da Formação Vila Maria (sensu Faria, 1982) ou topo da Formação Iapó (sensu Assine et al., 1994) na região norte da bacia do Paraná, a fácies folhelho com dropstones é interpretada como ação de decantação de sedimentos finos em contexto glacial de baixa energia. Os diamictitos estratificados depositam-se por fluxos gravitacionais associados à chuva de detritos (fácies diamictito maciço) ou turbidítico (fácies diamictito estratificado), com pulsos densos e episódicos derivados de águas de degelo carregadas de sedimentos (Moreira e Borghi, 1999).

O Grupo Trombetas da bacia do Amazonas (Cunha et al., 2007) e o Grupo Serra Grande da bacia do Parnaíba (Vaz et al., 2007) são comparados no presente trabalho, com o Grupo Rio Ivaí da bacia do Paraná. Estes grupos guardam similaridades de sucessões de litotipos, representando o registro da evolução paleoambiental da transição Ordoviciano-Siluriano. Estas sucessões litológicas e paleoambientais podem indicar que estas bacias foram submetidas ao mesmo evento glacial. A diferença de latitude entre estas bacias pode proporcionar diferenças nas idades dos depósitos glaciais, uma vez que estas bacias possuíam diferentes latitudes durante o Ordoviciano.

Na bacia do Amazonas, os sedimentos glaciais da Formação Nhamundá são capeados pelos sedimentos marinhos plataformais da Formação Pitinga, ambas do Grupo Trombetas (Nogueira et al., 1999; Cunha et al., 2007). Na bacia do Parnaíba os sedimentos flúvio-glaciais da Formação Ipu são sucedidos pelos depósitos marinhos plataformais da Formação Tianguá, ambas do Grupo Serra Grande (Vaz et al., 2007; Goes et al., 1994). A sucessão de sedimentos glaciais capeados por folhelhos marinhos plataformais observada nas bacias do Amazonas e Parnaíba pode ser coeva àquelas observadas no Grupo Rio Ivaí, porém pra conferir maior precisão a esta hipótese, será necessário investigar se nestas bacias ocorrem fósseis que permitam tal correlação. 
O registro fóssil do intervalo superior da Formação Vila Maria é composto pela icnoespécie Arthrophycus alleghaniensis que ocorre nos níveis siltosos centimétricos existentes entre os pacotes métricos de arenito. A ocorrência deste icnofóssil também foi registrada na Formação Nhamundá da bacia do Amazônas (Nogueira et al., 1999).

$\mathrm{Na}$ bacia de Taoudeni, continente africano, os sedimentos glaciais do Grupo Tichitt do Neordoviciano, são capeados pelos sedimentos marinhos plataformais do Grupo Oued Chig (Ghienne, 2003). Este intervalo litoestratigráfico da bacia de Taoudeni foi correlacionado, no presente trabalho, com os sedimentos coevos do Grupo Rio Ivaí no Brasil. O Grupo Tichitt foi comparado à Formação Iapó e o Grupo Oued Chig com a Formação Vila Maria. Esta similaridade indica que os depósitos glaciais destas duas bacias podem estar relacionados ao mesmo evento glacial que deixou registros no Gondwana durante o Ordoviciano (Fig. 5.1).

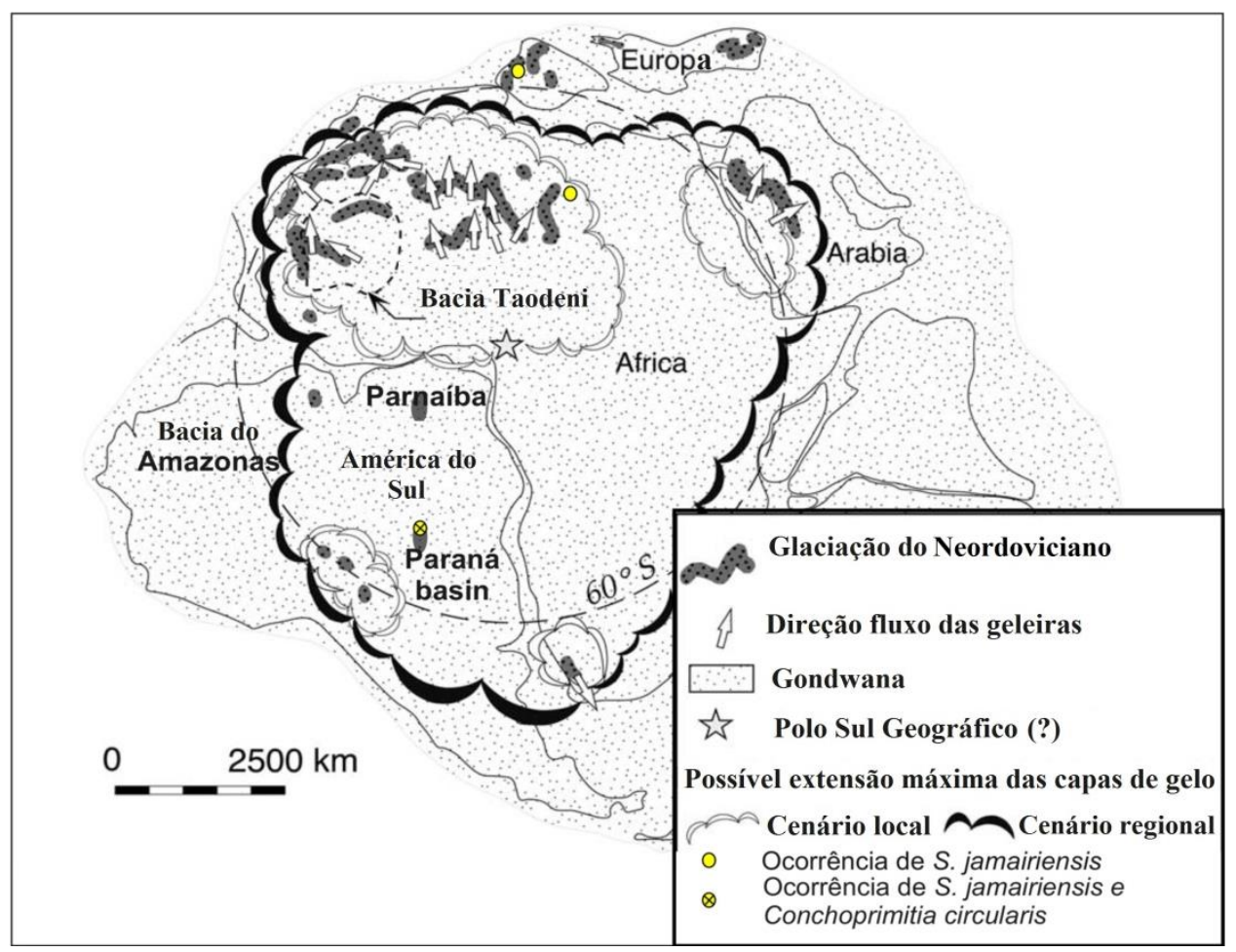

Figura 5. 1. Reconstrução paleogeográfica para o Neordoviciano e ocorrências das espécies de Ostracoda (modificado de Gienne, 2003).

A deposição do Grupo Rio Ivaí inicia-se pelos arenitos fluviais a costeiros da Formação Alto Garças com nível de mar baixo (Fig. 5.2). À medida que o sistema glacial foi instalado, o avanço da geleira sobre o substrato causou erosão e cisalhamento interno nos arenitos da Formação Alto Garças e início da deposição da Formação Iapó durante o Neordoviciano (Fig. 5.2). Ao fim da glaciação Iapó, são depositados os folhelhos com seixos caídos do topo da Formação Iapó, neste ambiente inicia-se o 
registro de Orbiculoideia? sp. Ainda no fim do Neordoviciano, com término da glaciação, são depositados os folhelhos marinhos plataformais da base da Formação Vila Maria, onde são encontrados ostracodes, moluscos, braquiópodes e incertae sedis.

O paleoambiente interpretado para a porção superior da Formação Vila Maria, já no Eosiluriano, é marinho plataformal de zona proximal. As intercalações de siltito entre arenitos estratificados indicam que as correntes cessavam temporariamente, tornando possível a colonização do fundo por Arthrophycus alleghaniensis. Esta icnoespécie é um importante horizonte bioestratigráfico, que marca com muita clareza o topo da Formação Vila Maria, podendo ser utilizado como horizonte de correlação bioestratigráfico.

A Formação Vila Maria contém o registro da transição Ordoviciano-Siluriano onde ostracodes Palaeocopida, presentes no intervalo pelítico basal, indicam que este intervalo pertence ao Neordoviciano, e registra a máxima transgressão marinha pósglacial (Fig. 5.2). Este intervalo é seguido por regressão marinha e rebound isostático que culmina nos arenitos progradantes estratificados do intervalo superior, registro de ambiente costeiro a plataformal raso colonizado por Arthrophycus alleghaniensis durante o Eosiluriano.

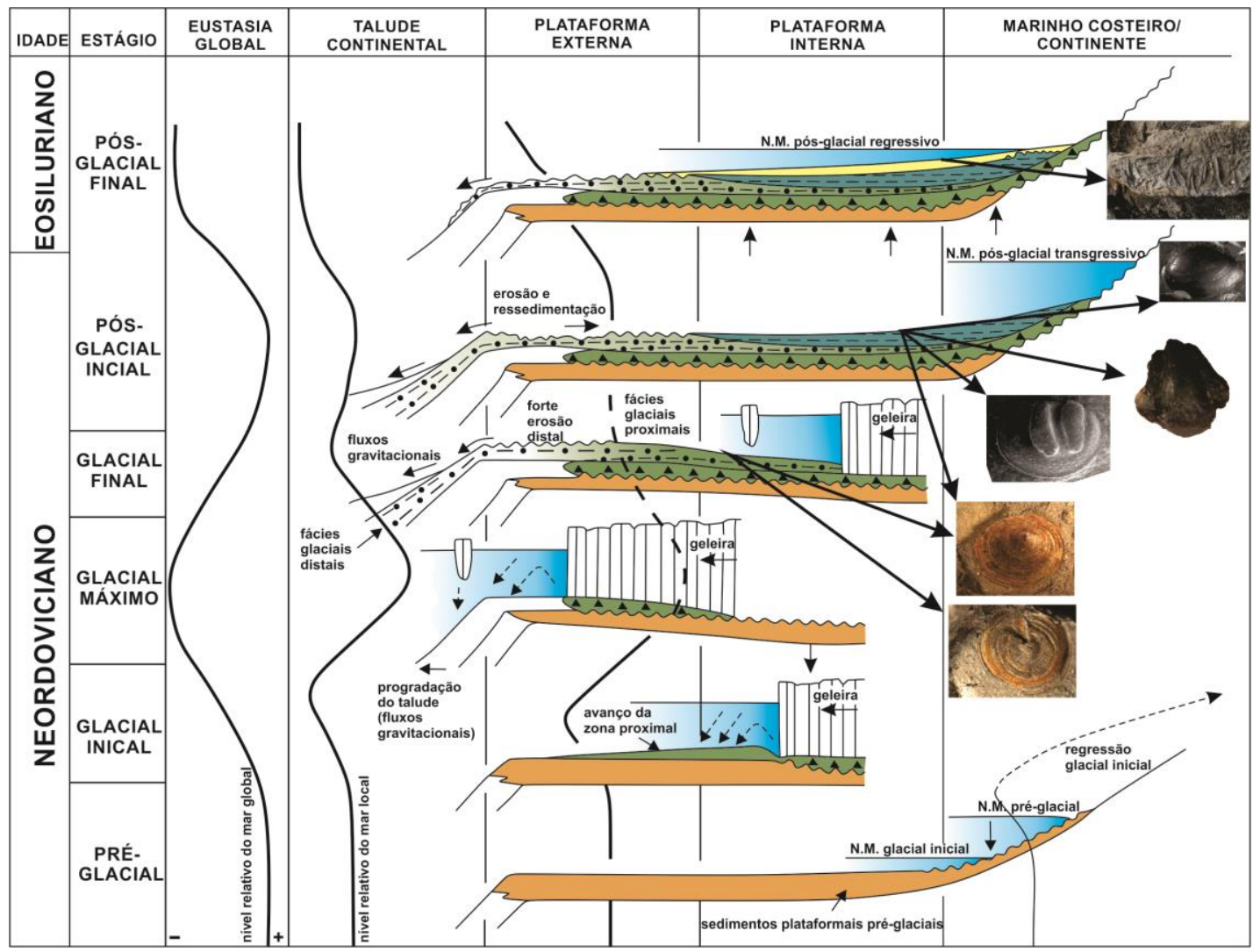

Figura 5. 2. Reconstrução paleoambiental para o limite Ordoviciano-Siluriano da bacia do Paraná (Modificado de Assine et al., 1998). 


\section{CONCLUSÃO}

Satiellina jamairiensis Vannier, 1986, Conchoprimitia circularis n. sp., e Gen. 1 et sp. 1 são os registros mais antigos de Ostracoda do Brasil. Satiellina jamairiensis e todas as espécies de Conchoprimitia são restritos ao Ordoviciano, portanto, considerando estas ocorrências, a porção basal da Formação Vila Maria pode ser atribuída ao Ordoviciano mais superior. Esta hipótese é ainda corroborada pela ocorrência de Orbiculoidea? sp. comum ao topo da Formação Iapó e às porções basal e intermediária da Formação Vila Maria. A ocorrência compartilhada desta espécie somada ao caráter transicional entre a Formação Iapó e Vila Maria indicam que não deve haver um hiato temporal muito grande entre a deposição destas formações, corroborando a datação baseada em Ostracoda. Foi apresentada a descrição, ilustração e a distribuição estratigráfica das espécies de Mollusca e incertae sedis provenientes dos folhelhos da base da Formação Vila Maria na seção-tipo suplementar e da Fazenda Três Barras, com intuito de auxiliar trabalhos futuros de detalhamento desta fauna.

A ocorrência de Arthrophycus alleghaniensis na porção superior da Formação Vila Maria, somado ao registro palinológico e de datação absoluta apresentado por Mizusaki et al. (2002) na porção intermediária da Formação Vila Maria, indicam que as porções intermediária e superior desta formação tenha se depositado durante $o$ Eosiluriano. Os dados sedimentológicos e estratigráficos sugerem a hipótese de um ciclo retrogradante-progradante durante o intervalo Neordoviciano e Eosiluriano (Landoveriano).

Adicionamente ao estudo do conteúdo paleontológico, sedimentológico e estratigráfico da Formação Vila Maria, foi apresentado atualização na cartografia geológica para os principais afloramentos desta formação no flanco norte da bacia do Paraná. O mapa geológico e vias de acessos contêm coordenadas UTM atualizadas e apresentam os principais acessos a cada afloramento descrito com toponímias precisas, com objetivo de promover resgate histórico dos afloramentos-chave da Formação Vila Maria e facilitar futuros trabalhos nesta formação, que é a única unidade estratigráfica formal da bacia do Paraná com seção-tipo no Estado de Goiás. Com este estudo inicial do ostracodes, há perspectivas de continuar os estudos de taxonomia e de correlação bioestratigráfica, pois há outros afloramentos com potencial para esta tipologia de estudos. Adicionalmente, os braquiópodes constituem outro importante grupo com 
potencial para estudos bioestratigráficos, no entanto estes ainda carecem de estudos taxonômicos detalhados.

\section{REFERÊNCIAS BIBLIOGRÁFICAS}

ADAMCZAK, F. 1961. Eridostraca a new suborder of ostracods and its phylogenetic significance. Acta Palaeontologica Polonica6,29-104.

ALVARENGA, C.J.S., E. M. GUIMARÃES, M. L. ASSINE, J. A. J. PERINOTTO, N. P. F. LARANJEIRA. 1998. Seqüências Ordovício-Siluriana e Devoniana no flanco norte da bacia do Paraná. Anais da Academia Brasileira de Ciências, 70: 587-606.

ASSINE, M. L, P. C. SOARES, E. J. MILANI. 1994. Sequências tectono-sedimentares mesopaleozóicas do Paraná, sul do Brasil. Revista Brasileira de Geociências 24(2):77-89, junho de 1994.

ASSINE, M. L., J. A. J. PERINOTTO, C. J. S. ALVARENGA, SETEMBRINO PETRI. 1998. Arquitetura estratigráfica, tratos deposicionais e paleogeografia da bacia do Paraná Brasil no Neo-Ordoviciano / Eo-siluriano. Revista Brasileira de Geociências 28(1):61-76.

ASSINE, M. L. e P. C. SOARES. 1989. Correlações nas Sequências Mesopaleozóicas da bacia do Paraná. Acta Geológica Leopoldensia.29: 39-48.

BAKER, F. 1924. Vogdesella, a new genus name for a Paleozoic crustacean. Proceedings of the Calofornia Academy of Science 13: 188-197.

BOSETTI, E. P., Y. Grahn, R. S. Horodyski, P. M. Mauller, P. Breuer, C. ZABINI. 2010. An earliest Givetian "Lilliput Effect" in the Paraná basin, and the collapse of the Malvinokaffric shelly fauna. Paläontol Z, Springer.

BRØGGER, W.C. 1882. Die Silurischen Etangen 2 und 3 im Kristianiagebiet und auf Eker, ihre Gliederung, Fossilien, Schichtenstörungen und Contactmetamorphosen. Universitets-Program, 2 Semester, A. W. Brøgger, Kristiania.

BURGESS, N.D. e J. B. RICHARDSON. 1991. Silurian cryptospores and miospores from the type Wenlock area, Shropshire, England.Palaeontology34, 601-28.

BURJACK, M. I., e M.T.B. POPP. 1981. A ocorrência do icnogênero Arthrophycus no Paleozóico da bacia do Paraná. Pesquisas, Porto Alegre, 14:163-168.

CARVALHO, I. S. 2002. Paleontologia. v1 Rio de Janeiro Ed. Interciência. 
CUNHA, P. R. C., J. H. G. MELO, O. B. SILVA. 2007. Bacia do Amazonas. Boletim de Geociências da PETROBRAS, 15(2), 227-251.

CUVIER, G. 1797. Tableau elementaire de l'histoire naturelle des animaux. Paris.

DAVIDSON, T. 1848. Mémoire sur les brachiopodes du Système silurien supérieur de l'Angleterre.Bulletin de la Société géologique de France, série 2, 5, 309-338, 370-374. EMIG, C.C. 2003. Proof that Lingula (Brachiopoda) is not a livingfossil, and emended diagnoses of the Family Lingulidae. Carnets de Géologie/Notebooks on Geology, Maintenon, Letter 2003/01.

D’ORBIGNY, A. 1847. Considérations zoologiques et géologiques sur les Brachiopodes ou Palliobranches. Comptes Rendus Hebdomadaires des Séances de l'Académie des Sciences 25, 193-195, 266-269.

EMIGC. C. 2003. - Proof that Lingula(Brachiopoda) is not a living-fossil, and emended diagnoses of the family Lingulidae. Carnets de Géologie/Notebooks on GeologyLetter 2003/01 (CG2003_L01_CCE).

FARIA, A. 1982. Formação Vila Maria - nova unidade litoestratigráfica siluriana da bacia do Paraná. Revista Ciências da Terra 3:12-15.

FARIA, A. DE e J.M. REIS NETO. 1978. Nova unidade litoestratigráfica pré-Furnas no sudoeste de Goiás. IN: Congresso Brasileiro de Geologia, XXX, Resumo das Comunicações. Recife, SBG, p. 136-37.

FERNANDES A. C. S., L. BORGHI, I. S. CARVALHO, C. J. DE ABREU. 2002. Guia de icnofósseis de invertebrados do Brasil. Editora Interciência, Rio de Janeiro, pp. 17-18.

FUCK R. A., M.M. PIMENTEL, J. H. D. SILVA. 1994. Compartimentação tectônica da porção oriental da Província Tocantins. In: CONGRESSO BRASILEIRO DE GEOLOGIA, 38, 1994. Balneário Camboriú. Anais... Balneário Camboriú: SBG, 1994. v.1, p. 215-216.

GHIENNE, J. F. 2003. Late Ordovician sedimentary environments, glacial cycles, and post-glacial transgression in the Taoudeni Basin, West Africa. Palaeogeography, Palaeoclimatology, Palaeoecology 189 (2003) 117-145.

GÓES, A. M. O., F. J. FEIJÓ. 1994. Bacia do Parnaíba. Boletim de Geociências da PETROBRÁS, 8 1: 57-67.

GORJANSKY, V. Y., L. E. POPOV. 1985. The morphology, systematic position and origin of the inarticulate brachiopods with calcareous shells Paleontologicheskij Zhurnal, 1985 (3) (1985), pp. 3-14. 
GRAHN, Y., E. PEREIRA, S. BERGAMASCHI. 2000. Silurian and lower Devonian chitinozoan biostratigraphy of the Paraná basin in Brazil and Paraguay. Palynology, volume $24-2000$

GRAY, J.E. 1840. Synopsis of the contents of the British Museum. 42th edition. 370 pp. British Museum, London.

GRAY, J., G. K. COLBATH; A. FARIA, A. J. BOUCOT, D. M. ROHR. 1985. Silurian-Age fossils from the Paraná basin, Southern Brazil. Geology, v. 13, p 521-525, July 1985.

HALL, J., 1852. Paleontology of New York II. Organicremains of the lower middle division of the NewYork system. Geological Survey of New York,Albany.

HALL, J. e J.M. CLARKE. 1890. Extract. Palaeontology of New York, Vol. 8, Part 1, 120-137. Charles van Benthuysen \& Sons, Albany HARLAN, R., 1831. Description of an extinct species of fossil vegetable, of the familyFucoides. J. Acad. Nat. Sci. Philadelphia, (ser. 1), 6 (for 1830) (2), pp. 289^295, pl. 15.

HENNINGSMOEN, G., 1953. Classification of Paleozoic straight-hinged ostracods. Norsk Geologisk Tidsskrift 31, 185-288.

HOLMERL. E. e E. POPOVL. 2000. Lingulida, in KAESLERR. L. (ed.), Treatise on Invertebrate Paleontology, Part H: Brachiopoda Revised. Geological Society of America, Boulder; University of Kansas Press, Lawrence, vol. 2: 32-95.

JONES, T. R. AND B. H. HOLL. 1869. Notes on the Paleozoic Bivalved Entomostraca. No. IX, Some Silurian species. Ann. Mag. Natural. History London, 4, 3, 15: 211-299.

KESLING, R. V. AND R. C. HUSSEY. 1953. A new family and genus of Ostracod Bill's Creek Shale of Michigan. Contr. Mus. Pal. Univ. Michigan. 11, 4: 77-95, Ann. Arbor. Michigan.

KŘÍŽ, J. e STEINOVÁ, M. 2009. Uppermost Ordovician bivalves from the Prague Basin (Hirnantian, Perunica, Bohemia).Bulletin of Geosciences 84(3), 409-436 (9 figures, 1 table). Czech Geological Survey, Prague.

KUHN, O. 1949. Lehrbuch der Paläozoologie Schweizerbart, Stuttgart.

KUTORGA, S.S. 1848. Über die Brachiopoden-familie der Siphonotretaceae. RussischKaiserliche Mineralogische Gesselschaft zu St. Petersbourg, Verhandlungen 1847, 250-286.

LAMARK. 1801. Système des animaux sans vertèbres, ou tableau général des classes, des ordres et des genres de ces animaux; présentant leurs caractères essentiels et 
leur distribution, d'après la considération de leurs..., Paris, Detreville, VIII: 1432.

LEGG, I.C., 1985. Trace fossils from a Middle Cambrian deltaic sequence, north Spain. In: Curran, H.A. (Ed.), Biogenic Structures: Their Use in Interpreting Depositional Environments. Soc. Econ. Paleontol. Mineral., Spec. Publ. 35, pp. 151-165, 4.

LOEBLICH, A. R. 1970. Morphology, ultrastructure and distribution of Paleozoic acritarchs. North American Paleontological Convention Proceedings, Part. G, p.705-788.

MAACK, R. 1947. Breves notícias sobre a geologia dos Estados do Paraná e SantaCatarina. Arquivo de Biologiae Biotecnologia,Curitiba, v. 2, p. 63-154.

MERGL, M. 2006. A review of Silurian discinoids brachiopods from historical British localities.Bulletin of Geosciences 81(4), 215-236.

MERGL, M., e D. MASSAA. 2005. A new giant discinoid brachiopod from the Lower Devonian of Algeria. Acta Palaeontol. Pol. 50 (2): 397-402.

MILANI, E. J., A.B. FRANÇA, R. L. SCHNEIDER, Bacia do Paraná. Boletim de Geociências da PETROBRAS, Rio de Janeiro,V.8, n.1, p. 69-82, jam./mar. 1994.

MILANI, E. J., M. L. ASSINE, P. C. SOARES, R. F. DAERNON. 1995. A Sequência ordovício-silurianada bacia do Paraná. B. Geoci. PETROBRAS, Rio de Janeiro, 9 (2/4): 301-320, abr.ldez. 1995.

MILANI, E.J., 1997. Evolução tectono-estratigráfica da bacia do Paraná e seu relacionamento com a geodinâmica fanerozóica do Gondwana sul-ocidental. 2 v. Tese de Doutorado, Universidade Federal do Rio Grande do Sul, Porto Alegre.

MILANI, E. J., U. F. FACCINI, C. M. S. SCHERER, L. M. ARAÚJO, J. A. CUPERTINO. 1998. Sequences and stratigraphic hierarchy of the Paraná Basin (Ordovician to Cretaceous), Southern Brazil. Boletim IG-USP, São Paulo, p. 125-173. (Série Científica, n. 29).

MILANI, E. J., J. H. G. MELO, P. A. SOUZA, L. A. FERNANDES, A. B. FRANÇA. 2007. A bacia do Paraná. Boletim Geociências da Petrobras, Rio de Janeiro, v. 15, n. 2, p. 265-287.

MIZUSAKI, A. M. P., J. H. G. MELO, M. L. VIGNOL-LELARGE, P. STEEMANS. 2002. Vila Maria Formation (Silurian, Paraná Basin, Brazil): integrated radiometric and palynological age determinations. Geol. Mag.,139 (3). 
MOORE, R. C. 1997. Treatise on invertebrate paleontology Part H, Brachiopoda GeologicaJ Society of America and University of Kansas Press, Boulder, Colorado and Lawrence, Kansas.

MOREIRA, M.I.C. AND L. BORGHI. 1999. Revisão cstratigráfica do intervalo Ordoviciano-Siluriano da bacia do Paraná. Anais da Academia Brasileira de Ciências, 71(4-I):743-766.

NOGUEIRA, A. C. R., W. TRUCKENBRODT, E. A. A. SOARES. 1999. O icnogênero arthrophycus de depósitos sublitorâneos da Formação Nhamundá (siluriano inferior) da bacia do Amazonas, Região de Presidente Figueiredo. Revista Brasileira de Geociências 29(2):135-140.

ÖPIK, A. A. 1935. Ostracoda from the lower Ordovician Megalaspis-limestone of Estonia and Russia. Annales Etc. of the Naturalists Society of Tartu University 42: $28-38$.

PEREIRA, E. 1998. Estratigrafia da Formação Vila Maria (Llandoveriano) na sub-bacia de Alto Garças (bacia do Paraná), Brasil. Anais da Academia Brasileira de Ciências, 70(3):501-525.

PEEL, J. S. 1974. Systematics, ontogeny and functional morphology of Silurian trilobed Bellerophontacean gastropods. Bulletin of the Geological Society of Denmark, vol. 23.

POPP, M.T.B.; M. I. BURJACK, L. R. ESTEVES. 1981. Estudo preliminar sobre o conteúdo paleontológico da Formação Vila Maria (pré- Devoniano) da Bacia do Paraná. Pesquisas, 14:169-180.

QUINTAS, M. C. L., M. S. M. MANTOVANI, P. V. ZALÁN. 1999. Contribuição ao estudo da evolução mecânica da bacia do Paraná. Revista Brasileira de Geociências 29(2):217-226.

RINDSBERG A. K., A. J. MARTIN. 2002. Arthrophycusin the Silurian of Alabama (USA) and the problem of compound trace fossils. Palaeogeography, Palaeoclimatology, Palaeoecology 192 (2003) 187-219.

SALAS, M. J. 2011. Early Ordovician (Floian) ostracods from the Cordillera Oriental, Northwest Argentina. Geological Journal 46: 637-650.

SCHALLREUTER, R. 1968. Drepanellacea (Ostracoda, Beyrichicopida) aus mittelordovizischen Backsteinkalkgeschieben II. Laterophoreslateris g.n. sp.n., Pseudulrichiabucera (Neckaja) und Pedomphalella Egrégia (Sarv.) Ber. Deutsch. Ges.geol., A. Wiss. Geol. Paläont., 13, 2: 247-261. 
SCHIMPER, W.P., A. SCHENCK. 1879-1890. Palaeophytologie. In: Zittel, K. A. v. (Ed.), Handbuch der Palaeontologie, 2. Oldenbourg, Mu«nchen and Leipzig, 958 pp. (pp. 1^152, 1879; pp. 329^396, 1885).

THORSLUND, P. 1948. The Chamops Series of the Kullatorp Core. Buli. Geol. Inst. Univ.Uppsala,32: 343-373.

TURNER, B.R., M. J. BENTON. 1983. Paleozoic trace fossils from the Kufra Basin, Libya. J. Paleontol. 57: 447-460.

VANNIER, J.M.C. 1983: On Bollia delgadoi Vannier sp. nov. Stereo Atlas Ostracod Shells, 10, 95-98.

VANNIER, J.M.C. 1986: Ostracodes Palaeocopa de 1'Ordovicien (Arenig-Caradoc) Ibero-Armoricain. Palaeontographica A193, 145-218.

VAZ, P. T., N. G. A. M. REZENDE, J. R. WANDERLEY FILHO, W. A. S. TRAVASSOS. 2007. Bacia do Parnaíba. Boletim de Geociências da PETROBRÁS, 15(2), 253-263.

VAIL, P.R., R. M. MITCHUM; S. THOMPSON. 1977. Seismic stratigraphy and global changes of sea level, part 4: global cycles of relative changes of sea level. Mem. Am. Assoc. Pet. Geol. 26, 83-97.

WILLARD, B. 1928. The brachiopods of the Ottosee and Holston formations of Tennessee and Virginia.Bulletin of the Harvard Museum of Comparative Zoology 68, 255-292.

WILLIAMS, A., C. H. C. BRUNTON, S. J. CARLSON. 1997. Treatise on Invertebrate Paleontology, part H, Brachiopoda, Revised, Volume 1: Introduction.i-xx, 539 pp. Geological Society of America, University of Kansas, Boulder \& Lawrence.

ZABINI, C. 2007. Lingulídeos da sucessão devoniana da bacia do Paraná, região dos campos gerais, Brasil: revisão de conceitos biológicos-ecológicos e análise tafonômica básica. Dissertação de mestrado IG/UFRGS.

ZALÁN, P.V., S. WOLFF, J.C.J. CONCEIÇÃO, I.S. VIEIRA, M.A.M. ASTOLFI, V.T. APPI, O.A. ZANOTTO. 1987. A divisão tripartite do Siluriano da Bacia do Paraná. Revista Brasileira de Geociências, 17(3):242-252. 


\section{ANEXO 1}

\section{JOURNAL OF PALEONTOLOGY}

Online Manuscript Submission and Peer Review

\section{To ensure proper functionality of this site, both JavaScript and Cookies must be enabled.}

HOME

\section{Detailed Status Information}

\begin{tabular}{|c|c|}
\hline Manuscript \# & $14-101$ \\
\hline Current Revision \# & 0 \\
\hline Submission Date & $2014-09-15 \quad 10: 08: 56$ \\
\hline Current Stage & Proofing Decision Letter Started \\
\hline Title & $\begin{array}{l}\text { TAXONOMY AND CHRONOSTRATIGRAPHY OF OSTRACODA } \\
\text { FROM VILA MARIA FORMATION, RIO IVAÍ GROUP: } \\
\text { ORDOVICIAN-SILURIAN BOUNDARY IN PARANÁ BASIN, } \\
\text { STATE OF GOIÁS, CENTRAL BRAZIL }\end{array}$ \\
\hline Manuscript Type & Regular Article \\
\hline Corresponding Author & Rodrigo Adôrno (Universidade de Brasília) \\
\hline Contributing Authors & $\begin{array}{l}\text { Dermeval Do Carmo, Maria Salas , Mário Assine , CAROLINA } \\
\text { ZABINI , EDI GUIMARÃES }\end{array}$ \\
\hline Abstract & $\begin{array}{l}\text { ABSTRACT-The study of the basal shales of the parastratotype section } \\
\text { of the Vila Maria Formation allowed identifying three species of } \\
\text { Ostracoda: Satiellina jamairiensis Vannier 1986; Conchoprimitia } \\
\text { circularis n. sp., and Gen. 1 et sp.1. this material is preserved as internal } \\
\text { and external molds . The first two species of Ostracoda, coupled with the } \\
\text { lithostratigraphic study of Rio Ivaí Group, suggest a Late Ordovician age } \\
\text { for shale deposition of the Vila Maria Formation, being the oldest record } \\
\text { of ostracods in the Parana basin of Brazil. This new record changes the } \\
\text { previous data, which classified this formation as restricted to the } \\
\text { Llandovery (early Silurian). In addition to the ostracods, a bivalve, an } \\
\text { archaeogastropoda, a Discinidae Brachiopoda and a Incertae Sedis were } \\
\text { recorded in the lower levels of Vila Maria Formation. Arthrophycus } \\
\text { alleghaniensis (Hall, 1852), the Llandovery ichnofossil species, is } \\
\text { restricted only to the upper portion of Vila Maria Formation. } \\
\text { Occurrences of this ichnofossil are positioned above the level where Late } \\
\text { Ordovician ostracods species occur, thus allowing to date the upper } \\
\text { portion of the Vila Maria Formation as Llandovery, which at least } \\
\text { partially confirms previously published dating. The new data herein } \\
\text { presented allow dating for the first time the deposition of Vila Maria } \\
\text { Formation as comprising the chronostratigraphic boundary uppermost } \\
\text { Ordovician- Llandovery. In addition to the study of the paleontological, } \\
\text { stratigraphic and paleogeographic records of the Vila Maria Formation, } \\
\text { the cartographic information regarding parastratotype section of Vila } \\
\text { Maria Formation was updated. }\end{array}$ \\
\hline Associate Editor & Assigned \\
\hline
\end{tabular}


Keywords Ostracods, Palaeocopida, Ordovician, Paraná Basin, Brazil Subject Areas Metazoa (not Chordata)/Arthropoda, Trace fossils, Metazoa (not Chordata)/Brachiopoda, Metazoa (not Chordata)/Mollusca

\begin{tabular}{|l||c|}
\hline \multicolumn{1}{|c|}{ Stage } & Start Date \\
\hline \hline Proofing Decision Letter Completed & $2014-09-17$ 13:29:34 \\
\hline Monitoring Editor Decision Completed & $2014-09-17$ 13:29:34 \\
\hline Waiting for Potential Reviewer Assignment & $2014-09-17$ 13:29:03 \\
\hline Monitoring Editor Assigned & $2014-09-17$ 13:29:03 \\
\hline \hline Potential Monitoring Editor Accept & $2014-09-17$ 13:29:03 \\
\hline Potential Monitoring Editor Assigned & $2014-09-17$ 13:29:03 \\
\hline Waiting for Potential Monitoring Editor Assignment & $2014-09-16$ 07:35:54 \\
\hline \hline Editor Assigned & $2014-09-16$ 07:16:50 \\
\hline Waiting for Editor Assignment & $2014-09-15$ 14:41:33 \\
\hline \hline Author Approved Converted Files & $2014-09-15$ 14:41:33 \\
\hline Waiting for Author Approval of Converted Files & $2014-09-15$ 13:54:24 \\
\hline \hline File Conversion Complete & $2014-09-15$ 13:54:24 \\
\hline Waiting for File Conversion & $2014-09-15$ 13:49:00 \\
\hline \hline Waiting for Files to be Sorted & $2014-09-15$ 13:47:42 \\
\hline \hline Manuscript Submitted & $2014-09-15$ 13:47:42 \\
\hline Manuscript Files Submitted & $2014-09-15$ 13:42:00 \\
\hline \hline Preliminary Manuscript Data Submitted & \\
\hline \hline
\end{tabular}

For assistance, please contact the Editorial Office jpaleo@si.edu 
TAXONOMY AND CHRONOSTRATIGRAPHY OF OSTRACODA FROM VILA MARIA FORMATION, RIO IVAÍ GROUP: ORDOVICIAN-SILURIAN BOUNDARY IN PARANÁ BASIN, STATE OF GOIÁS, CENTRAL BRAZIL

\section{RODRIGO RODRIGUES ADÔRNO}

Companhia de pesquisa de recursos Minerais-CPRM. Porto Velho. RO. CEP 76.801-581. Laboratório de Micropaleontologia. Instituto de Geociências. Universidade de Brasília. Campus Darcy Ribeiro. Brasília. DF. BRAZIL. CEP 70910-900 <rodrigo.r.adorno@gmail.com> DERMEVAL APARECIDO DO CARMO

Laboratório de Micropaleontologia. Instituto de Geociências. Universidade de Brasília. Campus Darcy Ribeiro. Brasília. DF. BRAZIL. CEP 70910-900 <derme@unb.br>

\section{MARIA JOSE SALAS}

CICTERRA-CONICET/Universidad Nacional de Córdoba and CIPAL, Av. Vélez Sarsfield 1611. X5016GCA, Córdoba, ARGENTINA. <mjsalas@efn.uncor.edu> MARIO LUIS ASSINE

Departmento de Geologia Aplicada. Universidade Estadual Paulista. Rio Claro. SP. BRAZIL. CEP 13506-900<assine@ rc.unesp.br>;

\section{CAROLINA ZABINI}

Universidade Tecnológica Federal do Paraná, Coordenação de Biologia. Dois Vizinhos, PR. BRAZIL. CEP 85660-000 <carolinazabini@utfpr.edu.br>

\section{EDI MENDES GUIMARÃES}

Laboratório de difração de raios X. Instituto de Geociências. Universidade de Brasília. Campus Darcy Ribeiro. Brasília. DF. BRAZIL. CEP 70910-900 <rxedi@unb.br>

ABSTRACT - The study of the basal shales of the parastratotype section of the Vila Maria Formation allowed identifying three species of Ostracoda: Satiellina jamairiensis Vannier 1986; Conchoprimitia circularis n. sp., and Gen. 1 et sp.1. this material is preserved as internal and external molds . The first two species of Ostracoda, coupled with the lithostratigraphic study of Rio Ivaí Group, suggest a Late Ordovician age for shale deposition of the Vila Maria Formation, being the oldest record of ostracods in the Parana basin of Brazil. This new record changes the previous data, which classified this formation as restricted to the Llandovery (early Silurian). In addition to the ostracods, a bivalve, an archaeogastropoda, 
a Discinidae Brachiopoda and a Incertae Sedis were recorded in the lower levels of Vila Maria Formation. Arthrophycus alleghaniensis (Hall, 1852), the Llandovery ichnofossil species, is restricted only to the upper portion of Vila Maria Formation. Occurrences of this ichnofossil are positioned above the level where Late Ordovician ostracods species occur, thus allowing to date the upper portion of the Vila Maria Formation as Llandovery, which at least partially confirms previously published dating. The new data herein presented allow dating for the first time the deposition of Vila Maria Formation as comprising the chronostratigraphic boundary uppermost Ordovician- Llandovery. In addition to the study of the paleontological, stratigraphic and paleogeographic records of the Vila Maria Formation, the cartographic information regarding parastratotype section of Vila Maria Formation was updated. Keywords: Ostracods, Palaeocopida, Ordovician, Paraná Basin, Brazil.

\section{INTRODUCTION}

IT IS presented herein for the first time the study of taxonomy of Ostracoda species from an early Paleozoic interval in Brazil, as well as their stratigraphic distribution and their chronostratigraphic implications are discussed. Additionally, it is presented a detailed description of the parastratotype section of the Vila Maria Formation. This approach to the study of ostracods integrated with the worldwide distribution of Arthrophycus alleghaniensis (Hall, 1852) is indicating a new concept of chronostratigraphic evolution for the Ordovician-Silurian interval of the Paraná basin.

Occurrences of Arthrophycus alleghaniensis (Hall, 1852) have been used to date the Vila Maria Formation as Llandovery since its identification (Burjack e Pop, 1981; Faria, 1982). In the present study, these occurrences of A. alleghaniensis are positioned in the stratigraphic log of the parastratotype-section, some meters above the uppermost level of occurrences of the Ordovician species of Ostracoda.

The cartographic databases were updated for the outcrops that are part of the main references of the Vila Maria Formation, in the northern part of the Paraná basin (type-section at Maria Village, parastratotype section at Aldeia creek and Três Barras Farm section) in the State of Goiás, central Brazil. A geological and access maps are presented in order to contribute for an easier location these important outcrops. Aldeia creek section is emphasized herein because the first occurrences of Ordovician species of Ostracoda in Brazil. 


\section{VILA MARIA FORMATION}

The oldest supersequence of the Paraná basin is represented by the sedimentary package of the Rio Ivaí Group assigned to the Upper Ordovician to Llandovery interval. This group is composed by three formations: Alto Garças, Iapó and Vila Maria (Assine et al., 1994; Milani et al., 2007). The Alto Garças Formation consists of thick to conglomeratic sandstones deposited directly on the basement of the basin. The Iapó Formation consists of glaciogenic diamictites characterized by dropstones and lenses of siltstone (Milani et al., 1994; Milani et al., 2007). Finally, the diamictites of the Iapó Formation are succeeded by the marine deposits of the Vila Maria Formation, whose are fossiliferous shales and representing the most important stratigraphic framework of the Rio Ivaí Group. The fossiliferous shales of Vila Maria Formation are generally red colored, micaceous and with ferruginous aspect, however they can be dark gray and yellow (Milani et al., 1994; Milani et al., 2007).

The Vila Maria Formation was initially suggested like a stratigraphic unit by Faria and Reis Neto (1978) in a short communication in XXX-Brazilian Geological Congress, and finally it was proposed as a formal unit by Faria (1982). Later, several articles have been developed in an attempt to divide this formation, as well as determine its boundaries (Zalán et al. 1987; Assine and Soares, 1989; Assine et al., 1994; Alvarenga et al., 1998). Other articles dealing with paleontological dating (Popp et al., 1981; Burjack and Popp, 1981; Faria, 1982; Gray et al., 1985) or radiometric dating integrated with palynological data were also published (Mizusaki et al., 2002).

The pioneering work on dating the Vila Maria Formation was conducted by Burjack and Popp (1981). According to this study the occurrence of Arthrophycus alleghaniensis (Hall, 1852) indicates Llandovery for this lithostratigraphic interval, position also adopted by Faria (1982). Occurrences of Brachiopoda, Bivalvia , Archaeogastropoda, Ostracoda and ichnofossils were all recorded in a brief descriptive documentation of fossil record of the Vila Maria Formation associated with A. alleghaniensis from outcrops at Caiapônia County, State of Goiás (Popp et al., 1981).

Palynological record consists of Elektoriskos pogonius Loeblich, 1970 and undetermined species and was recovered from shales of the Vila Maria Formation in the Três Barras Farm section (Fig. 2). From this palynological set, only Elektoriskos pogonius is indicative of Llandovery. In addition to this set of palynomorphs, undetermined graptolites were recorded as well as (Gray et al., 1985Palynological record consists of Elektoriskos pogoniusLoeblich, 1970 and undetermined species recoveredfrom shales 
of the Vila Maria Formation in the Três Barras Farmsection (Fig. 2). From this palynological set, only Elektoriskospogonius is indicative of Llandovery. In addition to this set of palynomorphs, undetermined graptolites were recorded as wellas (Gray et al., 1985). Mizusaki et al. (2002) presents a more diversified assemblage of palynomorphs comprising several species which indicate ages in the range CaradocLlandovery. Of all palynological association presented, only Laevolancisdivellomedia (Burgess \& Richardson, 1991), from a sample of the intermediate portion of the Vila Maria Formation, would be restricted to Llandovery. The palynomorphs occur in the intermediate portion of the Vila Maria Formation, indicated that this interval belong to the Llandovery, as well as the upper portion where occurs Arthrophycus alleghaniensis.

The only absolute dating was performed by Mizusaki et al. (2002) based on record from the outcrop of the Tres Barras Farm, location also studied by Gray et al., (1985). This dating indicated isochron age of $435.9 \pm 7.8 \mathrm{Ma}$ according to the $\mathrm{Rb} / \mathrm{Sr}$ method, with uncertainties related to isotopic homogenization during diagenesis and may, therefore, represent diagenetic events younger than the deposition age of these shales.

\section{LOCATION OF MAIN OUTCROPS}

Three outcrops of the Vila Maria Formation in Goiás State are highlighted and had their cartographic basis updated: type-section at Maria Village, south of Arenópolis County; parastratotype section at Aldeia Creek, Bela Vista Farm; and Três Barras Farm, Bom Jardim de Goiás County. Of these three, special attention was given to the parastratotype section of the Vila Maria Formation, where a well preserved ostracods have been recorded as a suitable positioning of A. alleghaniensis, Brachiopoda, Bivalvia and Gastropoda in the stratigraphic log (Fig. 3).

The parastratotype section is located in southwestern Goiás State, south of Bom Jardim de Goiás County (Fig. 1). The main access is by the national road BR 158 up to Bom Jardim de Goiás, following on unpaved road to Boa Vista Farm on top of Serra Negra mountains. 


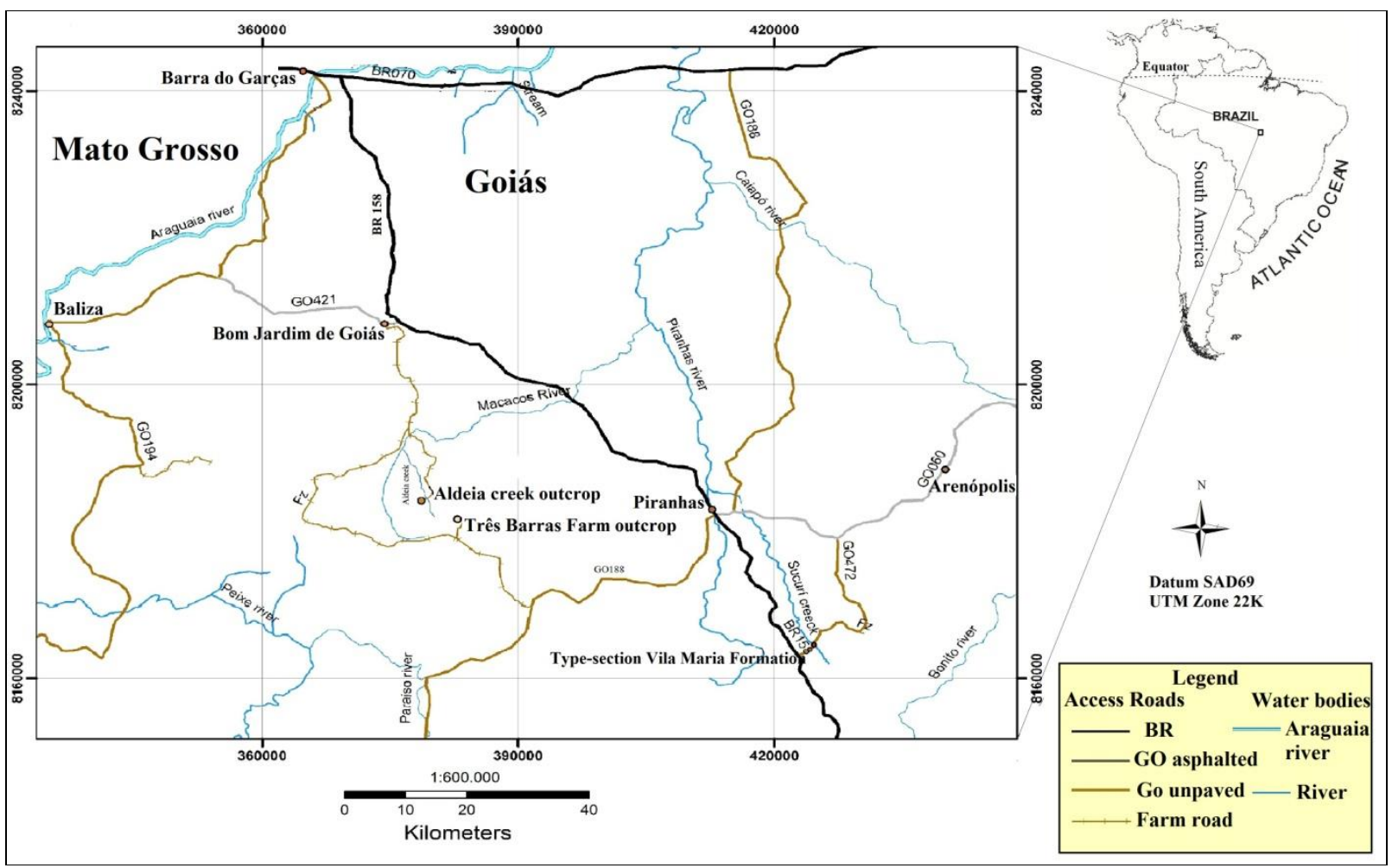

FIGURE 1-Location map and access roads for the parastratotype section in Boa Vista Farm, south of Bom Jardim de Goiás County, as well as the type-section and Três Barras Farm section, State of Goiás, Central Brazil.

\section{STUDIED MATERIAL}

Ostracods fossils from Vila Maria Formation occur as internal and external molds. The fauna was recovered from black shales in lower levels of Vila Maria Formation in the parastratotype section. The fossiliferous shales are overlapping the basal diamictites of Iapó Formation in a gradational contact. Above the fossiliferous levels outcrops micaceous siltstones that, toward the top of the Vila Maria Formation, are gradually followed by micaceous sandstones with a rich record of A. alleghaniensis. The kaolinic and white sandstones of the Furnas Formation are deposited above this formation in a paraconformity contact.

The geological map of the study area is an update version of that presented by Alvarenga et al., (1998), 1:1,000,000 scale, with UTM coordinates showing the insertion and positioning of the main outcrops of the Vila Maria Formation in the northern flank of the Paraná basin (Fig. 2). At this cartographic scale, it is not possible to identify formations of the Rio Ivaí Group; therefore, they are collectively grouped under the Rio Ivaí Group name. 
In the studied area, the Rio Ivaí Group outcrops along escarpments on hillsides and waterfalls in the Serra Negra mountains, Arenópolis and Bom Jardim de Goiás counties, Goiás State, central Brazil

(Fig. 2). These outcrops are distributed in a relatively narrow area East-Westward adjacent to a window precambrian basement (Fig. 2).

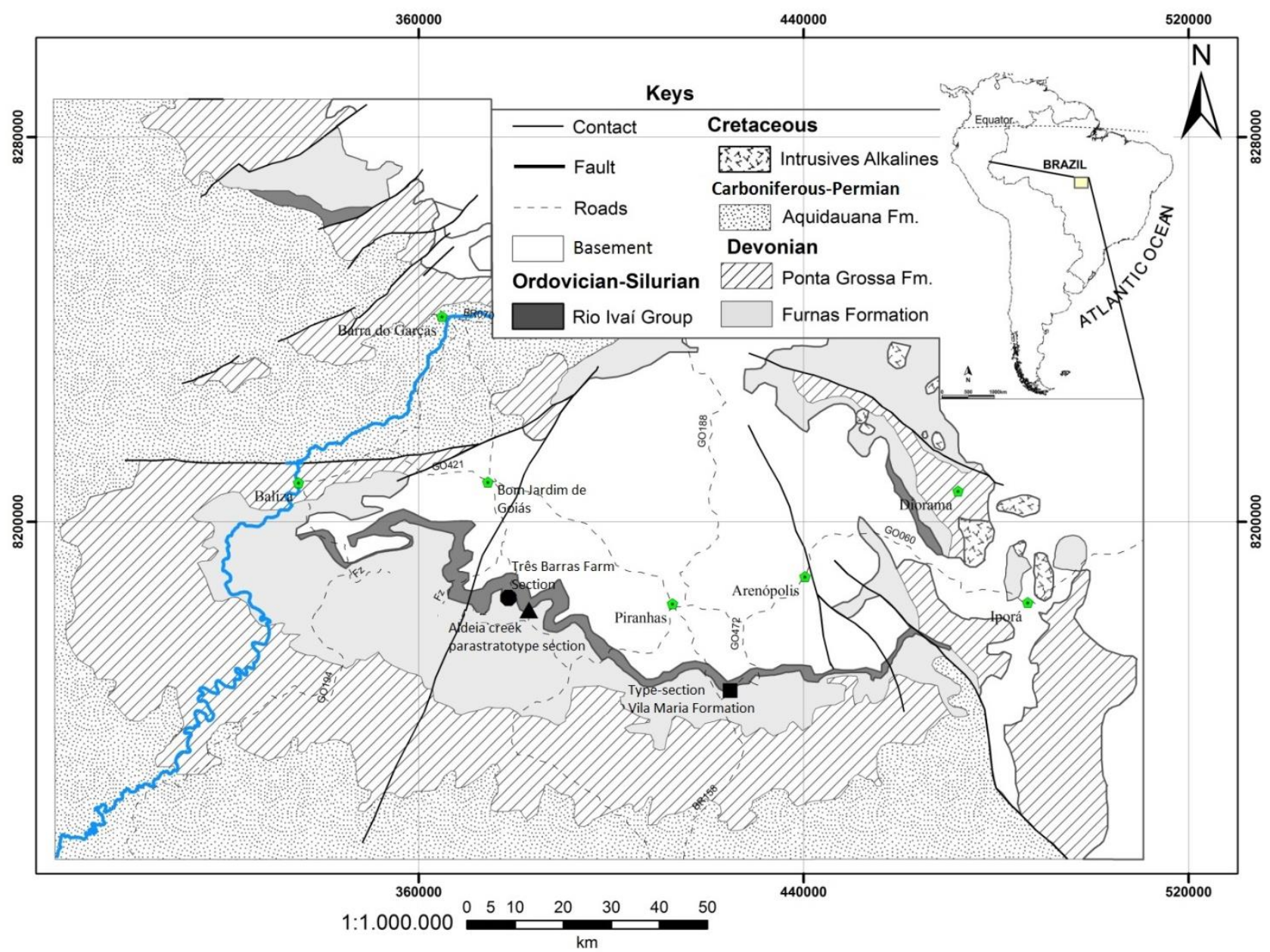

FIGURE 2-Geological map of the area of Rio Ivaí Group, southwestern Goiás state and southeastern

Mato Grosso state, central Brazil (Adapted from Alvarenga et al., 1998).

\section{METHODS}

Sampling and surveying of the stratigraphic log with positioning of fossils recovered from the parastratotype section of the Vila Maria Formation were performed during fieldtrip. The ostracods molds studied herein have been prepared mechanically using fine needles and ordinary cutting tools. The external molds have been cast using latex rubber. The rock molds and those made from latex were covered with a thin layer of carbon and imaged in a scanning electron microscope (SEM). 
Additionally, the molds of Ostracoda and Brachiopoda were also analyzed on SEM and are illustrated herein. So, two methods of analyses were conducted in the SEM: latex casts and original molds. It is possible to conclude, if used integrated way, both methods of analyzes give a better results for morphological description.

\section{REDESCRIPTION OF THE PARASTRATOTYPE SECTION}

Originally, the formalization of the lithostratigraphic unit named Vila Maria Formation was based on two sections, respectively referred to as type-section and parastratotype section. The parastratotype section deserved special attention because it presents a complete sedimentary record, consisting of a thick package of black shales at the base followed by siltstone and sandstone deposits toward the top, in addition has an important fossiliferous record.

The parastratotype section of the Vila Maria Formation shows glaciogenic sediments of the Iapó Formation with angular contact with precambrian basement. The basement is represented by deformed metadacites/metarhyolites (Fig. 4a). The Iapó Formation is composed of two diamictite packages separated by a half-meter layer of fine sandstone with ripples. This psephitic package is about $9 \mathrm{~m}$ thick.

The lower package of the Iapó Formation consists of polymitic diamictite stratified with angular clasts composed by quartzite, volcanic rocks and shales, immersed in a greenish sandy-silty matrix, stratified and rich in organic matter. This package reaches thickness of $1.5 \mathrm{~m}$ directly deposited on the irregular surface of the basement. The upper package is represented by stratified diamictites and intercalated by massive diamictites. The composition of the clasts and the relationship with the matrix are very similar to the baseline package. These diamictites are thicker than the baseline, reaching up to $7 \mathrm{~m}$ (Figures 4b, 4c).

Above the stratified and massive psephitic packages, there is an approximately $0.5 \mathrm{~m}$ thick layer composed of pebbly mudstone, presenting a black clayish matrix, rich in organic matter. In this pebbly mudstone layer is possible to identify nodules of pyrite and scattered rounded quartz pebbles, which mark the top of the Iapó Formation (Fig. 4d).

The Vila Maria Formation overlaps Iapó Formation in a gradational contact, with a transitional layer around $1 \mathrm{~m}$ thick. The thickness of Vila Maria Formation is $20 \mathrm{~m}$ and it consists of three intervals: lower, intermediate and upper. The lower portion of the Vila Maria Formation consists of fossiliferous 
black shales emphasized in the present study. The intermediate portion is characterized by micaceous siltstone with fossil occurrence restricted to Brachiopoda. The upper portion is composed by micaceous sandstones with rich occurrence of Arthrophycus alleghaniensis.

The lower portion of the Vila Maria Formation is characterized by a thick black shale package with approximately $11 \mathrm{~m}$ thick (Fig. 4f). Abundant internal and external molds of Ostracoda, Discinidae Brachiopoda, Bivalvia, Archaeogastropoda, and Incertae Sedis (Fig. 4; Fig. 5) occur in the lower portion. These shales are abruptly followed by a layer of siltstone with horizontal lamination forming the intermediate portion.

The intermediate portion is composed by purple and micaceous siltstones interbedded with thin lenses and layers of sandstones, forming the lenticular heterolithic-type bedding (Fig. 4g). When comparing the composition of these siltstones from the parastratotype section with those from the Três Barras Farm section and the type-section, it is clear the close relationship between the first two. The siltstone of type-section of Vila Maria Formation have a composition restricted to quartz, microcline, kaolinite and muscovite. The other two sections have a more complex composition: quartz, kaolinite, muscovite, microcline, hematite, calcite, albite and anatase (Fig. 3). The parastratotype and Três Barras Farm section show a thicker pelitic interval and a more diversified fossil record when compared with type-section of Vila Maria Formation. It seems there is a relationship between mineralogical and paleontological diversity associated to the great thickness of pelitic interval. Possibly these differences would be related to a relatively deeper water depositional setting for these two sections. 

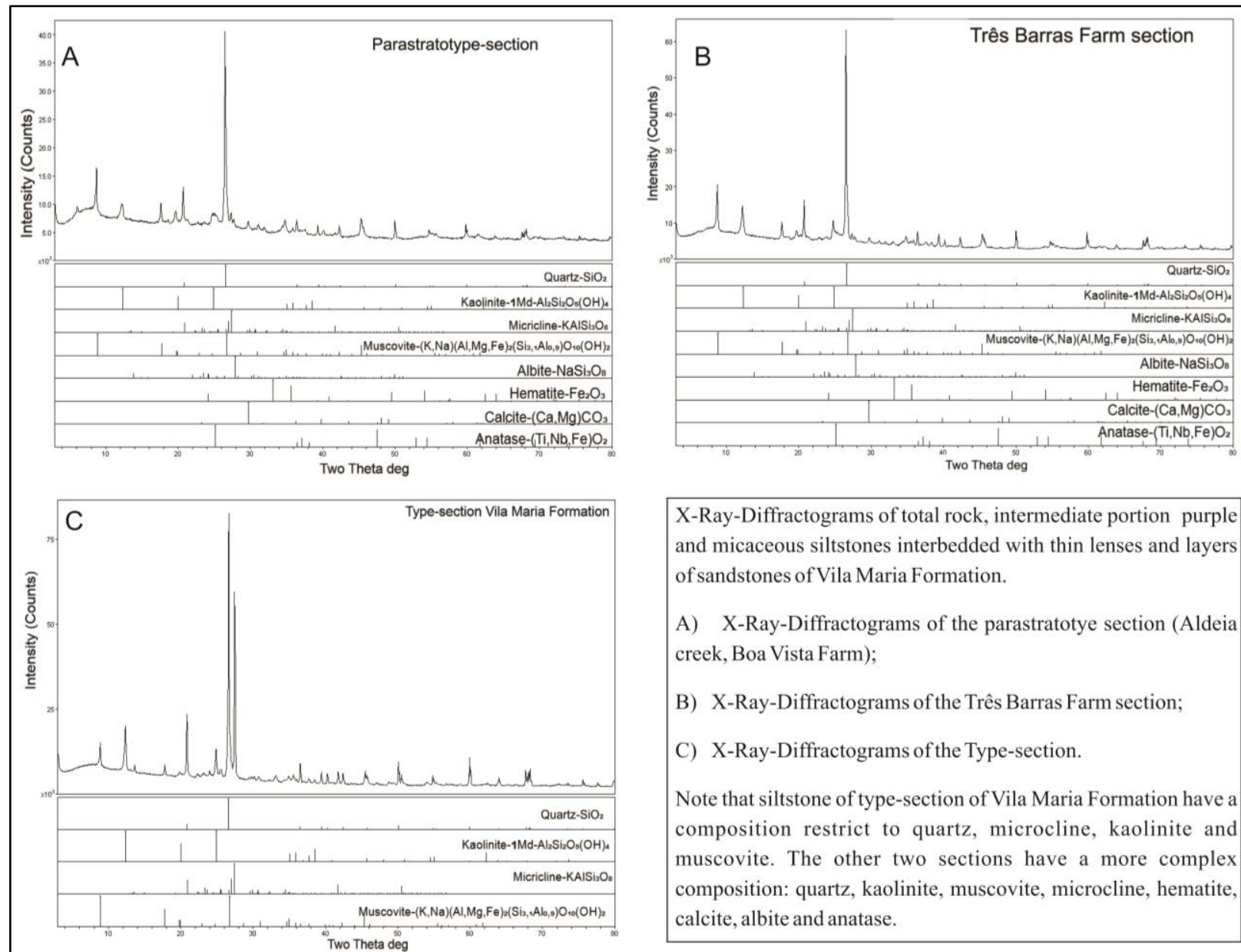

X-Ray-Diffractograms of total rock, intermediate portion purple and micaceous siltstones interbedded with thin lenses and layers of sandstones of Vila Maria Formation.

A) X-Ray-Diffractograms of the parastratotye section (Aldeia creek, Boa Vista Farm);

B) X-Ray-Diffractograms of the Três Barras Farm section;

C) X-Ray-Diffractograms of the Type-section.

Note that siltstone of type-section of Vila Maria Formation have a composition restrict to quartz, microcline, kaolinite and muscovite. The other two sections have a more complex composition: quartz, kaolinite, muscovite, microcline, hematite, calcite, albite and anatase.

FIGURE 3-X-Ray-Diffractograms of total rock, intermediate portion siltstone of Vila Maria Formation,

State of Goiás, central Brazil.

The upper portion of Vila Maria Formation reaches a maximum thickness of $7 \mathrm{~m}$. The sandstones of the upper portion vary from very fine to medium grain sizes. They are well selected and have sub-angular to rounded grains. The layers are tabular with a maximum thickness of $5 \mathrm{~m}$. Internally, these sandstones can be massive, but there are intervals with parallel lamination, and low-angle hummocky cross-stratification (Fig. 4h; Fig. 4j). Thin layers of micaceous siltstone interbedded with medium sandstones are observed in the upper portion. The ichnospecies Arthrophycus alleghaniensis occurs in the sandstone-siltstone interfaces at the top of the Vila Maria Formation (Fig. 4i). The Vila Maria Formation is capped by the whitish and kaolinitic sandstones of the Furnas Formation. There is a paraconformity contact between the top of the Vila Maria Formation and the base of the Furnas Formation. 


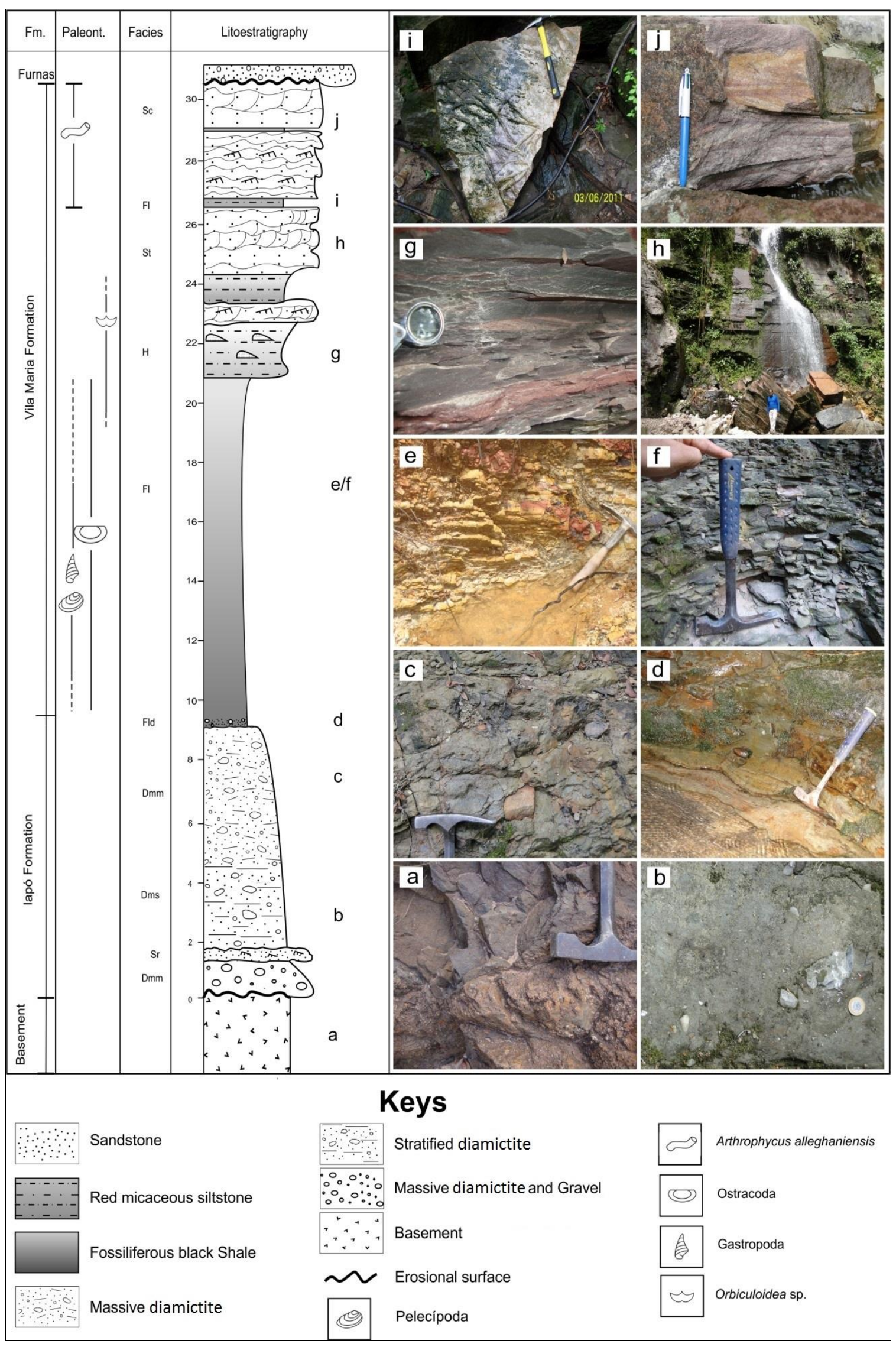

FIGURE 4-Stratigraphic log showing fossiliferous occurrences for the parastratotype section in Aldeia creek, Bela Vista Farm, Bom Jardim de Goiás County, State of Goiás, central Brazil. UTM Coordinates: 
Zone 22K. 382963E 8181666N. Facies: Massive diamictites (Dmm); stratified diamictites (Dms); sandstones with ripples ( $\mathrm{Sr})$, pelites with dropstones (Fld) (pebbly mudstones); shales (Fl); siltstones with lenticular heterolithic bedding (Linsen) $(\mathrm{H})$; sandstones with tabular stratification $(\mathrm{St})$; sandstones with cross-stratification (Sc). a) Crystalline Basement metariolites/metadacites. b) Diamictite. c) Stratified diamictite outcrop of the Iapó Formation (Dms). d) Contact of the massive diamictite of the Iapó Formation (Dmm) with dropstone at the upper portion of Iapó Formation (Fld). e) Basal shale of the Vila Maria Formation ( $\mathrm{Fl})$. f-g) micaceous siltstone with heterolithic structures highlighted in the picture "g". h) Overview of the waterfall in Aldeia Creek showing the thick sandy-silty package at the top of the Vila Maria Formation. i) ichnofossil Arthrophycus alleghaniensis. j) cross laminations in sandstones.

\section{TAXONOMY OF OSTRACODA}

The ostracod specimens recovered from the Vila Maria Formation are internal and external molds preserved in shale. Three species of Ostracoda are identified: Satiellina jamairiensis Vannier, 1986, Conchoprimitia circularis n. sp. and Gen. 1 et sp. 1 (undetermined species). The suprageneric taxonomy adopted in this article follows that of Vannier et al., (1986) and Salas et al., (2011). Specimens considered in this article are housed in the collections of the Museum of Geosciences, Laboratory of Micropaleontology, Institute of Geosciences, Universidade de Brasília, Brazil, identified with the prefix CP-.

Class OSTRACODA Latreille, 1806

Order PALAEOCOPIDA Henningsmoen, 1953

Family INCERTAE

Genus SATIELLINA Vannier, 1986

Type species.-Bollia delgadoi Vannier, 1983.

Diagnosis.-Outline of valves sub-elliptical. Lobes L1 and L2 are slightly unequal, and prominent, surpassing the dorsal edge of the carapace, united ventrally by a somewhat clear zygal junction forming a U-shaped arc. There is a slightly vertical depression among the lobes called sulcus. Extralobar convex 
surface. No marginal edge. Dimorphism expressed by heteromorphic characters with a well-developed posterior extralobar surface (Vannier, 1986).

Remarks.-Satiellina Vannier, 1986 has three species: Satiellina delgadoi (Vannier, 1986), Satiellina henningsmoeni (Nion in Robardet et al 1972) and Satiellina jamairiensis Vannier, 1986. Originally, Vannier (1986) emphasized that Satiellina differentiates from Bollia Jones and Holl, 1869, Pseudobollia Schallreuter, 1968 and Quadrijugator Kesling and Hussey, 1953 by the extralobar convex surface. The generic diagnosis was translated to english to contribute to further comparison

\section{SATIELLINA JAMAIRIENSIS Vannier, 1986}

Figure 5.1-5.7

Holotype.-Specimen IGR-30770/1; right valve external mold (Vannier, 1986).

Local type.-Poll-D1-23 (depth 1994m) Djeffara Formation Ashgil? Ghadames Basin, Libya (Vannier, 1986).

Diagnosis.-Species of Satiellina genus with no ventral connection between the lobes L1 and L2. The arc zygal is quite prominent. The boundary between the arc formed by the lobes and extralobar surface is defined by a well-marked groove (Vannier, 1986).

Material.-Ten molds of adult carapaces were recovered from the outcrop of the additional type-section, Aldeia creek, Bom Jardim de Goiás County, State of Goiás, central Brazil (Table 1).

TABLE 1-Measurements of Satiellina jamairiensis Vannier, 1986, valves recovered from the parastratotype section, Aldeia creek Boa Vista Farm, Bom Jardim de Goiás County, State of Goiás, central Brazil.

\begin{tabular}{lllll}
\hline Specimen & $\mathrm{L}(\mu \mathrm{m})$ & $\mathrm{H}(\mu \mathrm{m})$ & $\mathrm{L}: \mathrm{H}$ & Illustration \\
\hline CP-634 & 630 & 450 & 1.4 & Figure 5. 1-5. 2 \\
CP-637 & - & - & & Figure 5. 4 \\
CP-642 & - & - & & - \\
CP-643 & 550 & 450 & 1.22 & Figure 5. 5 \\
CP-645 & 550 & 400 & 1.37 & Figure 5. 3 - \\
CP-646 & 550 & 400 & 1.37 & Figure 5. 6 \\
CP-647 & - & - & & -
\end{tabular}




$\begin{array}{llll}\text { CP-662 } & - & - & - \\ \text { CP-664 } & - & - & -\end{array}$

Occurrence.-Ordovician-Ghadames Basin, northern Libya (Vannier, 1986), parastratotype section of the Vila Maria Formation, Rio Ivaí Group, northern flank of the Paraná basin.

Remarks.-The lobes of the specimens recovered from the Vila Maria Formation terminate before reaching the dorsal margin, the ventral region of the posterior lobe is wider, and the extralobar surface is convex, features that match those originally described for $S$. jamairiensis. The species Satiellina including S. jamairiensis exhibit sexual dimorphism, but the small number of specimens recovered in this study did not allow the observation of this feature. The studied species resembles Satiellina delgadoi Vannier, 1986, by having convex lateral surface and subelliptical-subcircular external contour, as well as obtuse cardinal angles and two lobes perpendicular to the dorsal margin. However, S. delgadoi is distinguished by lobes that do not exceed the dorsal limit. The anterior lobe is less developed and thinner than in $S$. delgadoi.

Suborder ERIDOSTRACINA Adamczak 1961

Family CONCHOPRIMITIIDAE Henmingsmoen 1953

Genus CONCHOPRIMITIA Öpik, 1935

Type species.—Conchoprimitia gammae Öpik, 1935.

Diagnosis. - Small (1.5 to $3 \mathrm{~mm}$ long) Primitiidae with a straight hinge line, with one or two pairs of bands. Bordered by grooves resembling the growth lines of shells or brachiopods, somewhat developed. Family Primitiidae. Lower to Upper Ordovician (Öpik, 1935).

Remarks.-Salas et al., (2011) presents a detailed discussion of the paleogeographic distribution and morphological characteristics of this genus. This genus differentiates itself by the convex carapace, the long hinge and postplete contour. Considering lower Paleozoic ostracoda is not very studied, the Generic diagnosis is reproduced to contribute to further comparison. 
Figure 5.8-5.12

Material.-Holotype CP-631 (Fig. 5. 8); paratypes CP-635; CP-639, CP-660 and CP-649 were illustrated (Fig. 5.9-5.12; Table 2).

Diagnosis. - Circular outline, postplete, with shallow groove and pre-adutorial node marked in the anterior-dorsal region. Straight dorsal margin, convex ventral margin with rounded anterior and posterior ends. Outer surface presents subtle scores on external mold.

Description.-Carapace displays postplete subcircular contour. Straight hinge line. Greatest length at the mid-height. Dorsal margin is rectilinear and extends approximately two-thirds of the valve length. The convex ventral margin, with larger radius of curvature coincides with the greatest height. Anterior end is rounded with greater convexity at mid-height. Posterior end is also rounded with a radius of curvature greater than that of the anterior end. Cardinal angles are obtuse; anterior is $120^{\circ}$, and posterior, $140^{\circ}$. Circular slightly pre-adutorial node located in the anterodorsal region, with low relief and poorly defined boundaries, raising the dorsal margin. Shallow pre-adutorial groove perpendicular to the dorsal margin, restricted to the extent of node, not reaching the dorsal margin. Valves present discontinuity in the convexity of the outer surface across the marginal extension, better marked in the posterior region than in the anterior. The dorsal view shows biconvex valves with smooth curvature and wider in the median region. The outer Surface is punctate.

Etymology.-The names refers to to the roughly circular outline of the carapace.

TABLE 2-Measure of Conchoprimitia circularis, parastratotype section of the Vila Maria Formation, Aldeia creek Boa Vista Farm, Bom Jardim de Goiás County, State of Goiás, central Brazil

\begin{tabular}{lllll}
\hline Specimen & $\mathrm{L}(\mu \mathrm{m})$ & $\mathrm{H}(\mu \mathrm{m})$ & $\mathrm{L}: \mathrm{H}$ & Illustration \\
\hline CP-631 & 650 & 430 & 1.51 & Figure 5. 8 \\
Holotype & & & & \\
CP-632 & & & & - \\
CP-633 & 655 & 450 & 1.45 & - \\
CP635 & 650 & 430 & 1.5 & Figure 5. 9 \\
CP-638 & 600 & 450 & 1.33 & -
\end{tabular}




\begin{tabular}{llccc} 
CP-639 & 600 & 420 & 1.42 & Figure 5. 10 \\
\hline CP-648 & 580 & 400 & 1.45 & - \\
\hline CP-649 & 580 & 400 & 1.45 & Figure 5. 12 \\
CP-657 & & 300 & & - \\
\hline CP-660 & 300 & 200 & 1.5 & Figure 5. 11 \\
\hline CP-661 & 300 & 200 & 1.5 & - \\
\hline CP-663 & 500 & 300 & 1.67 & - \\
CP-666 & 600 & 400 & 2 & - \\
\hline
\end{tabular}

Type locality.-Basal shales of the parastratotype section of the Vila Maria Formation, Rio Ivaí Group, Aldeia creek, Bela Vista Farm, Bom Jardim de Goiás County, State of Goiás, Central Brazil. UTM Coordinates: Zone 22K. 382963E 8181666N.

Occurrence.-Brazil, parastratotype section of the Vila Maria Formation, Rio Ivaí Group, Paraná Basin. Upper Ordovician, basal shales. Preservation restricted to internal and external molds.

Remarks.-The circular to subcircular contour of the valve is quite characteristic of the genus

Conchoprimitia. The Conchoprimitia circularis n. sp. was compared to species of Conchoprimitia and also to a species of Vogdesella, Baker, 1924. The new species has a circular contour and dimensions similar to the species Conchoprimitia socialis (Brogger, 1882), and Vogdesella subovata (Thorslund, 1948). The dimensions of C. circularis are compatible with both Vogdesella subovata and Conchoprimitia socialis. Conchoprimitia circularis differs from both by having larger anterior nodule, more developed and closer to the anterior end. The groove present in C. circularis is better marked than that of $C$. socialis. Furthermore, $C$. circularis differs from $C$. socialis for having a scored outer surface while $C$. socialis has a smooth outer surface. The contour of the $C$. circularis valve is more elongated, lacking a muscle scars as seen in Vogdesella subovata. This differentiation from this species and genus allows characterizing it as a new species of the genus Conchoprimitia due to greater similarities.

Gen. 1 et sp. 1 .

Figure 5. 13-5.14 and 5. 17 
Description.-Carapace presents subelliptical and amplete contour, maximum length located in the median region of the height. Valve has a straight dorsal margin extending more than three quarters of the length. Convex anterior margin curves gently to the ventral margin. Convex-circular ventral margin has gentle curvature. The radius of the convex posterior margin is slightly smaller than the anterior while larger curvatures are seen in the dorsal-medial region. Obtuse cardinal angles are about $120^{\circ}$. There is a slightly marked round pre-adutorial node in the anterior-dorsal region. This low relief node has unclear boundaries that do not reach the dorsal margin. Very subtle adutorial groove, located at the posterior limit of the pre-adutorial nodule region. Convex surface of the carapace displays soft curvature, wider at midlength.

Remarks. - This form is known from only three specimens, represented by internal molds. No detailed taxonomic assignment can be proposed until additional material is available. 


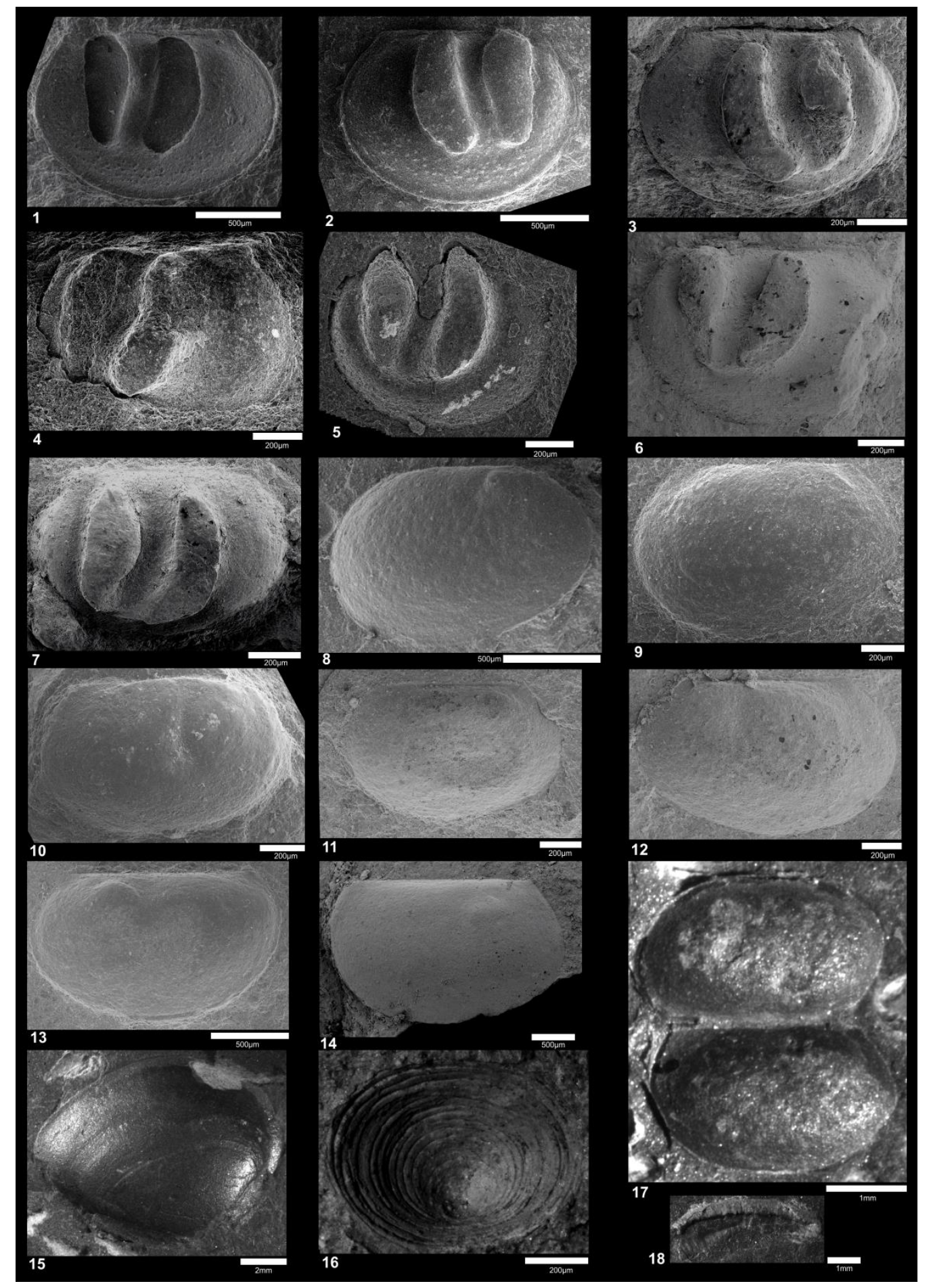

FIGURE 5-1-7, Satiellina jamairiensis Vannier, 1986. 1-2, CP-634, right valve, lateral view, 1 external mold, 2 latex cast of the mold;3, CP-645, right valve, lateral view of an internal mold; 4-7, left valves, lateral views of internal molds, 4, CP-637; 5, CP-643; 6, CP-651; 7, CP-646. 8-12, Conchoprimitia circularis n. sp; 8-11, left valves, lateral views of internal molds, 8, Holotype CP-631; 9, Paratype CP635; 10, Paratype CP-639; 11, Paratype CP-660, right views; 12, Paratype CP-649, left valve, lateral view of an interanal mold. 13-14, 17, Gen. et sp. 1 (undetermined species), 13, CP-636 left valve. lateral view 
of an internal mold; 14, CP-644, right valve, lateral view of internal mold; 17, CP-668, Open carapace, Right valve (bottom) and left valve (upper). 15, Bivalvia indet; 16, cf. Orbiculoidea sp., dorsal valve 18, Incertae Sedis.

\section{STRATIGRAPHIC DISTRIBUTION AND PALEOENVIRONMENT ANALISES}

The ostracods presented in this paper are from the shales of the basal portion of the Vila Maria Formation. This pelitic package approximately $11 \mathrm{~m}$ thick is interpreted as deposited in a periglacial marine environment from mid to outer continental shelf, under calm conditions. This environment was colonized by a rich fauna consisting of Brachiopoda, Bivalves, Archaeogastropoda together with the marine benthic Ostracoda species herein studied.

The intermediate portion of the Vila Maria Formation consists of a transitional horizon that changes from the fossiliferous shales rich in organic matter in the basal portion to the sandstones of the upper portion. This transition layer is composed of siltstones with heterolithic structures, flaser bedding type, which mark the beginning of the entry of bottom currents transporting sandy sediments. In this particular region, only cf. Orbiculoidea sp. were recovered, indicating that new environmental conditions were unfavorable to colonization or preservation of other invertebrate organisms. The contribution of sandy sediments becomes increasingly abundant towards the top of this formation, indicating a decreasing sea level. This reduction in relative sea level may be associated with isostatic rebound due to ice load shedding after the maximum glacial peak and glacier retreat.

The upper portion of the Vila Maria Formation is characterized by sandstones deposition indicating that sea level has undergone a gradual decrease. This regressive cycle caused the disappearance of all elements of the biota recorded in the basal and the intermediate portions. This interval has only occurrences of Arthrophycus alleghaniensis. The probable cause for the total absence of records of fossil remains at this portion appears to be related to the increasing energy from the environment, which may avoid the maintenance of the biota.

FINAL DISCUSSION 
The interpretation of paleontological and stratigraphic data above discussed is consistent with the paleoenvironmental evolution of the Rio Ivaí Group presented by Assine et al., (1998). The global eustatic sea level dropped during the glacial peak, but in periglacial seas, subject to the advance of glaciers, the relative sea level rised as a result of subsidence due to overload caused by the weight of glacier. At the final stages of glaciation, the melting of glacier retreat provided a large sediment input that influenced the depositional periglacial marine systems composed of dropstones that make up the upper portion of the Iapó Formation (Assine et al., 1998).

The glacial system of the basal portion of the Vila Maria Formation sensu Faria (1982) is equivalent to the top of Iapó Formation sensu Assine et al. (1994) in the northern part of the Paraná basin. To Moreira et al. (1999), the shale facies with dropstones is interpreted as settling of fine sediments in a low-energy glacial context. Stratified diamictites are deposited by gravity flows associated with rain of debris (massive diamictite facies) or turbidity (stratified diamictite facies) with dense, episodic pulses derived from sediment-laden by defrost water.

The Trombetas Group of the Amazon basin (Cunha et al., 2007) and Serra Grande Group of the Parnaíba Basin (Vaz et al., 2007) are compared with the Rio Ivaí Group of the Paraná basin in this study, due to the similarities of the lithotypes succession that represent the paleoenvironmental evolution record of the Ordovician-Silurian transition. These lithologic and paleoenvironmental successions may indicate that these basins were subjected to the same glacial event. The difference between these basins latitude may determine different ages of the glacial deposits, since these basins had different latitudes during the Ordovician.

In the Amazon basin, the glacial sediments of the Nhamundá Formation are capped by continental shelf marine sediments of the Pitinga Formation, both of the Trombetas Group (Nogueira et al., 1999; Cunha et al., 2007). In the Parnaíba basin, the fluvial-glacial sediments of Ipu Formation are succeeded by marine deposits of the continental shelf of the Tianguá Formation, both of the Serra Grande Group (Vaz et al., 2007; Goes et al., 1994). The succession of glacial sediments capped by continental shelf marine shales observed in Rio Ivaí Group is coeval to those observed in Serra Grande and Trombetas groups.

The fossil record of the upper portion of the Vila Maria Formation is restricted to the ichnospecies Arthrophycus alleghaniensis that occurs in the centimetric silty levels observed in sandstone 
packages. This occurrence of A. alleghaniensis was also recorded in the Nhamundá Formation of the Amazon basin (Nogueira et al., 1999).

In the Taoudeni basin, in central and northwestern Mauritania, west Africa, the glacial sediments of the Tichitt Group from the Upper Ordovician are capped by the continental shelf marine sediments of the Oued Chig Group (Ghienne, 2003). This lithostratigraphic interval of the Taoudeni basin was correlated in this study, with the coeval sediments of the Rio Ivaí Group, in Brazil. The Tichitt Group was compared to the Iapó Formation and the Oued Chig Group with the Vila Maria Formation. These lithostratigraphic and chronostratigraphic similarities indicate that the glacial deposits of these two basins may be related to the same glacial event that left records in Gondwana during the Late Ordovician.

The paleoenvironment interpreted for the upper portion of the Vila Maria Formation is marine inner shelf. The interbedded siltstone between laminated sandstones indicates that the current ceased temporarily, enabling the Arthrophycus alleghaniensis to colonize the bottom. This ichnospecies is an important biostratigraphic horizon that marks very clearly the top of the Vila Maria Formation, and can be used for correlation.

Palaeocopida ostracods present in the pelitic basal portion suggest that this interval belongs to uppermost Ordovician, and records the maximum post-glacial marine transgression. This interval is followed by a marine regression and isostatic rebound culminating in laminated sandstones of the upper portion record of a shallow coastal to shelf continental environment colonized by Arthrophycus alleghaniensis during the Llandovery. The new data herein presented allow dating for the first time the deposition of Vila Maria Formation as comprising the chronostratigraphic boundary Upper OrdovicianLlandovery.

Satiellina jamairiensis and Conchoprimitia species are restricted to the Ordovician (Fig. 6), indicating by correlation that at least the lower range of the Vila Maria Formation should be positioned in the uppermost Ordovician. The three species constitute the earliest Ostracoda record of Brazil.

The dating based on the global distribution of Satiellina jamairiensis and Conchoprimita circularis is supported by the transitional contact between Iapó and Vila Maria formations. The Iapó Formation is considered as the Upper Ordovician glaciation record in the Paraná basin (Assine et al., 1998). A significant hiatus is not expected between these formations, considering the transitional and consistent nature of the contact, which supports the Late Ordovician dating of the base of the Vila Maria Formation. 
The lithostratigraphic correlations with the Amazonas and Parnaíba basins in Brazil and Taoudeni in Africa, coupled with the occurrence of Arthrophycus alleghaniensis corroborate the Lower Silurian dating of the upper portion of the Vila Maria Formation. It is noteworthy that this ichnospecies was used as a guide fossil of this interval, allowing to consider that the upper portion of the Vila Maria Formation constitutes the Llandovery Series of the Parana basin. Thus, the ostracod data, as well as those of ichnofossils indicate that the Vila Maria Formation is the sedimentary record spanning from the uppermost Ordovician to the Llandovery.

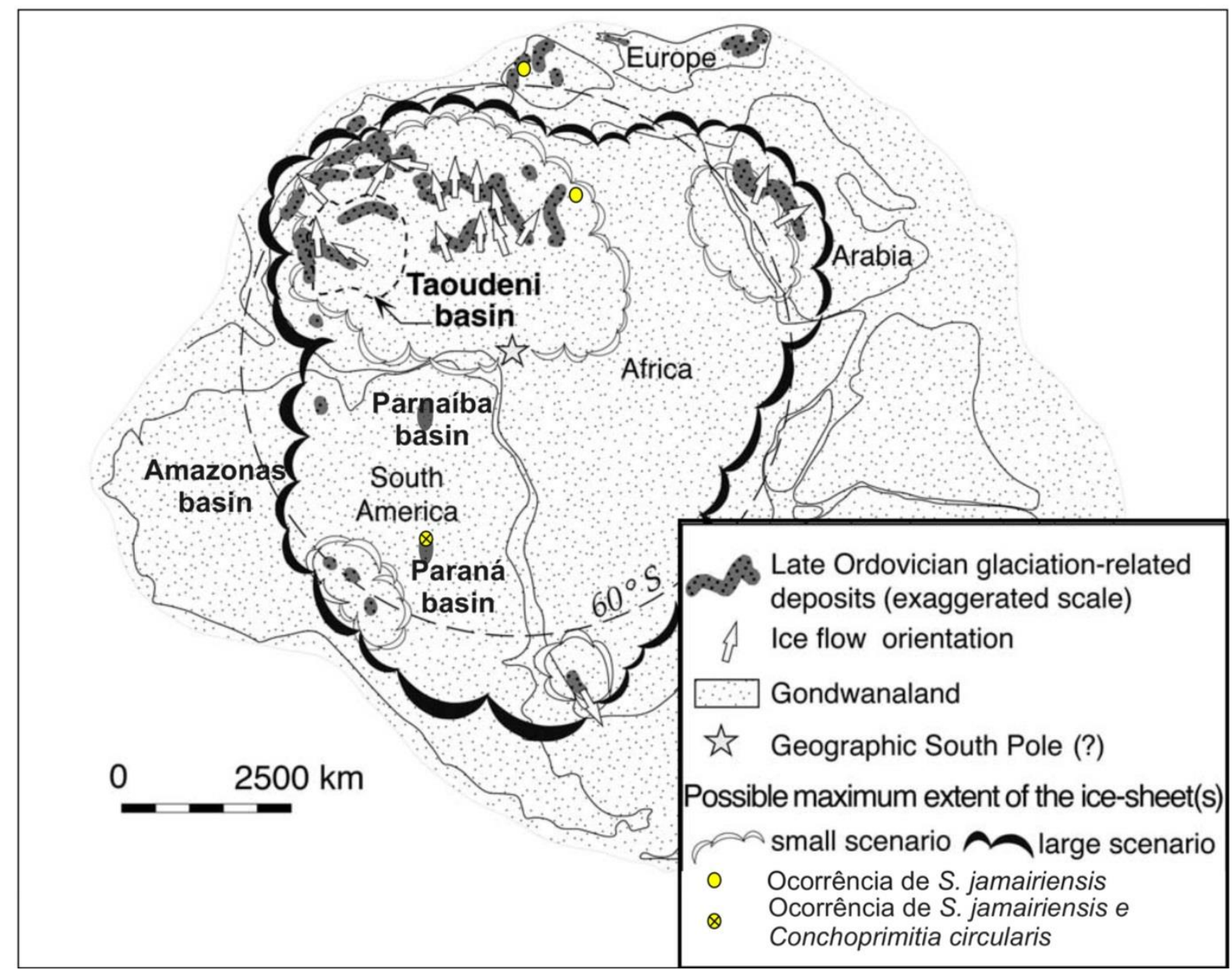

FIGURE 6-Paleogeographical reconstruction showing the occurrences of identified Ostracoda species and the extent and flow direction of existing glaciers during the Late Ordovician (Adapted from Gienne, 2003). 
Satiellina jamairiensis Vannier, 1986, Conchoprimitia circularis n. sp., and unidentified ostracod are the earliest record of Ostracoda in Brazil. Satiellina jamairiensis and the all known Conchoprimitia species are restricted to the Ordovician. So, considering these occurrences the basal portion of the Vila Maria Formation can be attributed to the uppermost Ordovician. The occurrence of Arthrophycus alleghaniensis in the upper portion of the Vila Maria Formation corroborate the Llandovery dating for this interval. Lithostratigraphic data and sedimentary structures suggest the hypothesis of a marine transgressive-regressive during the latest Ordovician-Llandovery interval.

In addition to the study of the paleontological, stratigraphic and paleogeographic records of the Vila Maria Formation, the cartographic information regarding type-locality and parastratotype locality of Vila Maria Formation was updated, as well as other key-localities of this interval in the northern portion of the Paraná basin. The map produced in this study contain the updated locations with UTM coordinates and main access roads to the studied outcrops and other important outcrops aiming to conduct a historical review of these outcrops and facilitate future work on Vila Maria Formation, the unique lithostratigraphic unit of Paraná basin proposed in areas of State of Goiás.

\section{ACKNOWLEDGEMENTS}

The authors are grateful to the Museum of Geosciences for housing the illustrated material. To CICTERRA - CONICET, Universidad Nacional de Córdoba, Argentina, for assigning the space and equipment to study the fossil material. To CNPq and FUB/FINATEC for the financial support and PETROBRAS/ANP for granting the OSTRAKi project. The authors are grateful, as well to the Microprobe Laboratory of the Institute of Geosciences, and the Laboratory of Electron Microscopy, Institute of Biological Sciences, University of Brasilia for the metallization and imaging services of the illustrated materials. To the University of Brasília to the call DPP-1/2014 for Supporting Publications.

\section{REFERENCES}

ADAMCZAK, F. 1961. Eridostraca a new suborder of ostracods and its phylogenetic significance. Acta Palaeontologica Polonica6,29-104. 
Alvarenga, C.J.S., E. M. Guimarẽes, M. L. ASSine, J. A. J. PERinOtTO, N. P. F. LARANJEIRA. 1998. Sequiências Ordovício-Siluriana e Devoniana no flanco norte da bacia do Paraná. Anais da Academia Brasileira de Ciências, 70: 587-606.

ASSINE, M. L, P. C. SOARES, E. J. MILANI. 1994. Sequências tectono-sedimentares mesopaleozóicas do Paraná, sul do Brasil. Revista Brasileira de Geociências 24(2):77-89, junho de 1994.

ASSine, M. L., J. A. J. PERINOTTO, C. J. S. ALVARENGA, SETEMBRINO PETRI. 1998. Arquitetura estratigráfica, tratos deposicionais e paleogeografia da bacia do Paraná Brasil no Neo-Ordoviciano / Eo-siluriano. Revista Brasileira de Geociências 28(1):61-76.

ASSINE, M. L. AND P. C. SOARES. 1989. Correlações nas Sequências Mesopaleozóicas da bacia do Paraná. Acta Geológica Leopoldensia.29: 39-48.

BAKER, F. 1924. Vogdesella, a new genus name for a Paleozoic crustacean. Proceedings of the Calofornia Academy of Science 13: 188-197.

BRØGGER, W.C. 1882. Die Silurischen Etangen 2 und 3 im Kristianiagebiet und auf Eker, ihre Gliederung, Fossilien, Schichtenstörungen und Contactmetamorphosen. Universitets-Program, 2 Semester, A. W. Brøgger, Kristiania.

BURGESS, N.D.\& J. B. RICHARDSON. 1991. Silurian cryptospores and miospores from the type Wenlock area, Shropshire, England.Palaeontology34, 601-28.

BURJACK, M.I AND M.T.B. POPP. 1981. A ocorrência do icnogênero Arthrophycus no Paleozóico da bacia do Paraná. Pesquisas, Porto Alegre, 14:163-168.

CUNHA, P. R. C., J. H. G. MELO, O. B. SILVA. 2007. Bacia do Amazonas. Boletim de Geociências da PETROBRAS, 15(2), 227-251.

FARIA, A. 1982. Formação Vila Maria - nova unidade litoestratigráfica siluriana da Bacia do Paraná. Revista Ciências da Terra 3:12-15.

FARIA, A. DE AND, J.M. REIS NETO. 1978. Nova unidade litoestratigráfica pré-Furnas no sudoeste de Goiás. IN: Congresso Brasileiro de Geologia, XXX, Resumo das Comunicações. Recife, SBG, p. 136-37.

GHIENNE, J. F. 2003. Late Ordovician sedimentary environments, glacial cycles, and post-glacial transgression in the Taoudeni Basin, West Africa. Palaeogeography, Palaeoclimatology, Palaeoecology 189 (2003) 117-145. 
GÓES, A. M. O., F. J. FEIJÓ. 1994. Bacia do Parnaíba. Boletim de Geociências da PETROBRÁS, 8 1: $57-67$.

GRAY, J., G. K. COLBATH; A. FARIA, A. J. BOUCOT, D. M. ROHR. 1985. Silurian-Age fossils from the Paraná basin, Southern Brazil. Geology, v. 13, p 521-525, July 1985.

HALL, J., 1852. Paleontology of New York II. Organicremains of the lower middle division of the NewYork system. Geological Survey of New York,Albany.

HENNINGSMOEN, G., 1953. Classification of Paleozoic straight-hinged ostracods. Norsk Geologisk Tidsskrift 31, 185-288.

JONES, T. R. AND B. H. HOLL. 1869. Notes on the Paleozoic Bivalved Entomostraca. No. IX, Some Silurian species. Ann. Mag. Natural. History London, 4, 3, 15: 211-299.

KESLING, R. V. AND R. C. HUSSEY. 1953. A new family and genus of Ostracod Bill's Creek Shale of Michigan. Contr. Mus. Pal. Univ. Michigan. 11, 4: 77-95, Ann. Arbor. Michigan.

LOEBLICH, A. R. 1970. Morphology, ultrastructure and distribution of Paleozoic acritarchs. North American Paleontological Convention Proceedings, Part. G, p.705-788.

MILANI, E. J., A.B. FRANÇA, R. L. SCHNEIDER, Bacia do Paraná. Boletim de Geociências da PETROBRAS, Rio de Janeiro,V.8, n.1, p. 69-82, jam./mar. 1994.

MILANI, E. J., J. H. G. MELO, P. A. SOUZA, L. A. FERNANDES, A. B. FRANÇA. 2007. A Bacia do Paraná. Boletim Geociências da Petrobras, Rio de Janeiro, v. 15, n. 2, p. 265-287.

MIZUSAKI, A. M. P., J. H. G. MELO, M. L. VIGNOL-LELARGE, P. STEEMANS. 2002. Vila Maria Formation (Silurian, Paraná Basin, Brazil): integrated radiometric and palynological age determinations. Geol. Mag.,139 (3).

MOREIRA, M.I.C. AND L. BORGHI. 1999. Revisão cstratigráfica do intervalo Ordoviciano-Siluriano da bacia do Paraná. Anais da Academia Brasileira de Ciências, 71(4-I):743-766.

NOGUEIRA, A. C. R., W. TRUCKENBRODT, E. A. A. SOARES. 1999. O icnogênero arthrophycus de depósitos sublitorâneos da Formação Nhamundá (siluriano inferior) da bacia do Amazonas, Região de Presidente Figueiredo. Revista Brasileira de Geociências 29(2):135-140.

ÖPIK, A. A. 1935. Ostracoda from the lower Ordovician Megalaspis-limestone of Estonia and Russia. Annales Etc. of the Naturalists Society of Tartu University 42: 28-38. 
POPP, M.T.B.; M. I. BURJACK, L. R. ESTEVES. 1981. Estudo preliminar sobre o conteúdo paleontológico da Formação Vila Maria (pré- Devoniano) da Bacia do Paraná. Pesquisas, 14:169-180.

ROBARDET, M., J. L. HENRY, J. NION, PARIS, F. AND J. PILLET. 1972. La Formation du Pont-deCaen (Caradocien) dans les synclinaux de Domfront et de Sées (Normandie). Ann. Soe. Géol. Nord, 92: 117-137.

SALAS, M. J. 2011. Early Ordovician (Floian) ostracods from the Cordillera Oriental, Northwest Argentina. Geological Journal 46: 637-650.

SCHALLREUTER,R. 1968. Drepanellacea (Ostracoda, Beyrichicopida) aus mittelordovizischen Backsteinkalkgeschieben II. Laterophoreslateris g.n. sp.n., Pseudulrichiabucera (Neckaja) und Pedomphalella Egrégia (Sarv.) Ber. Deutsch. Ges.geol., A. Wiss. Geol. Paläont., 13, 2: 247-261.

THORSLUND, P. 1948. The Chamops Series of the Kullatorp Core. Buli. Geol. Inst. Univ.Uppsala,32: 343-373.

VANNIER, J.M.C. 1983: On Bollia delgadoi Vannier sp. nov. Stereo Atlas Ostracod Shells, 10, 95-98.

VANNIER, J.M.C. 1986: Ostracodes Palaeocopa de l'Ordovicien (Arenig-Caradoc) Ibero-Armoricain. Palaeontographica A193, 145-218.

VAZ, P. T., N. G. A. M. REZENDE, J. R. WANDERLEY FILHO, W. A. S. TRAVASSOS. 2007. Bacia do Parnaíba. Boletim de Geociências da PETROBRÁS, 15(2), 253-263.

ZALÁN, P.V., S. WOLFF, J.C.J. CONCEIÇÃO, I.S. VIEIRA, M.A.M. ASTOLFI, V.T. APPI, O.A. ZANOTTO. 1987. A divisão tripartite do Siluriano da Bacia do Paraná. Revista Brasileira de Geociências, 17(3):242-252. 